\title{
Exponential Amplification Using Photoredox Autocatalysis
}

\author{
Seunghyeon Kimª, Alejandra Vanessa Martinez Dibildox ${ }^{\mathrm{b}}$, Alan Aguirre-Soto ${ }^{\mathrm{b}}$, and Hadley D. \\ Sikes ${ }^{\mathrm{a}, \mathrm{c} *}$ \\ aDepartment of Chemical Engineering, Massachusetts Institute of Technology, Cambridge, MA 02139, USA \\ ${ }^{b}$ School of Engineering and Sciences, Tecnologico de Monterrey, Monterrey, N.L. 64849, MX \\ 'Antimicrobial Resistance Integrated Research Group, Singapore-MIT Alliance for Research and Technology, \\ 1 CREATE Way, Singapore 138602, Singapore \\ *E-mail: sikes@mit.edu
}

KEYWORDS. photoredox autocatalysis, photo-oxidation, eosin Y, exponential amplification, COVID-19, antigen

\begin{abstract}
Exponential molecular amplification such as the polymerase chain reaction is a powerful tool that allows ultrasensitive biodetection. Here we report a new exponential amplification strategy based on photoredox autocatalysis, where eosin $\mathrm{Y}$, a photocatalyst, amplifies itself by activating a non-fluorescent eosin $\mathrm{Y}$ derivative $\left(\mathrm{EYH}_{2}\right)$ under green light. The deactivated photocatalyst is stable and rapidly activated under low intensity light, making the eosin Y amplification suitable for resource-limited settings. Through steady-state kinetic studies and reaction modeling, we found that $\mathrm{EYH}_{2}$ is either oxidized to eosin $\mathrm{Y}$ via one-electron oxidation by triplet eosin $\mathrm{Y}$ and subsequent $1 \mathrm{e}^{-} / \mathrm{H}^{+}$transfer, or activated by singlet oxygen with the risk of degradation. By reducing the rate of the $\mathrm{EYH}_{2}$ degradation, we successfully improved $\mathrm{EYH}_{2}-$ to-eosin Y recovery, achieving efficient autocatalytic eosin Y amplification. Additionally, to demonstrate its flexibility in output signals, we coupled the eosin Y amplification with photo-induced chromogenic polymerization, enabling sensitive visual detection of analytes. Finally, we applied the exponential amplification methods in developing bioassays for detection of biomarkers including SARS-CoV-2 nucleocapsid protein, an antigen used in the diagnosis of COVID-19.
\end{abstract}

\section{INTRODUCTION}

The development of rapid, affordable, and highly sensitive biodetection methods for resource-limited settings is of paramount importance in detection and diagnosis of infectious diseases. Advances in point-of-care diagnostic tests have enabled rapid detection of high concentrations of biomarkers at low cost, ${ }^{1,2}$ but these tests have limited utility for clinical decision-making due to lower sensitivity than other laboratory methods such as the polymerase chain reaction (PCR). $3^{-5}$ On the other hand, PCR can detect low-abundance target nucleic acids ${ }^{6}$ or antigens (via immuno-PCR ${ }^{7}$ by amplifying specific nucleic acids exponentially, but this method often takes several hours, and is not easily translated to resource-limited settings due to reliance on laboratory instruments (thermal cyclers and analyzers), poor stability of enzyme-based reagents, and requirement of trained personnel. ${ }^{8-10}$ To address these issues, efforts have been made to develop isothermal nucleic acid amplification strategies, ${ }^{9,11}$ long-term storage methods for reagents, ${ }^{12}$ and automated formats. ${ }^{9,11,13}$

Alternatively, several research groups have dedicated to developing non-PCR exponential molecular amplification methods by carefully designing small molecule amplification reagents. These reagents can amplify activating molecules such as acetate, ${ }^{14}$ hydrogen peroxide, ${ }^{15-17}$ fluoride, ${ }^{18-22}$ thiol, ${ }^{23}$ piperidine, ${ }^{24}$ and photosensitizers ${ }^{25,26}$ through autoinductive or autocatalytic reactions ${ }^{27,28}$ such as activation of a supramolecular catalyst, ${ }^{14}$ a cascade of self-immolative reactions, ${ }^{15-24}$ and photo-unmasking of photosensitizers. ${ }^{25,26}$ However, despite the successful detection of analytes in aqueous solutions such as enzymes, ${ }^{15}$ nerve agents, ${ }^{22,23}$ metal ions, ${ }^{19,24}$ and avidin, ${ }^{26}$ these amplification methods have never been used to detect biomarkers of infectious diseases.

To address this gap, broadly applicable exponential amplification methods for sensitive biodetection need to be developed with the following considerations. First, the activating molecules should be easily conjugated to affinity reagents or liberated from the conjugated probes, amplifying signals associated with specific binding events. Second, the amplification reagents should be thermally stable for long-term storage without refrigeration, and soluble in water to avoid handling of organic solvents by untrained users. Furthermore, the amplification time should be short (within minutes), and readily controlled with external stimuli such as heat and light to prevent false positive results and provide quantitative information. Most importantly, autoinductive cascade or autocatalysis should be carefully designed to achieve exponential amplification of biodetection signals.

Herein, we demonstrate a new exponential signal amplification strategy based on photoredox autocatalysis, which 
can be applied to various biodetection assays. Inspired by the activation of non-fluorescent probes such as $\mathbf{1}$ and $\mathbf{2}$ via photo-induced oxidation (Scheme 1A), ${ }^{29-34}$ we designed eosin Y (EY)-based photoredox autocatalysis where doubly reduced and protonated eosin $\mathrm{Y}\left(\mathrm{EYH}_{2}\right)$ is converted into EY by triplet EY $\left(3 \mathrm{EY}^{*}\right)$ or other oxidizing species produced during the photoredox catalysis of EY (Scheme 1B). EY was chosen as the photocatalyst for the autocatalytic reaction because (1) EY-conjugated affinity reagents can be readily prepared,35-37 (2) EY has a high triplet quantum yield (o.6 $0.7)^{38,39}$ and a long triplet lifetime $(1.85 \mathrm{~ms})^{40}$ in water, (3) $\mathrm{EYH}_{2}$ cannot absorb visible light, ${ }^{41,42}(4)$ both $\mathrm{EY}$ and $\mathrm{EYH}_{2}$ are water-soluble due to ionizable groups, and (5) $\mathrm{EYH}_{2}$ is potentially stable against oxidation during storage. ${ }^{41,43}$

Our initial hypothesis was that the additional EY generated in previous photoredox cycles can activate $\mathrm{EYH}_{2}$ in the next cycle, so it was expected that the amount of EY would increase exponentially (Scheme 2). However, quenching of activating molecules and other side reactions could hamper efficient activation of $\mathrm{EYH}_{2}$ and cause degradation of $\mathrm{EY}$ and $\mathrm{EYH}_{2}$. To enhance the kinetics and efficiency of the autocatalytic reaction, we studied the mechanism of EY amplification. Employing the mechanistic insights from the steady-state kinetic studies and reaction modeling, we could dramatically improve $\mathrm{EYH}_{2}$-to-EY recovery and achieve a rapid and sensitive autocatalytic EY amplification.

Additionally, we demonstrate that the autocatalytic EY amplification can be coupled with other photochemical reactions to generate different forms of signals. Combining the EY amplification with oxidative polymerization of 3,3diaminobenzidine (DAB), the amplification system produced colorimetric signals with brown insoluble polymer. Finally, we applied the exponential amplification methods in developing bioassays for detection of biomarkers including SARS-CoV-2 nucleocapsid protein, an antigen used to diagnose COVID-19.

\section{RESULTS AND DISCUSSION}

\section{Synthesis and characterization of $\mathrm{EYH}_{2}$}

Synthesis of $\mathrm{EYH}_{2}$ was achieved by reducing 1,4-benzoquinone-like structure of EY to hydroquinone-like structure with sodium borohydride in aqueous solution as described in Figure $\mathbf{1 A},{ }^{42}$ leading to a loss of conjugation in the $\pi$-system. It should be noted that $\mathrm{EY}$ and $\mathrm{EYH}_{2}$ represent eosin $\mathrm{Y}$ and dihydroeosin $\mathrm{Y}$ in this paper, regardless of actual charges of the molecules. Because of the ionizable groups in $\mathrm{EYH}_{2}$, it is soluble in neutral-to-high $\mathrm{pH}$ solutions, but its solubility decreases as $\mathrm{pH}$ decreases. Thus, $\mathrm{EYH}_{2}$ was easily purified by precipitation at low $\mathrm{pH}$ and then stored in DMSO (see the Materials and Methods section in Supporting Information).
Scheme 1. (A) General activation pathway of dihydroxanthene dyes ( 1 and 2 ). (B) Hypothesized activation pathway of $\mathrm{EYH}_{2}$ to $\mathrm{EY}$ via photoredox autocatalysis (present work).

(A)

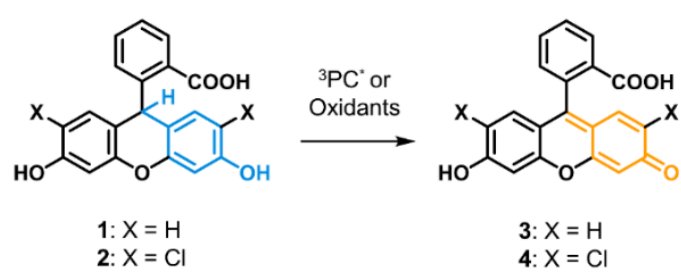

(B)

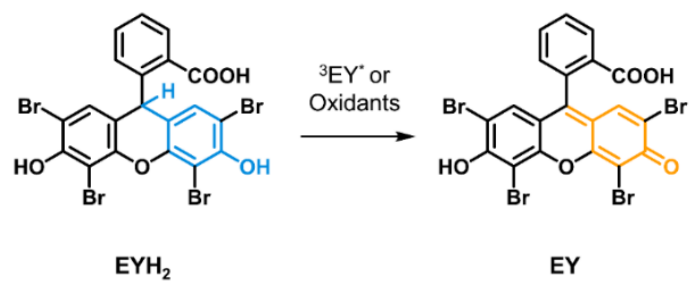

$3 \mathrm{PC}^{*}$ : photocatalyst in triplet excited state. ${ }^{3} \mathrm{EY}^{*}$ : triplet EY

Scheme 2. Autocatalytic amplification of EY.

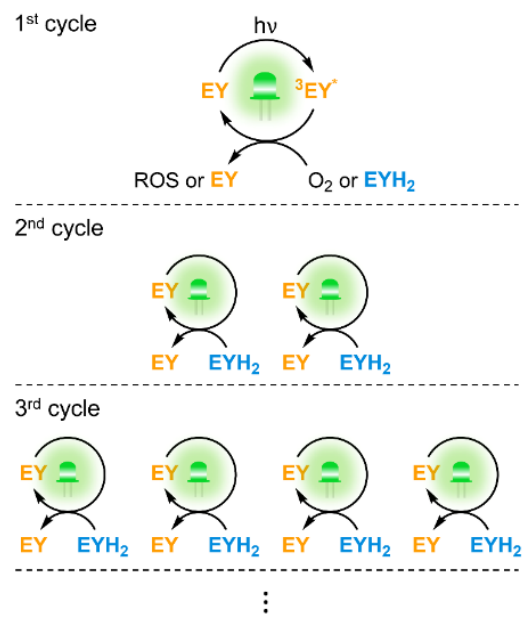

Triplet EY $\left(3 \mathrm{EY}^{*}\right)$ is either quenched by oxygen $\left(\mathrm{O}_{2}\right)$ to generate reactive oxygen species (ROS) or oxidizes $\mathrm{EYH}_{2}$ to produce EY. The amplification reagent $\left(\mathrm{EYH}_{2}\right)$ is activated by small amount of EY in an autocatalytic manner to amplify the number of EY in the system.

By monitoring EY and $\mathrm{EYH}_{2}$ concentrations in the $\mathrm{EYH}_{2}$ solution, we confirmed the long-term (at least 4 months) stability of $\mathrm{EYH}_{2}$ at $25^{\circ} \mathrm{C}$ (Figure $\mathbf{1 B}$ ). Considering that the $\mathrm{EYH}_{2}$ stock solutions in DMSO were kept in centrifuge tubes without airtight sealing, the results support the high stability of protonated $\mathrm{EYH}_{2}$ against oxidation in DMSO at $25^{\circ} \mathrm{C}$ although the oxidation is slightly faster at $40^{\circ} \mathrm{C}$.

Next, we tested if $\mathrm{EYH}_{2}$ could be photo-activated by EY with and without oxygen (Figure $\mathbf{1 C}$ ). In both conditions, $\mathrm{EYH}_{2}$ was activated to generate EY upon light irradiation, but the EY amplification rates were very different. In the absence of oxygen, EY generation was much faster than in the presence of oxygen, and the EY concentration reached 9.6 $\mu \mathrm{M}$, implying $100 \% \mathrm{EYH}_{2}$-to-EY recovery. The EY concentration in air-saturated solution, on the other hand, did 
not reach $4 \mu \mathrm{M}$ even after extended illumination (30 min). Unfortunately, oxygen must be included in the EY amplification system because removing oxygen in practical settings is not feasible, and the amplification should occur as fast as possible. Thus, we sought to improve our mechanistic understanding of the EY amplification and the role of oxygen to achieve a more rapid and sensitive autocatalytic amplification method by removing inefficiencies in the system.

(A)<smiles>[R17]=C1Oc2c(cc(Br)c(Br)c2Br)C(c2ccccc2C(=O)[O-])=C1C=CBr</smiles>

(B)

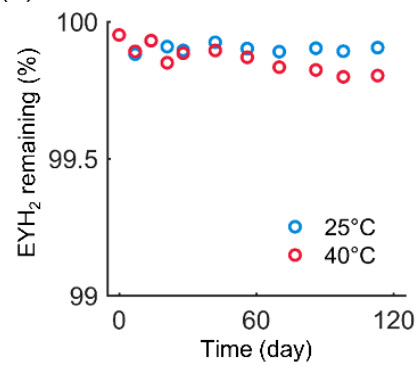

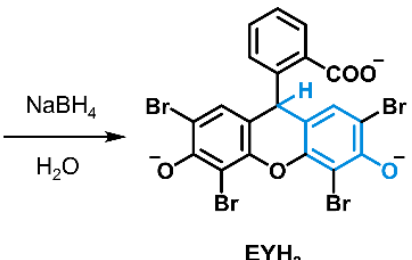

(C)

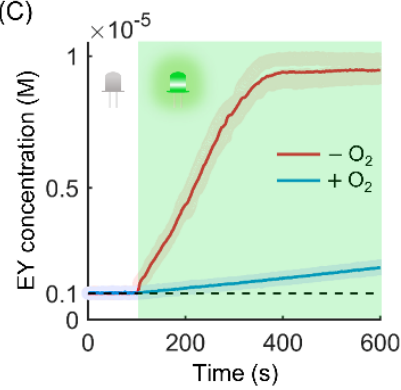

Figure 1. Synthesis and characterization of the amplification reagent $\left(\mathrm{EYH}_{2}\right)$. (A) Synthesis of $\mathrm{EYH}_{2}$. (B) Thermal stability of $\mathrm{EYH}_{2}$ in DMSO at $25^{\circ} \mathrm{C}$ and $40^{\circ} \mathrm{C}$. (C) Activation of $8.6 \mu \mathrm{M}$ $\mathrm{EYH}_{2}$ by $1 \mu \mathrm{M} \mathrm{EY}$ in $0.2 \mathrm{M}$ phosphate buffer ( $\mathrm{pH} 7.4$ ) under 2.6 $\mathrm{mW} / \mathrm{cm}^{2}$ green light $\left(\lambda_{\max }=535 \mathrm{~nm}\right)$ in deaerated and air-saturated solution.

\section{Investigation of EY amplification mechanism}

Using UV-Vis spectroscopy, we monitored the steadystate kinetics of EY amplification in deaerated and air-saturated solutions ( $\mathrm{pH}$ 7.4) (Figures $\mathbf{2} \mathbf{A}$ and $\boldsymbol{S}_{7}$ ). On the basis of kinetic analysis, we proposed elementary reactions associated with $\mathrm{EYH}_{2}$ activation and integrated them into the reported photochemical reactions of EY (Table S1). To estimate unknown parameters and validate the proposed reactions, we first developed the simplest kinetic model for one-species system (EY) where all rate constants could be obtained from literature, and increased complexity of the model by adding other species $\left(\mathrm{EYH}_{2}\right.$ and $\left.\mathrm{O}_{2}\right)$ and associated reactions to the system (see the Model Development section in Supporting Information for details on reaction mechanism and kinetic modeling).

When the deaerated solutions including $\mathrm{EY}$ and $\mathrm{EYH}_{2}$ are irradiated with green light, EY is excited to singlet state $\left({ }^{1} \mathrm{EY}^{*}\right)$ (Table Si, Eq. 1), whose energy is lost through vibrational relaxation and internal conversion (Eq. 2), fluorescence (Eq. 3), and intersystem crossing (Eq. 4). The triplet EY $\left({ }^{3} \mathrm{YY}^{*}\right)$ generated from intersystem crossing either decays via phosphorescence (Eq. 5) and energy transfer to EY (Eq. 6) and $\mathrm{EYH}_{2}$ (Eq. 8), or activate $\mathrm{EYH}_{2}$ via reductive quenching (Eq. 7), which produces eosin $\mathrm{Y}$ radical anion $\left(\mathrm{EY}^{-}\right)$and one-electron oxidized $\mathrm{EYH}_{2}$. At neutral $\mathrm{pH}$, the singly oxidized $\mathrm{EYH}_{2}$ appears to undergo $1 \mathrm{e}^{-} / 1 \mathrm{H}^{+}$transfer to buffer components and become EY (Figure S8). Lastly, the fate of $\mathrm{EY}^{--}$radicals can be described with acid-base equilibria (Eq. 9-10) in phosphate buffer solutions ( $\mathrm{pH}$ 7.4) and $\mathrm{pH}$-dependent disproportionation reactions (Eq. 1113). $3^{11}$
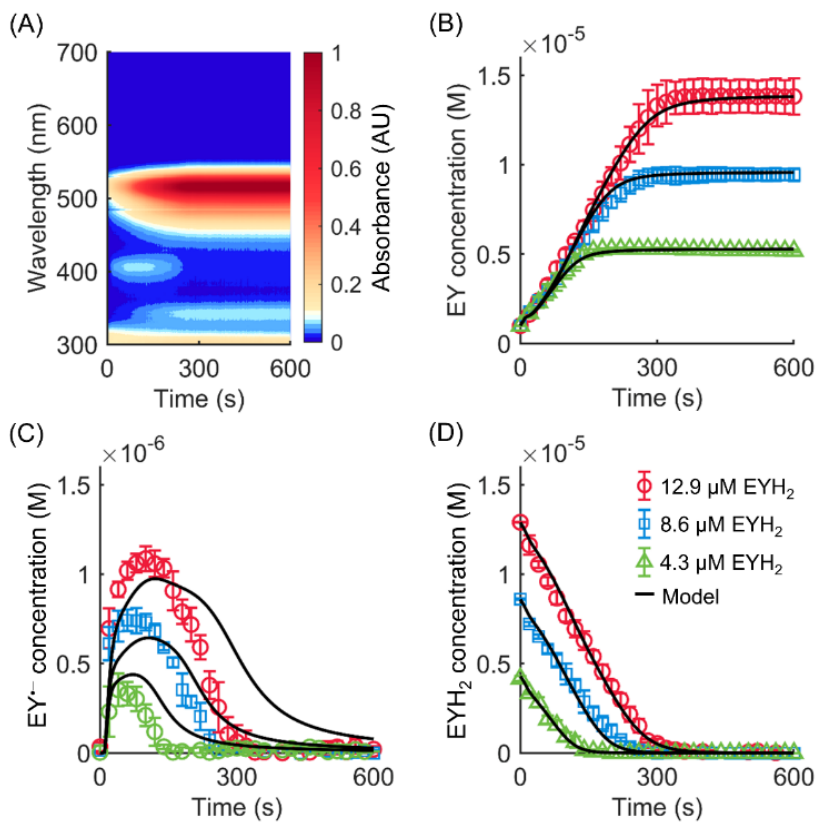

Figure 2. Steady-state kinetic studies of EY amplification in deaerated solutions. Various concentrations (4.3, 8.6, and 12.9 $\mu \mathrm{M})$ of $\mathrm{EYH}_{2}$ with $1 \mu \mathrm{M} \mathrm{EY}$ in deaerated solutions were irradiated under $2.6 \mathrm{~mW} / \mathrm{cm}^{2}$ green light $\left(\lambda_{\max }=535 \mathrm{~nm}\right)$. (A) Heatmap plot of UV-Vis absorbance change over time. Colormap was adjusted to clearly show formation of transient species, $\mathrm{EY}^{-}$, at $405 \mathrm{~nm}$. Absorbance vs. wavelength graph is also available in Figure $\mathbf{S}_{\mathbf{7}}$. Steady-state kinetics of (B) EY monitored at $516 \mathrm{~nm}$, (C) EY-- monitored at $405 \mathrm{~nm}$, and (D) $\mathrm{EYH}_{2}$ monitored at $312 \mathrm{~nm}$ during the irradiation. Black solid lines demonstrate the concentration of each species predicted by a kinetic model.

The kinetic model constructed with this mechanism provided consistent results with the concentration profiles of $\mathrm{EY}$ and $\mathrm{EYH}_{2}$ (Figures $\mathbf{2} \mathbf{B}$ and $\mathbf{2 D}$ ). However, the concentration profile of $\mathrm{EY}^{-}$was not perfectly predicted by the model. One reason for the discrepancy is that the radical concentration is particularly sensitive to kinetic parameters obtained from literature, which were measured or estimated in slightly different conditions. The other reason is that the model ignored the oxygen dissolution and diffusion from air or through the purging gas, whereas in the experiment there could be a slight leak due to improper sealing of the cuvette. Indeed, the concentration of EYcould be very sensitive to leaked traces of oxygen because the oxidation of $\mathrm{EY}^{-}$by oxygen is almost a diffusion-controlled reaction $\left(1 \times 10^{9} \mathrm{M}^{-1} \mathrm{~s}^{-1}\right) .{ }^{44}$ By considering the exposure to oxygen, the model could better predict the radical concentration profile (Figure S11). Therefore, we expect that if the air leak was strictly avoided, EY-- would decay much slowly as predicted by the current model (Figure $2 \mathrm{C}$ ). 
Notably, in deaerated conditions, two $\mathrm{EYH}_{2}$ activation reactions (two EY radicals) are required to produce one additional EY molecule due to the nature of disproportionation reactions (Eq. 11-13). In air-saturated solutions, on the other hand, one $\mathrm{EYH}_{2}$ activation leads to one EY production because $\mathrm{EY}^{--}$is rapidly oxidized to EY by oxygen ( 0.25 $\mathrm{mM})^{45}$, producing superoxide $\left(\mathrm{O}_{2}^{-{ }^{-}}\right)$(Eq. 14) and hydrogen peroxide $\left(\mathrm{H}_{2} \mathrm{O}_{2}\right)$ through series of reactions (Eq. 15-20). ${ }^{46}$ However, as shown in Figure $\mathbf{1 C}$, the EY amplification becomes sluggish in the presence of oxygen, which is mainly because of the physical quenching of ${ }^{3} \mathrm{EY}^{*}$ by oxygen, producing ground-state EY and ${ }^{~} \mathrm{O}_{2}$ (Eq. 21).44,47 The singlet oxygen is known to decay through interactions with solvent (Eq. 22) ${ }^{48}$ and dissolved oxygen (Eq. 23)..$^{30}$

The kinetic model updated with the above reactions could not predict the trend of experimental data (Figure S13). The model provided much slower $\mathrm{EYH}_{2}$ activation than experimental data and $100 \%$ recovery of $\mathrm{EYH}_{2}$ to EY, but in reality significant loss of EY species (EY, EY--, and $\mathrm{EYH}_{2}$ ) occurred during EY amplification in the presence of oxygen. To address this deviation, we focused on the reactivity of ${ }^{1} \mathrm{O}_{2}$, which is one of the most reactive species that is generated in the system and has higher energy by 94 $\mathrm{kJ} / \mathrm{mol}$ than the ground-state oxygen. ${ }^{49}$ The singlet oxygen has been proposed as the oxidant for other dihydroxanthene dyes previously, ${ }^{30,34}$ and is known to oxidize hydroquinone to benzoquinone, ${ }^{50}$ so ${ }^{1} \mathrm{O}_{2}$ is plausible to contribute to $\mathrm{EYH}_{2}$ oxidation (Eq. 24). Additionally, ${ }^{1} \mathrm{O}_{2}$ has been reported to participate in Diels-Alder type reactions on various chromophores such as anthracenes and perylenes, which results in a loss of conjugation. ${ }^{51-54}$ Substituted phenols can rapidly react with ${ }^{1} \mathrm{O}_{2}$ to yield oxygenated products. 55.56 Therefore, the oxidation of $\mathrm{EYH}_{2}$ and EY by ${ }^{1} \mathrm{O}_{2}$ could be disruptive, which leads to degradation of $\mathrm{EYH}_{2}$ (Eq. 25) and EY (Eq. 26). These ${ }^{1} \mathrm{O}_{2}$-driven reactions (Eqs. 24-26) were experimentally confirmed using a ${ }^{1} \mathrm{O}_{2}$ quencher (sodium azide) and a ${ }^{1} \mathrm{O}_{2}$ enhancer (deuterium oxide) (Figure S14). Updated with these ${ }^{1} \mathrm{O}_{2}$-driven activation and degradation reactions, the model successfully described the EY amplification kinetics and $\mathrm{EYH}_{2}$-to-EY recovery (model: $34.3 \%$; experiment: $34.5 \%$ ) in air-saturated solutions (Figure $3 \mathrm{~A}$ ).

\section{Optimization of EY amplification with insights from the mechanism}

From the proposed mechanism for EY amplification (Scheme 3), where $\mathrm{EYH}_{2}$ is oxidized to $\mathrm{EY}$ by ${ }^{3} \mathrm{EY}^{*}$ and ${ }^{1} \mathrm{O}_{2}$, we identified reactions retarding the EY amplification in air-saturated solution: (1) quenching of $3 \mathrm{EY}^{*}$ by oxygen and (2) degradation of $\mathrm{EYH}_{2}$ by ${ }^{1} \mathrm{O}_{2}$. Although the triplet quenching was facilitated by high concentration of oxygen ( $\sim 0.25 \mathrm{mM})$ compared to that of $\mathrm{EYH}_{2}(\sim 12 \mu \mathrm{M})$, increasing light intensity could raise the ${ }^{3} \mathrm{EY}^{*}$ production rate, enhancing kinetics of $\mathrm{EYH}_{2}$ oxidation by the triplet. However, according to the model, this measure might not improve the recovery of $\mathrm{EYH}_{2}$ to $\mathrm{EY}$ because faster degradation of $\mathrm{EYH}_{2}$ and $\mathrm{EY}$ by ${ }^{1} \mathrm{O}_{2}$ could be accompanied by the increased light intensity, limiting the maximum concentration of amplified EY (Figure S16). Thus, to improve the amplification factor $\left([\mathrm{EY}]_{\text {final }} /[\mathrm{EY}]_{\text {initial }}\right)$, it is of primary importance to increase the recovery by preventing the ${ }^{1} \mathrm{O}_{2}$-involved degradation of $\mathrm{EYH}_{2}$ and $\mathrm{EY}$.

Scheme 3. Mechanism of EY autocatalytic amplification through photosensitized oxidation of $\mathrm{EYH}_{2}$.

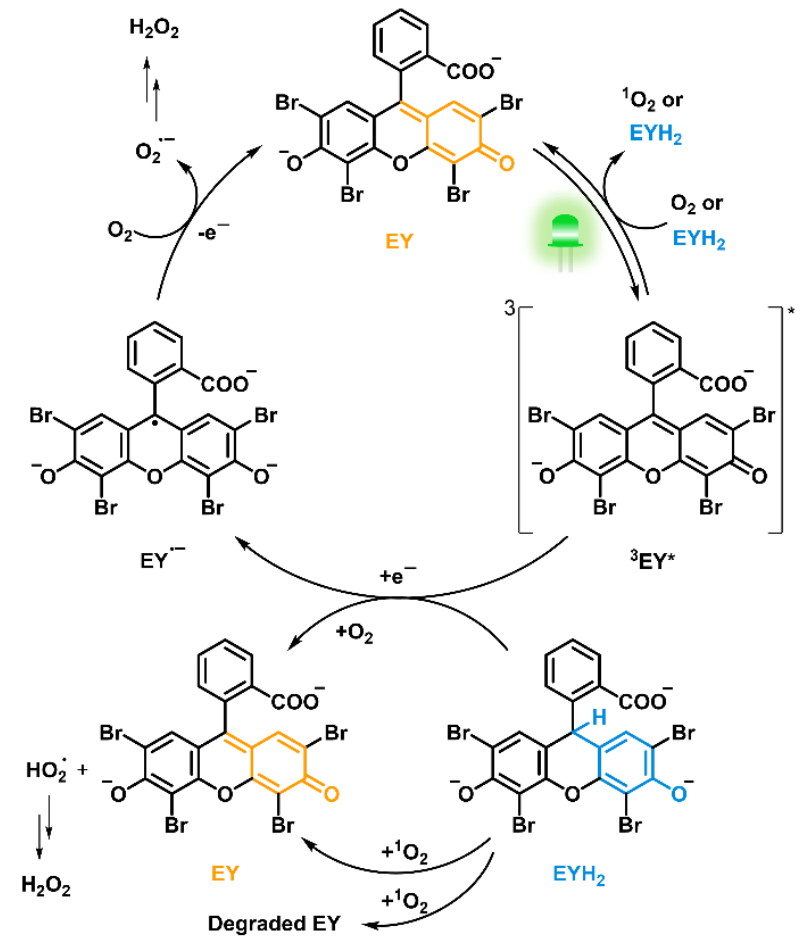

EY is photoreduced by $\mathrm{EYH}_{2}$ upon absorption of green light. $\mathrm{EY}^{-}$is rapidly oxidized back to EY via single electron transfer to oxygen. The oxidized $\mathrm{EYH}_{2}$ react with oxygen to yield EY and hydroperoxyl radical. Singlet oxygen, generated by energy transfer from $3 \mathrm{EY}^{*}$ to ground-state oxygen, not only activates $\mathrm{EYH}_{2}$, but also degrades the inactivated EY.

Considering that the yield of photosensitized ${ }^{1} \mathrm{O}_{2}$ production can be dependent on $\mathrm{pH}$ because the degree of protonation in triplet photosensitizers may impact the energy transfer to ground-state oxygen, ${ }^{57,58}$ we investigated the effects of $\mathrm{pH}$ on EY amplification. As shown in Figure $3 \mathbf{B}$, the recovery increased from $34 \%$ to $52 \%$ as $\mathrm{pH}$ decreased from 7.8 to 6.1 whereas the $\mathrm{EYH}_{2}$ oxidation rate decreased. At present, it is not clear whether ${ }^{1} \mathrm{O}_{2}$ quantum yield was reduced or the rate of $\mathrm{EYH}_{2}$ degradation by ${ }^{1} \mathrm{O}_{2}$ decreased at low $\mathrm{pH}$ by protonation $\left(\mathrm{pK}_{\mathrm{a}}=6.5\right.$, Figure $\left.\mathrm{S17}_{17}\right)$ of $\mathrm{EYH}_{2}$, but lowering $\mathrm{pH}$ was very effective to improve the recovery. Therefore, we used $\mathrm{pH} 6$ phosphate buffer (o.2 $\mathrm{M})$ for the following experiments and increased light intensity to compensate for the reduction in $\mathrm{EYH}_{2}$ oxidation rate. In addition, we confirmed that residual DMSO from the $\mathrm{EYH}_{2}$ stock solution did not affect the EY amplification kinetics (Figure S18), supporting DMSO as a safe storage solvent for $\mathrm{EYH}_{2}$.

As another approach to suppressing the $\mathrm{EYH}_{2}$ and EY degradation by ${ }^{1} \mathrm{O}_{2}$, we included methoxy poly(ethylene glycol) (mPEG) in the buffer solution because localization of $\mathrm{EY}$ and $\mathrm{EYH}_{2}$ in carbon-rich $\mathrm{mPEG}$ phase could increase the rate of $\mathrm{EYH}_{2}$ oxidation by ${ }^{3} \mathrm{EY}^{*}$ relatively to reaction 

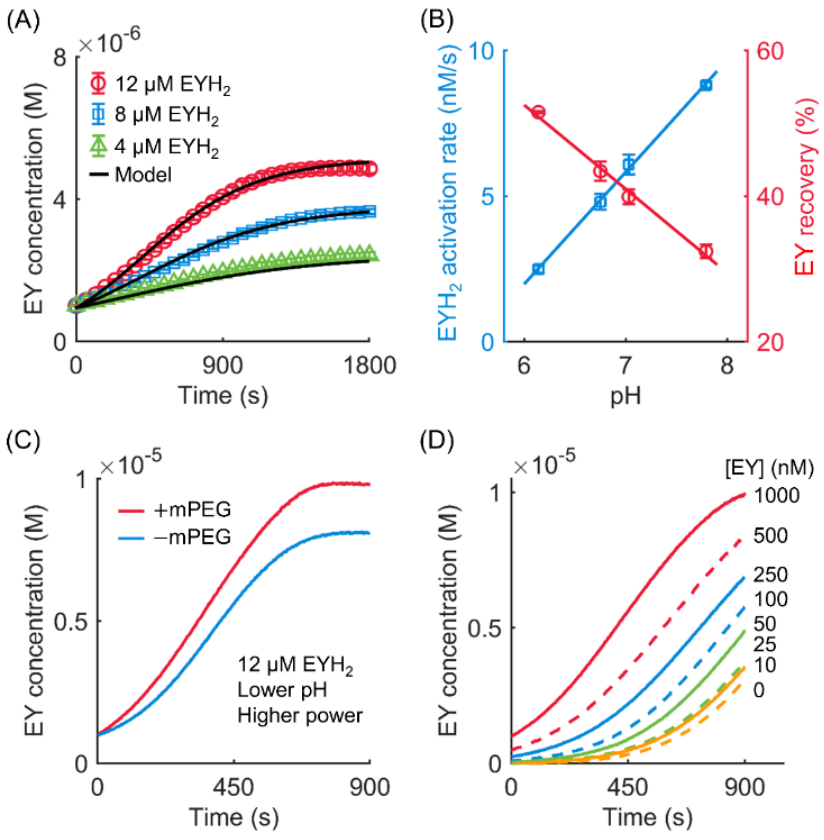

Figure 3. Steady-state kinetic studies of EY amplification in the presence of oxygen. Various concentrations (4, 8, and 12 $\mu \mathrm{M})$ of $\mathrm{EYH}_{2}$ with $1 \mu \mathrm{M} \mathrm{EY}$ and $\sim 0.25 \mathrm{mM}$ oxygen 45 were irradiated under $1.2 \mathrm{~mW} / \mathrm{cm}^{2}$ green light $\left(\lambda_{\max }=535 \mathrm{~nm}\right)$. (A) Steady-state kinetics of EY amplification monitored at $516 \mathrm{~nm}$ during the irradiation. Black solid lines show EY concentration predicted by a kinetic model. (B) $\mathrm{pH}$ dependence of $\mathrm{EYH}_{2}$ activation rate and $\mathrm{EY}$ recovery from $\mathrm{EYH}_{2}$. (C) Impact of methoxy poly(ethylene glycol) (mPEG, $20 \mathrm{mM}$ ) on the EY recovery. Lower $\mathrm{pH}, 6$, and higher power, $10 \mathrm{~mW} / \mathrm{cm}^{2}\left(\lambda_{\max }=530\right.$ $\mathrm{nm})$, were used to improve the EY recovery and the $\mathrm{EYH}_{2} \mathrm{ac}-$ tivation rate. The graph shows sigmoidal increase in EY concentration. (D) EY is amplified as $\mathrm{EYH}_{2}$ is consumed, enabling to detect EY as low as $10 \mathrm{nM}$ using a UV-Vis spectrometer with a detection limit of $50 \mathrm{nM}$ EY. The amplification reagent was composed of $12 \mu \mathrm{M} \mathrm{EYH}$ and $40 \mathrm{mM} \mathrm{mPEG}$ in $0.2 \mathrm{M}$ phosphate buffer (pH 6).

rates between ${ }^{1} \mathrm{O}_{2}$ and $\mathrm{EYH}_{2}$, and might also cause faster depletion and slower replenishment of oxygen, 59 inhibiting ${ }^{1} \mathrm{O}_{2}$ production. Surprisingly, the recovery further increased to $74 \%$ when mPEG was added to the buffer solution (Figure ${ }_{3} \mathrm{C}$ ). Together with enhanced light intensity, it also clearly displayed a sigmoidal response curve, which is a typical indicator of autocatalytic reactions. ${ }^{27,28}$ We excluded ${ }^{1} \mathrm{O}_{2}$ quenching by mPEG because the lifetime of ${ }^{1} \mathrm{O}_{2}$ does not change in PEG solution. ${ }^{60}$ Excited states kinetics (e.g. triplet lifetime) of EY could change with the $\mathrm{mPEG}$ addition as reported in other environments, ${ }^{61}$ but longer triplet lifetime (simulated by ignoring all decay pathways except for quenching by oxygen) could provide only minor improvement $(\sim 1 \%)$ in the recovery. Thus, it is reasonable to propose that the nanoscale liquid-liquid phase separation locally concentrates $\mathrm{EY}$ and $\mathrm{EYH}_{2}$ and selectively increases the rate of oxygen-free $\mathrm{EYH}_{2}$ oxidation, assisting to improve the recovery.

After optimizing the mPEG concentration (Figure S19), we performed EY amplification experiments with various initial concentrations of EY (Figure 3D). Under 10
$\mathrm{mW} / \mathrm{cm}^{2}$ green light, EY was successfully amplified with 12 $\mu \mathrm{M} \mathrm{EYH} \mathrm{H}_{2}$ and $40 \mathrm{mM} \mathrm{mPEG}$ in $0.2 \mathrm{M}$ phosphate buffer $(\mathrm{pH}$ $6)$, revealing that the limit of detection for this proof-ofconcept EY detection assay was $10 \mathrm{nM}$. Considering that the UV-Vis spectrophotometer used in the experiments could not detect below $50 \mathrm{nM}$ EY before the amplification, this is an exciting demonstration that the autocatalytic EY amplification strategy is capable of improving the assay sensitivity.
(A)
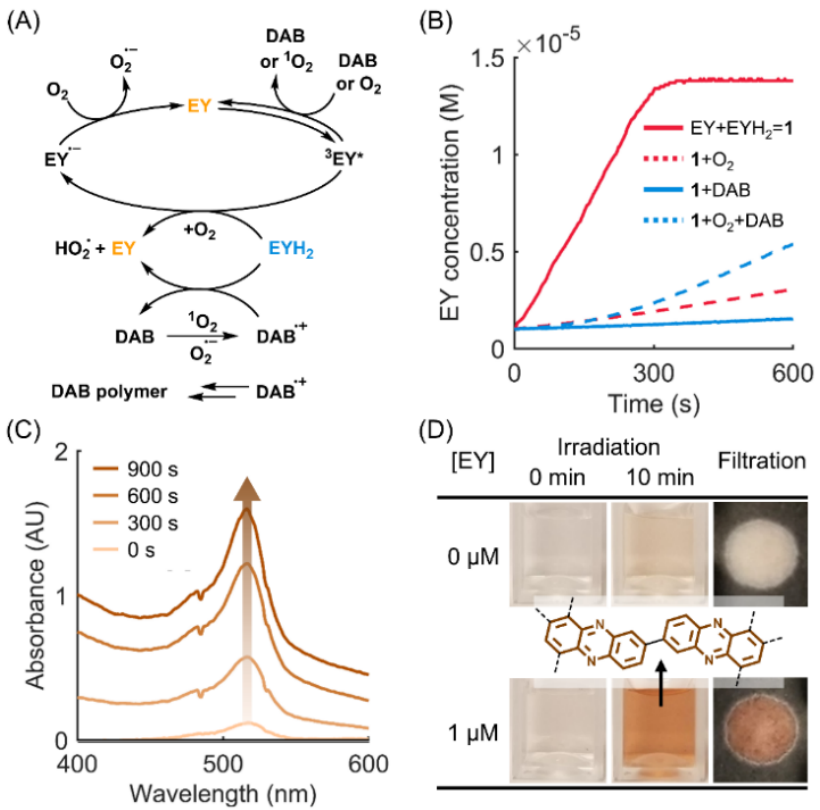

Figure 4. EY amplification coupled with 3,3'-diaminobenzidine (DAB) polymerization. (A) Mechanism of the EY-DAB amplification. $\mathrm{EYH}_{2}$ is activated not only by $3 \mathrm{EY}^{*}$, but also by oxidized DAB radicals $\left(\mathrm{DAB}^{*+}\right)$ formed from $\mathrm{DAB}$ and ${ }^{1} \mathrm{O}_{2}$ or $\mathrm{O}_{2}{ }^{-}$reaction. The $\mathrm{DAB}^{\circ+}$ also reacts with each other to form brown polymer. Detailed reaction mechanism for EY and DAB is available in ref. 62. (B) Steady-state kinetic studies of EY amplification with oxygen and DAB. System 1 included only $1 \mu \mathrm{M}$ EY and $\sim 12 \mu \mathrm{M} \mathrm{EYH}{ }_{2}$ in $\mathrm{pH} 7.4$ phosphate buffer (o.2 M). The concentrations of added oxygen and DAB were $\sim 0.25 \mathrm{mM}$ and $0.6 \mathrm{mM}$, respectively. (C) Absorbance change during EY-DAB amplification under $10 \mathrm{~mW} / \mathrm{cm}^{2}$ green light $\left(\lambda_{\max }=530 \mathrm{~nm}\right)$. The solution included $1 \mu \mathrm{M} \mathrm{EY,} 12 \mu \mathrm{MEYH}_{2}$, and o.6 mM DAB in $0.2 \mathrm{M} \mathrm{Na}_{2} \mathrm{HPO}_{4}$ (pH 9). (D) Visual detection of $1 \mu \mathrm{M}$ EY using EY-DAB amplification. The same conditions as described in (C) apply here. After 10-min EY-DAB amplification, brown phenazine polymer formed in the solution with $1 \mu \mathrm{M} \mathrm{EY,}$ which can be filtered by cellulose paper.

\section{Coupling EY amplification with DAB polymerization}

Importantly, the EY amplification can be coupled with various photochemical reactions to generate different forms of signals. To demonstrate this potential, we combined the EY amplification with photoinduced oxidative polymerization of 3,3'- diaminobenzidine (DAB). Because $\mathrm{DAB}$ is known to form a brown-colored phenazine polymer when oxidized by ${ }^{1} \mathrm{O}_{2}$ or $\mathrm{O}_{2}{ }^{-}, 35,62,63$ we expected that the incorporation of DAB would also contribute to improving the $\mathrm{EYH}_{2}$-to-EY recovery by consuming ${ }^{1} \mathrm{O}_{2}$ in addition to producing colorimetric signals, which has proven to be 
true (Figure S2o). Interestingly, there was an unexpected synergy in the EY-DAB amplification. As proposed in Figure $4 \mathbf{A}, \mathrm{EYH}_{2}$ can be activated by the oxidized $\mathrm{DAB}$ radicals $\left(\mathrm{DAB}^{+}\right)$formed from the reaction between DAB and ${ }^{1} \mathrm{O}_{2}$ or $\mathrm{O}_{2}{ }^{-}$, meaning that the side products of EY amplification can be recycled by DAB to activate more $\mathrm{EYH}_{2}$. This is supported by kinetic studies of EY amplification with oxygen and DAB (Figure ${ }_{4} \mathbf{B}$ ). Compared to system 1 including only $\mathrm{EY}$ and $\mathrm{EYH}_{2}$, addition of either oxygen or DAB to 1 retarded $\mathrm{EY}$ amplification due to rapid quenching of $3 \mathrm{EY}^{*}$ by the additives. On the other hand, when both oxygen and DAB were added to 1 , the EY amplification rate did not further decrease, but increased. Together with the higher recovery with $\mathrm{DAB}$, this counter-intuitive result indicates that $\mathrm{DAB}^{++}$can activate $\mathrm{EYH}_{2}$ less disruptively than ${ }^{1} \mathrm{O}_{2}$. After optimizing conditions for EY-DAB amplification to maximize EY-specific polymerization response (Figures S21-S23), we proceeded to the visual detection of EY in solution. As shown in Figure ${ }_{4} \mathrm{C}$, EY-DAB amplification increases not only the absorbance $\left(\lambda_{\max }=516 \mathrm{~nm}\right)$ of $\mathrm{EY}$, but also the absorbance in the visible range $(400-700 \mathrm{~nm})$ in the presence of EY $(1 \mu \mathrm{M})$. This broad absorption band is attributed to the insoluble DAB polymer, which enables visual detection of $1 \mu \mathrm{M}$ EY in solution (Figure ${ }_{4} \mathrm{D}$ ).

\section{Application of EY amplification in biodetection as- says}

Finally, we applied the EY and EY-DAB amplification strategies to specific detection of biomolecules. Firstly, we developed a rapid ( $<30 \mathrm{~min}$ ) cellulose particle-based fluorescence assays with EY amplification to detect SARS-CoV2 nucleocapsid protein (N-protein), a biomarker of COVID-19. ${ }^{64-66}$ As described in Figure $5 \mathbf{A}$, capture binder (SsoNP.E2) ${ }^{67}$ is genetically fused to cellulose binding domain (CBD) for oriented immobilization on microcrystalline cellulose particles. Once SARS-CoV-2 N-protein (o$100 \mathrm{nM}$ ) in samples is captured on the cellulose particles, the captured target is labeled with reporter binder (SsoNP.E1 fused to biotinylated maltose binding domain) ${ }^{67}$ and EY-conjugated streptavidin (streptavidin-EY). The fluorescence intensity from EY associated with the captured target is then amplified by oxidizing $\mathrm{EYH}_{2}$ under green light $\left(5 \mathrm{~mW} / \mathrm{cm}^{2}, \lambda_{\max }=530 \mathrm{~nm}\right)$. As can be seen in Figure $5^{\mathbf{B}}$, the EY amplification improved the detection limit of the N-protein by $\sim 30$-fold from $30 \mathrm{nM}$ to $1 \mathrm{nM}$, which is clinically relevant level. ${ }^{68}$

Next, we incorporated EY-DAB amplification into colorimetric assays. Using the same cellulose particle-based platform, we detect streptavidin-EY as a model protein with capture binder (rcSso7d.SA) genetically fused to CBD. ${ }^{69}$ As presented in Figure 6A, after the target protein is captured on the cellulose particles, EY-DAB amplification reagents are added and irradiated under green light to produce the brown polymer. Comparing pre- and post-amplification results in Figure 6B, we can see that the EYDAB amplification allows visual detection of $10 \mathrm{nM}$ streptavidin-EY.
(A)
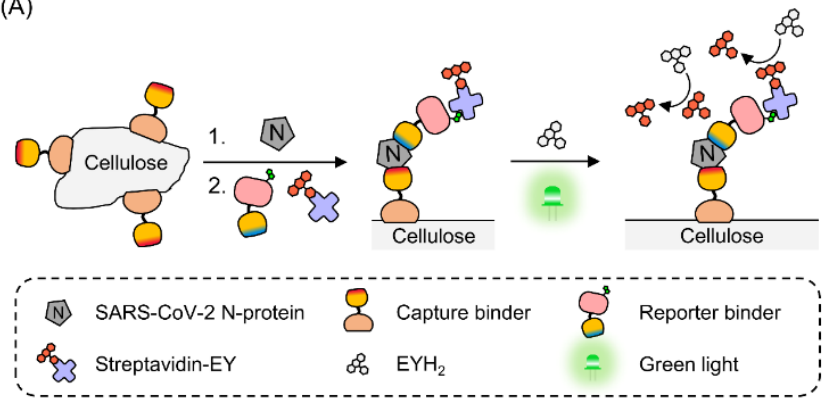

(B)

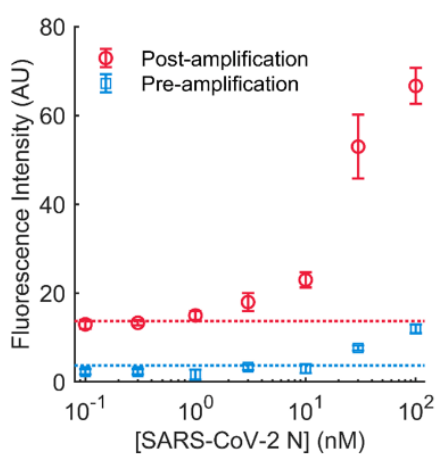

Figure 5. Detection of SARS-CoV-2 N-protein using cellulosebased fluorescence assay with EY amplification. (A) Schematic description of the assay. Detailed protocol and conditions are available in the Supporting Methods section. (B) SARS-CoV-2 $\mathrm{N}$-protein fluorescence assay results before and after EY amplification. The EY amplification improved the detection limit of SARS-CoV-2 N-protein by $\sim 30$-fold from $30 \mathrm{nM}$ (pre-amplification, blue square) to $1 \mathrm{nM}$ (post-amplification, red circle). The dotted line $(\mathrm{Neg}+3 \sigma)$ represents the mean fluorescence intensity (Neg) of o nM samples plus three times their standard deviation $(\sigma)$ for each case.

These proof-of-concept assays reveal that the autocatalytic EY amplification strategy using water-soluble, thermally stable, and rapidly activatable $\mathrm{EYH}_{2}$ can be easily incorporated into various types of biodetection assays using EY-conjugated affinity reagents. Additionally, the method can improve the detection limit by amplifying biodetection signals with low intensity light $\left(5 \mathrm{~mW} / \mathrm{cm}^{2}\right)$, so it could be especially useful with low-cost, portable, but not very sensitive fluorescent reader or imaging setup as opposed to sophisticated instruments in centralized laboratories. Currently, the EY impurity (o.05\%, $6 \mathrm{nM})$ in the amplification reagents including $12 \mu \mathrm{M} \mathrm{EYH}{ }_{2}$ induces the autocatalytic EY amplification even without target-associated EY, increasing background signals and negatively affecting the detection limit. To overcome this issue, our current efforts are focused on employing affinity reagents conjugated with red light-absorbing photosensitizers such as methylene blue (MB) and sequential red/green light illumination to initially generate EY from target-associated $\mathrm{MB}$ and then amplify EY autocatalytically. 
(A)

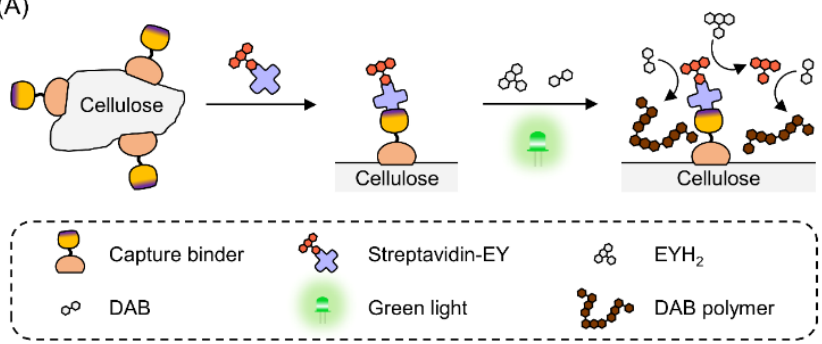

(B)

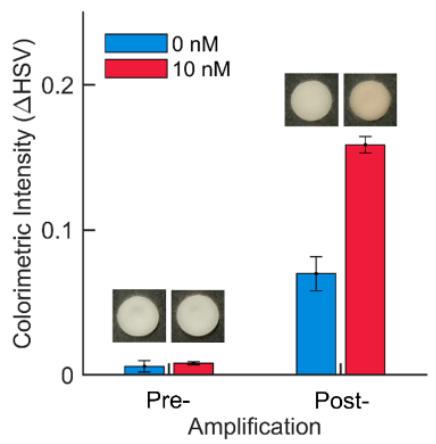

Figure 6. Detection of EY-conjugated streptavidin (streptavidin-EY) using cellulose-based colorimetric assay with EY-DAB amplification. (A) Schematic description of the assay. Detailed protocol and conditions are available in the Supporting Methods section. (B) Streptavidin-EY colorimetric assay results before and after EY-DAB amplification. Representative images are provided above corresponding bar graphs. Images for replicates are available in Figure $\mathbf{S 2 4}$. Colorimetric intensity was calculated in HSV (Hue, Saturation, Value) color space using a reported method in literature. $7^{0}$

\section{CONCLUSION}

In summary, we have developed an autocatalytic signal amplification method for sensitive biodetection by employing photocatalytic activation of EYHz. This inactivated photocatalyst is easily prepared, water-soluble, thermally stable, and rapidly activated by ${ }^{3} \mathrm{EY}^{*}$ and ${ }^{1} \mathrm{O}_{2}$ produced during photocatalysis of EY, amplifying the amount of EY in aqueous solution. The EY amplification can also be coupled with various photochemical reactions to produce different forms of signals. To demonstrate this potential, DAB polymerization was combined with EY amplification to enable visual detection of EY. Furthermore, using EYconjugated affinity reagents, we developed a fluorescence assay for detection of SARS-CoV-2 nucleocapsid protein, a biomarker of COVID-19, and a colorimeric assay for detection of streptavidin, revealing that the EY amplification strategy can be easily adopted to amplify biodetection signals in different kinds of assays. Considering the long shelflife of $\mathrm{EYH}_{2}$ and the rapid EY amplification under low intensity light, we anticipate that this non-enzymatic autocatalytic amplification reaction is especially useful in developing rapid and highly sensitive point-of-care assays.

\section{ASSOCIATED CONTENT}

Supporting Information. Materials and Methods; Model development; Table S1; Figures S1-S24. This material is available free of charge via the Internet at http://pubs.acs.org.

\section{AUTHOR INFORMATION}

\section{Corresponding Author}

*E-mail:sikes@mit.edu

\section{ORCID}

Seunghyeon Kim: oooo-ooo1-6515-2679

Alan Aguirre-Soto: oooo-0003-0455-5401

Hadley D. Sikes: oooo-0oo2-7096-138X

\section{Author Contributions}

The paper was written through contributions of all authors.

Notes

The authors declare no competing financial interest.

\section{ACKNOWLEDGMENT}

This work was supported by the National Research Foundation of Singapore through the Antimicrobial Resistance Interdisciplinary Research Group and the MISTI MIT-Mexico Seed Fund. S.K. acknowledges support from the Kwanjeong Educational Foundation. A.A.-S. acknowledges a CONACYT Postdoctoral Research Award (263622). The authors thank Yining Hao and Dousabel M. Y. Tay for sharing affinity proteins (biotinylated MBP-SsoNP.E1, SsoNP.E2-CBD, and rcSso7d.SA-CBD) and SARS-CoV-2 nucleocapsid protein that they expressed and purified.

\section{REFERENCES}

(1) Kozel, T. R.; Burnham-marusich, A. R. Point-of-Care Testing for Infectious Diseases: Past, Present, and Future. J. Clin. Microbiol. 2017, 55, 2313-2320.

(2) Chen, H.; Liu, K.; Li, Z.; Wang, P. Point-of-Care Testing for Infectious Diseases. Clin. Chim. Acta 2019, 493, 138-147.

(3) Uyeki, T. M.; Prasad, R.; Vukotich, C.; Stebbins, S.; Rinaldo, C. R.; Ferng, Y.-H.; Morse, S. S.; Larson, E. L.; Aiello, A. E.; Davis, B.; Monto, A. S. Low Sensitivity of Rapid Diagnostic Test for Influenza. Clin. Infect. Dis. 2009, 48, e89-e92.

(4) Vasoo, S.; Stevens, J.; Singh, K. Rapid Antigen Tests for Diagnosis of Pandemic (Swine) Influenza A/H1N1. Clin. Infect. Dis. 2009, 49, 1090-1093.

(5) Perchetti, G. A.; Huang, M.-L.; Mills, M. G.; Jerome, K. R.; Greninger, A. L. Analytical Sensitivity of the Abbott BinaxNOW COVID-19 Ag CARD. J. Clin. Microbiol. 2021, 59, eo2880-20.

(6) Erlich, H. A.; Gelfand, D.; Sninsky, J. J. Recent Advances in the Polymerase Chain Reaction. Science 1991, 252, 1643-1651.

(7) Sano, T.; Smith, C. L.; Cantor, C. R. Immuno-PCR: Very Sensitive Antigen Detection by Means of Specific Antibody-DNA Conjugates. Science 1992, 258, 120-122.

(8) Niemz, A.; Ferguson, T. M.; Boyle, D. S. Point-of-Care Nucleic Acid Testing for Infectious Diseases. Trends Biotechnol. 2011, 29 (5), 240-250.

(9) Zhao, Y.; Chen, F.; Li, Q.; Wang, L.; Fan, C. Isothermal Amplification of Nucleic Acids. Chem. Rev. 2015, 115, 12491-12545. 
(10) Kilic, T.; Weissleder, R.; Lee, H. Molecular and Immunological Diagnostic Tests of COVID-19: Current Status and Challenges. iScience 2020, 23 (8), 101406.

(11) Craw, P.; Balachandran, W. Isothermal Nucleic Acid Amplification Technologies for Point-of-Care Diagnostics: A Critical Review. Lab Chip 2012, 12 (14), 2469.

(12) Kumar, S.; Gallagher, R.; Bishop, J.; Kline, E.; Buser, J.; Lafleur, L.; Shah, K.; Lutz, B.; Yager, P. Long-Term Dry Storage of Enzyme-Based Reagents for Isothermal Nucleic Acid Amplification in a Porous Matrix for Use in Point-of-Care Diagnostic Devices. Analyst 2020, 145, 6875-6886.

(13) Zhang, Y.; Ozdemir, P. Microfluidic DNA Amplification-A Review. Anal. Chim. Acta 2009, 638, 115-125.

(14) Yoon, H. J.; Mirkin, C. A. PCR-like Cascade Reactions in the Context of an Allosteric Enzyme Mimic. J. Am. Chem. Soc. 2008, 130 (35), 11590-11591.

(15) Sella, E.; Shabat, D. Dendritic Chain Reaction. J. Am. Chem. Soc. 2009, 131, 9934-9936.

(16) Yoshii, T.; Onogi, S.; Shigemitsu, H.; Hamachi, I. Chemically Reactive Supramolecular Hydrogel Coupled with a Signal Amplification System for Enhanced Analyte Sensitivity. J. Am. Chem. Soc. 2015, 137 (9), 3360-3365.

(17) Pallu, J.; Rabin, C.; Creste, G.; Branca, M.; Mavré, F.; Limoges, B. Exponential Molecular Amplification by $\mathrm{H}_{2} \mathrm{O}_{2-}$ Mediated Autocatalytic Deprotection of Boronic Ester Probes to Redox Cyclers. Chem. - A Eur. J. 2019, 25 (31), 7534-7546.

(18) Perry-Feigenbaum, R.; Sella, E.; Shabat, D. Autoinductive Exponential Signal Amplification: A Diagnostic Probe for Direct Detection of Fluoride. Chem. - A Eur. J. 2011, 17, 12123-12128.

(19) Baker, M. S.; Phillips, S. T. A Two-Component Small Molecule System for Activity-Based Detection and Signal Amplification: Application to the Visual Detection of Threshold Levels of Pd(II). J. Am. Chem. Soc. 2011, 133, 5170-5173.

(20) Baker, M. S.; Phillips, S. T. A Small Molecule Sensor for Fluoride Based on an Autoinductive, Colorimetric Signal Amplification Reaction. Org. Biomol. Chem. 2012, 10, 3595-3599.

(21) Gu, J. A.; Mani, V.; Huang, S.-T. Design and Synthesis of Ultrasensitive Off-On Fluoride Detecting Fluorescence Probe via Autoinductive Signal Amplification. Analyst 2015, 140, 346-352.

(22) Sun, X.; Dahlhauser, S. D.; Anslyn, E. V. New Autoinductive Cascade for the Optical Sensing of Fluoride: Application in the Detection of Phosphoryl Fluoride Nerve Agents. J. Am. Chem. Soc. 2017, 139, 4635-4638.

(23) Sun, X.; Anslyn, E. V. An Auto-Inductive Cascade for the Optical Sensing of Thiols in Aqueous Media: Application in the Detection of a VX Nerve Agent Mimic. Angew. Chemie - Int. Ed. 2017, 56, 9522-9526.

(24) Mohapatra, H.; Schmid, K. M.; Phillips, S. T. Design of Small Molecule Reagents That Enable Signal Amplification via an Autocatalytic, Base-Mediated Cascade Elimination Reaction. Chem. Commun. 2012, 48, 3018-3020.

(25) Kottani, R.; Majjigapu, J. R. R.; Kurchan, A.; Majjigapu, K.; Gustafson, T. P.; Kutateladze, A. G. Photoinduced Signal Amplification through Controlled Externally Sensitized Fragmentation in Masked Sensitizers. J. Am. Chem. Soc. 2006, 128 (46), 14794-14795.

(26) Gustafson, T. P.; Metzel, G. A.; Kutateladze, A. G. Photochemically Amplified Detection of Molecular Recognition Events: An Ultra-Sensitive Fluorescence Turn-Off Binding Assay. Org. Biomol. Chem. 2011, 9, 4752-4755.

(27) Blackmond, D. G. An Examination of the Role of Autocatalytic Cycles in the Chemistry of Proposed Primordial Reactions. Angew. Chemie - Int. Ed. 2009, 48, 386-390.

(28) Goggins, S.; Frost, C. G. Approaches Towards Molecular Amplification for Sensing. Analyst 2016, 141 (11), 3157-3218.
(29) Uchida, K.; Koizumi, M. Photosensitized Oxidation of Leuco-Uranine. II. Kinetics of an Acridine-Sensitized Photoöxidation in the Deaerated Solution. Bull. Chem. Soc. Jpn. 1962, 35 (11), 1875-1881.

(30) Usui, Y.; Iwanaga, C.; Koizumi, M. Reactions of Singlet Oxygen and Half-Reduced Oxygen Which Are Produced Simultaneously by the Interaction of Triplet Dye and Oxygen. Bull. Chem. Soc. Jpn. 1969, 42, 1231-1239.

(31) Krüger, U.; Memming, R. Formation and Reactions of Long Lived Xanthene Dye Radicals. I. Photochemical Studies on Reactions of Semireduced Fluoresceïn. Berichte der BunsenGesellschaft für Phys. Chemie 1974, 78 (7), 670-678.

(32) Wardman, P. Fluorescent and Luminescent Probes for Measurement of Oxidative and Nitrosative Species in Cells and Tissues: Progress, Pitfalls, and Prospects. Free Radic. Biol. Med. 2007, 43 (7), 995-1022.

(33) Wrona, M.; Patel, K. B.; Wardman, P. The Roles of Thiol-Derived Radicals in the Use of $2^{\prime}, 7^{\prime}-$ Dichlorodihydrofluorescein as a Probe for Oxidative Stress. Free Radic. Biol. Med. 2008, 44, 56-62.

(34) Daghastanli, N. A.; Itri, R.; Baptista, M. S. Singlet Oxygen Reacts with 2',7'-Dichlorodihydrofluorescein and Contributes to the Formation of $2^{\prime}, 7^{\prime}$-Dichlorofluorescein. Photochem. Photobiol. 2008, 84, 1238-1243.

(35) Deerinck, T. J.; Martone, M. E.; Lev-Ram, V.; Green, D. P. L.; Tsien, R. Y.; Spector, D. L.; Huang, S.; Ellisman, M. H. Fluorescence Photooxidation with Eosin: A Method for High Resolution Immunolocalization and In Situ Hybridization Detection for Light and Electron Microscopy. J. Cell Biol. 1994, 126 (4), 901-910.

(36) Hansen, R. R.; Sikes, H. D.; Bowman, C. N. Visual Detection of Labeled Oligonucleotides Using Visible-LightPolymerization-Based Amplification. Biomacromolecules 2oo8, 9, 355-362.

(37) Johnson, G. A.; Muthukrishnan, N.; Pellois, J. P. Photoinactivation of Gram Positive and Gram Negative Bacteria with the Antimicrobial Peptide (KLAKLAK) ${ }_{2}$ Conjugated to the Hydrophilic Photosensitizer Eosin Y. Bioconjug. Chem. 2013, 24, 114-123.

(38) Bowers, P. G.; Porter, G. Triplet State Quantum Yields for Some Aromatic Hydrocarbons and Xanthene Dyes in Dilute Solution. Proc. R. Soc. Lond. A. Math. Phys. Sci. 1967, 299, 348-353.

(39) Encinas, M. V.; Rufs, A. M.; Bertolotti, S. G.; Previtali, C. M. Xanthene Dyes/Amine as Photoinitiators of Radical Polymerization: A Comparative and Photochemical Study in Aqueous Medium. Polymer 2009, 50 (13), 2762-2767.

(40) Bilski, P.; Dabestani, R.; Chignell, C. F. Photoprocesses of Eosine and Rose Bengal Ion Pairs with Cationic Surfactant in Non-Polar Solvent: Application in Photosensitization Studies. J. Photochem. Photobiol. A Chem. 1994, 79, 121-130.

(41) Zhang, J.; Sun, L.; Yoshida, T. Spectroelectrochemical Studies on Redox Reactions of Eosin Y and Its Polymerization with $\mathrm{Zn}^{2+}$ Ions. J. Electroanal. Chem. 2011, 662, 384-395.

(42) Weng, G.; Mahmoud, M. A.; El-Sayed, M. A. Nanocatalysts Can Change the Number of Electrons Involved in Oxidation-Reduction Reaction with the Nanocages Being the Most Efficient. J. Phys. Chem. C 2012, 116, 24171-24176.

(43) Aguirre-Soto, A.; Kaastrup, K.; Kim, S.; Ugo-Beke, K.; Sikes, H. D. Excitation of Metastable Intermediates in Organic Photoredox Catalysis: Z-Scheme Approach Decreases Catalyst Inactivation. ACS Catal. 2018, 8, 6394-6400.

(44) Görner, H. Oxygen Uptake Induced by Electron Transfer from Donors to the Triplet State of Methylene Blue and Xanthene Dyes in Air-Saturated Aqueous Solution. Photochem. Photobiol. Sci. 2008, 7, 371-376. 
(45) Concentration of dissolved oxygen in water. http://water.usgs.gov/software/DOTABLES (Accessed on April 2021)

(46) Kralik, P.; Kusic, H.; Koprivanac, N.; Bozic, A. L. Degradation of Chlorinated Hydrocarbons by $\mathrm{UV} / \mathrm{H}_{2} \mathrm{O}_{2}$ : The Application of Experimental Design and Kinetic Modeling Approach. Chem. Eng. J. 2010, 158 (2), 154-166.

(47) Rizzuto, F.; Spikes, J. D. The Eosin-Sensitized Photooxidation of Substituted Phenylalanines and Tyrosines. Photochem. Photobiol. 1977, 25, 465-476.

(48) Wilkinson, F.; Brummer, J. G. Rate Constants for the Decay and Reactions of the Lowest Electronically Excited Singlet State of Molecular Oxygen in Solution. J. Phys. Chem. Ref. Data 1981, 10 (4), 809-999.

(49) DeRosa, M. C.; Crutchley, R. J. Photosensitized Singlet Oxygen and Its Applications. Coord. Chem. Rev. 2002, 233-234, $351^{-371}$.

(50) Trashin, S.; Rahemi, V.; Ramji, K.; Neven, L.; Gorun, S. M.; De Wael, K. Singlet Oxygen-Based Electrosensing by Molecular Photosensitizers. Nat. Commun. 2017, 8, 16108.

(51) Foote, C. S. Photosensitized Oxygenations and the Role of Singlet Oxygen. Acc. Chem. Res. 1968, 1 (4), 104-110.

(52) Schmidt, R.; Drews, W.; Brauer, H.-D. WavelengthDependent Photostable or Photoreversible Photochromic System. J. Phys. Chem. 1982, 86, 4909-4913.

(53) Maeda, H.; Nanai, Y.; Mizuno, K.; Chiba, J.; Takeshima, S.; Inouye, M. Photooxygenation of Alkynylperylenes. Formation of Dibenzo[jk,mn]phenanthrene-4,5-diones. J. Org. Chem. 2007, 72, 8990-8993.

(54) Filatov, M. A.; Baluschev, S.; Landfester, K. Protection of Densely Populated Excited Triplet State Ensembles against Deactivation by Molecular Oxygen. Chem. Soc. Rev. 2016, 45 (17), 4668-4689.

(55) Tratnyek, P. G.; Holgné, J. Oxidation of Substituted Phenols in the Environment: A QSAR Analysis of Rate Constants for Reaction with Singlet Oxygen. Environ. Sci. Technol. 1991, 25, 1596-1604.

(56) Al-Nu'Airat, J.; Dlugogorski, B. Z.; Gao, X.; Zeinali, N.; Skut, J.; Westmoreland, P. R.; Oluwoye, I.; Altarawneh, M. Reaction of Phenol with Singlet Oxygen. Phys. Chem. Chem. Phys. 2019, 21, 171-183.

(57) Bonneau, R.; Pottier, R.; Joussot-Dubien, J. pH Dependence of Singlet Oxygen Production in Aqueous Solutions Using Thiazine Dyes as Photosensitizers. Photochem. Photobiol. 1975, 21, 159-163.

(58) Ehrenberg, B.; Anderson, J. L.; Foote, C. S. Kinetics and Yield of Singlet Oxygen Photosensitized by Hypericin in Organic and Biological Media. Photochem. Photobiol. 1998, 68 (2), 135-140.

(59) Aguirre-Soto, A.; Kim, S.; Kaastrup, K.; Sikes, H. D. On the Role of N-Vinylpyrrolidone in the Aqueous Radical-Initiated
Copolymerization with PEGDA Mediated by Eosin Y in the Presence of $\mathrm{O}_{2}$. Polym. Chem. 2019, 10 (8), 926-937.

(6o) Jarnikova, E. S.; Parkhats, M. V.; Stasheuski, A. S.; Lepeshkevich, S. V.; Dzhagarov, B. M. Quantum Yield and Rate Constant of the Singlet ${ }^{1} \Delta_{\mathrm{g}}$ Oxygen Luminescence in an Aqueous Medium in the Presence of Nanoscale Inhomogeneities. Opt. Spectrosc. 2017, 122 (4), 596-601.

(61) Penzkofer, A.; Tyagi, A.; Slyusareva, E.; Sizykh, A. Phosphorescence and Delayed Fluorescence Properties of Fluorone Dyes in Bio-Related Films. Chem. Phys. 2010, 378, 58-65.

(62) Natera, J. E.; Massad, W. A.; Amat-Guerri, F.; García, N. A. Elementary Processes in the Eosin-Sensitized Photooxidation of 3,3'-Diaminobenzidine for Correlative Fluorescence and Electron Microscopy. J. Photochem. Photobiol. A Chem. 2011, 220 (1), 25-30.

(63) Seligman, A. M.; Karnovsky, M. J.; Wasserkrug, H. L.; Hanker, J. S. Nondroplet Ultrastructural Demonstration of Cytochrome Oxidase Activity with a Polymerizing Osmiophilic Reagent, Diaminobenzidine (DAB). J. Cell Biol. 1968, 38, 1-14.

(64) Bar-on, Y. M.; Flamholz, A.; Phillips, R.; Milo, R. SARSCoV-2 (COVID-19) by the Numbers. Elife 2020, 1-15.

(65) Carter, L. J.; Garner, L. V.; Smoot, J. W.; Li, Y.; Zhou, Q.; Saveson, C. J.; Sasso, J. M.; Gregg, A. C.; Soares, D. J.; Beskid, T. R.; Jervey, S. R.; Liu, C. Assay Techniques and Test Development for COVID-19 Diagnosis. ACS Cent. Sci. 2020, 6 (5), 591-605.

(66) Weissleder, R.; Lee, H.; Ko, J.; Pittet, M. J. COVID-19 Diagnostics in Context. Sci. Transl. Med. 2o2o, 12, eabc1931.

(67) Kim, S.; Yee, E.; Miller, E. A.; Hao, Y.; Tay, D. M. Y.; Sung, K.-J.; Jia, H.; Johnson, J. M.; Ball, A.; Conway, H.; Saeed, M.; Mace, C. R.; Yurt, D. Y.; Sikes, H. D. Developing a SARS-CoV-2 Antigen Test Using Engineered Affinity Proteins. ChemRxiv. DOI: 10.26434/chemrxiv.14442785.v1

(68) Pollock, N. R.; Savage, T. J.; Wardell, H.; Lee, R. A.; Mathew, A.; Stengelin, M.; Sigal, G. B. Correlation of SARS-CoV-2 Nucleocapsid Antigen and RNA Concentrations in Nasopharyngeal Samples from Children and Adults Using an Ultrasensitive and Quantitative Antigen Assay. J. Clin. Microbiol. 2021, 59 (4), e03077-20.

(69) Miller, E. A.; Baniya, S.; Osorio, D.; Maalouf, Y. J. Al; Sikes, H. D. Paper-Based Diagnostics in the Antigen-Depletion Regime: High-Density Immobilization of rcSso7d-CelluloseBinding Domain Fusion Proteins for Efficient Target Capture. Biosens. Bioelectron. 2018, 102, 456-463.

(70) Lathwal, S.; Sikes, H. D. Assessment of Colorimetric Amplification Methods in a Paper-Based Immunoassay for Diagnosis of Malaria. Lab Chip 2016, 16 (8), 1374-1382. 


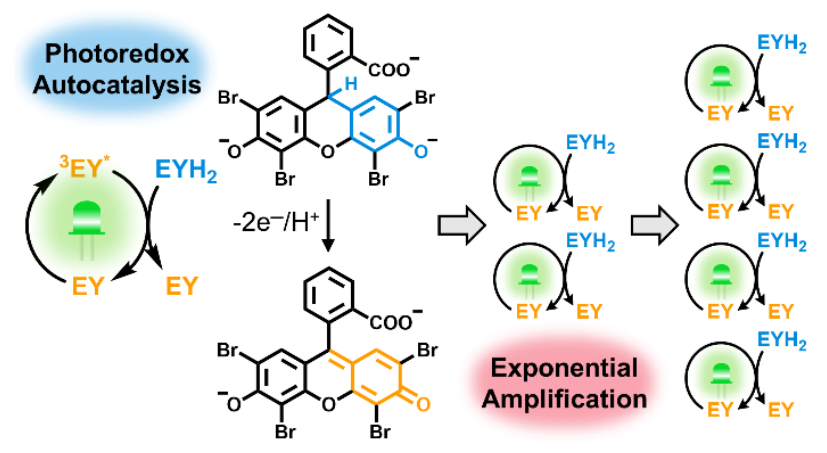




\section{Supporting Information}

\section{Exponential Amplification Using Photoredox Autocatalysis}

Seunghyeon Kim ${ }^{a}$, Alejandra Vanessa Martinez Dibildox ${ }^{b}$, Alan Aguirre-Soto ${ }^{b}$, and Hadley D. Sikes ${ }^{a, c^{*}}$

${ }^{a}$ Department of Chemical Engineering, Massachusetts Institute of Technology, Cambridge, MA 02139, USA

${ }^{b}$ School of Engineering and Sciences, Tecnologico de Monterrey, Monterrey, N.L. 64849, MX

${ }^{c}$ Antimicrobial Resistance Integrated Research Group, Singapore-MIT Alliance for Research and Technology,

1 CREATE Way, Singapore 138602

${ }^{*}$ Corresponding Author:

Prof. Hadley D. Sikes

E-mail: sikes@mit.edu 


\section{Table of Contents}

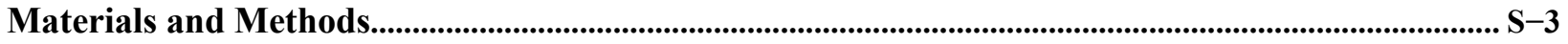

Model Development .............................................................................................................................................. S-8

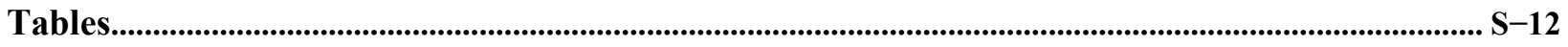

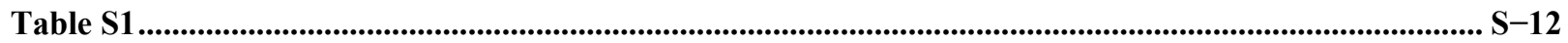

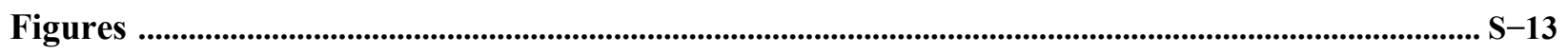

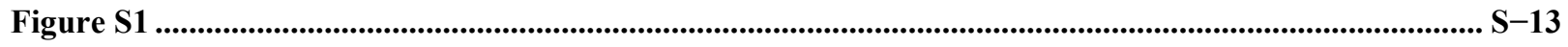

Figure S2

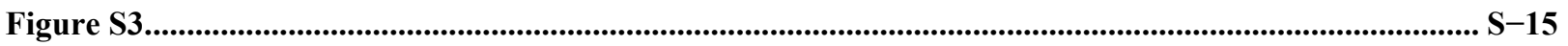

Figure S4

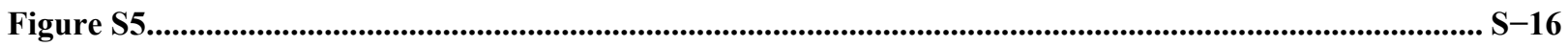

Figure S6.................................................................................................................................................................. S

Figure S7

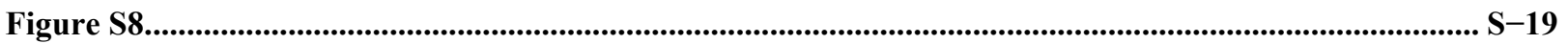

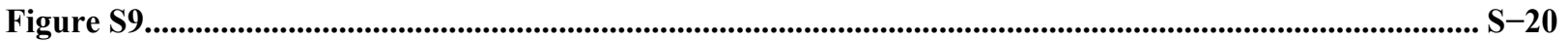

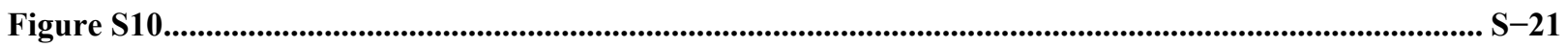

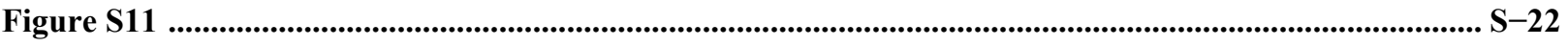

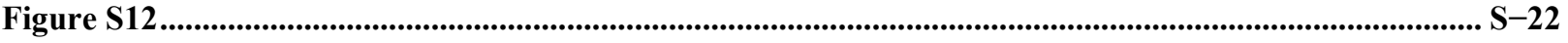

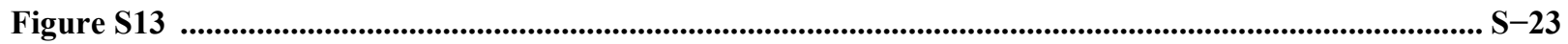

Figure S14 _................................................................................................................................................................ S-24

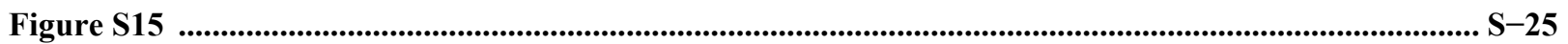

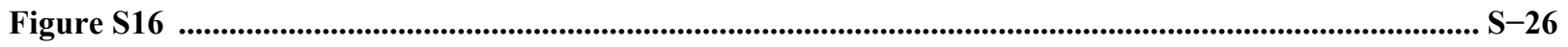

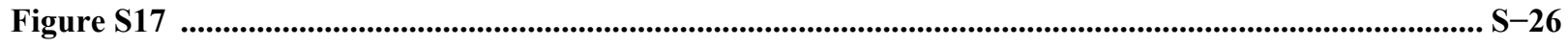

Figure S18 …........................................................................................................................................................... S-27

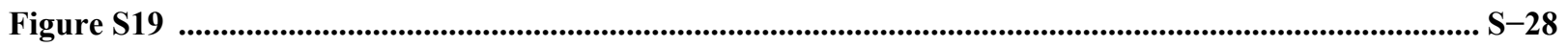

Figure S20 _......................................................................................................................................................................... S-29

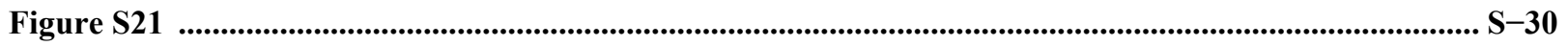

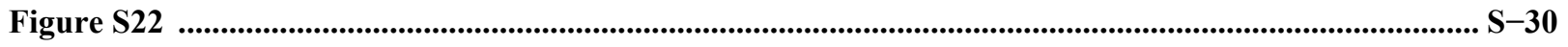

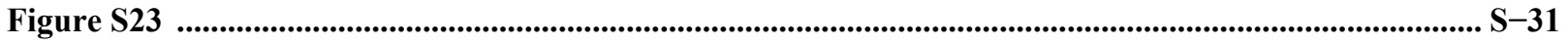

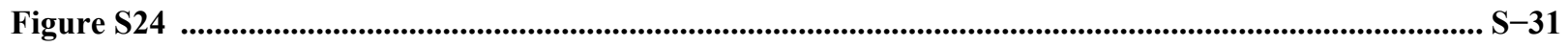

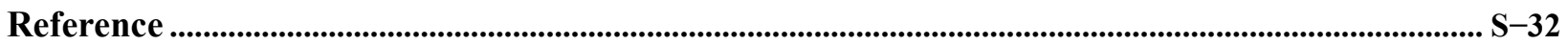




\section{Materials and Methods}

\section{Materials}

Sodium borohydride $\left(\mathrm{NaBH}_{4}, \geq 98 \%\right), 2^{\prime}, 4^{\prime}, 5^{\prime}, 7^{\prime}$-tetrabromofluorescein (eosin $\mathrm{Y}, \sim 99 \%$ ), dimethyl sulfoxide (DMSO, $\geq 99.9 \%$ ), microcrystalline cellulose (powder, $20 \mathrm{um}$ ), Triton X-100, 3-[(3cholamidopropyl)dimethylammonio]-1-propanesulfonate hydrate (CHAPS, $\geq 98 \%$ ), and Microspin G-25 columns were purchased from Millipore Sigma (St. Louis, MO, USA). Dimethyl sulfoxide- $d_{6}$ (DMSO- $d_{6}$, 99.9\%) was purchased from Cambridge Isotope Laboratories, Inc. (Tewksbury, MA, USA). Acetone ( $\geq$ 99.5\%), sodium hydroxide $(\mathrm{NaOH}, \geq 98 \%)$, hydrochloric acid $(\mathrm{HCl}, 2.0 \mathrm{~N})$, sodium phosphate dibasic $\left(\mathrm{Na}_{2} \mathrm{HPO}_{4}\right.$, anhydrous, $\left.\geq 99 \%\right)$, sodium dihydrogen phosphate monohydrate $\left(\mathrm{NaH}_{2} \mathrm{PO}_{4} \cdot \mathrm{H}_{2} \mathrm{O}, \geq 98 \%\right)$, potassium superoxide $\left(\mathrm{KO}_{2}, \geq 96 \%\right)$, hydrogen peroxide $\left(\mathrm{H}_{2} \mathrm{O}_{2}, 30 \%\right)$, methoxy poly(ethylene glycol) (mPEG, M.W. 1900), 3,3'-diaminoben-zidine tetrahydrochloride hydrate (DAB, 97\%), and Whatman No.1 Chromatography paper were purchased from VWR (Radnor, PA, USA). Eosin-5-isothiocyanate (EITC, $\geq$ 98\%) was purchased from Marker Gene Technology (Eugene, OR, USA). Bovine serum albumin (BSA, $10 \mathrm{w} / \mathrm{v} \%$ ) in $1 \times$ PBS was purchased from Thermo Fisher Scientific (Waltham, MA, USA). Streptavidin was purchased from Rockland Immunochemicals, Inc. (Limerick, PA, USA). SARS-CoV-2 nucleocapsid protein (N-protein), biotinylated maltose binding protein (MBP)-fused reporter binder (SsoNP.E1), and cellulose-binding domain (CBD)-fused capture binder (SsoNP.E2) were expressed and purified by Yining Hao as described previously. ${ }^{1}$ CBD-fused, streptavidin binder (rcSso7d.SA) was expressed and purified by Dousabel M. Y. Tay using a reported method in literature. ${ }^{2}$

\section{Synthesis and characterization of $\mathrm{EYH}_{2}$ or 2-(2,4,5,7-Tetrabromo-3,6-dihydroxy-9H-xanthen-9- yl)benzoic acid}

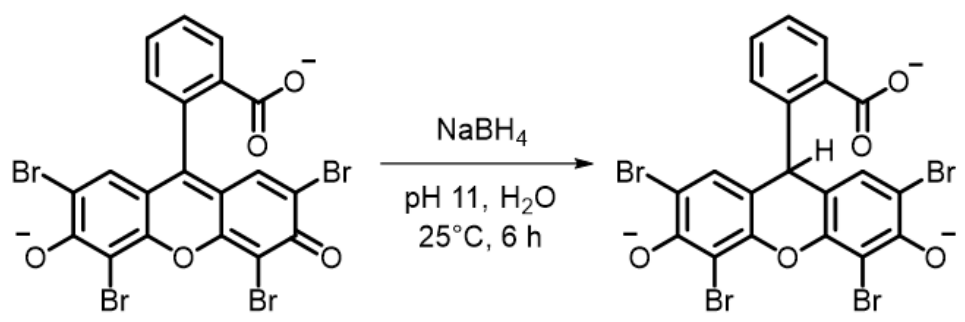

$\mathrm{EYH}_{2}$ was synthesized using the method of Weng et al. ${ }^{3}$ with modifications. An oven-dried round bottom flask containing an stir bar was charged with sodium borohydride $(4.54 \mathrm{~g}, 0.12 \mathrm{~mol})$ and $1 \mathrm{mM}$ eosin Y (EY) solution $(120 \mathrm{~mL}, \mathrm{pH} 11)$. The flask was sealed, attached to a nitrogen-filled balloon, and covered 
with aluminum foil. The solution was stirred at $25^{\circ} \mathrm{C}$ for $6 \mathrm{~h}$ in the dark room. While cooling the flask in a cold bath (ice-water), 4 equiv. of acetone $(35.2 \mathrm{~mL}, 0.48 \mathrm{~mol})$ to sodium borohydride was added to quench the reaction for an hour. After removing acetone using vacuum pump as much as possible, hydrochloric acid $(2.0 \mathrm{~N})$ was added to the reaction mixture until the solution became turbid. The solution was divided into four centrifuge tubes $(50 \mathrm{~mL})$ and centrifuged. The precipitates were washed three times with

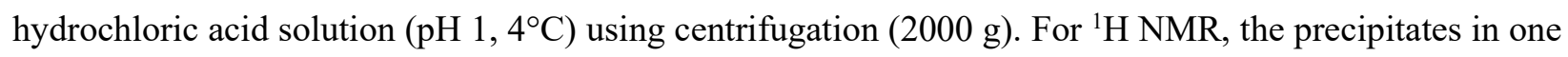
centrifuge tube were dried under nitrogen gas overnight and dissolved in DMSO- $d_{6}$. For ${ }^{13} \mathrm{C}$ NMR, the precipitates in three centrifuge tubes were collected in one vial by dissolving with ethanol and then a concentrated NMR sample was prepared by removing the ethanol under vacuum and adding DMSO- $d_{6}$. To quantify the product, 1,3,5-trimethoxybenzene was added to the NMR tube as an internal standard. From this quantitative NMR, the yield (67.5\%) of $\mathrm{EYH}_{2}$ was obtained. ${ }^{1} \mathrm{H}$ NMR (400 MHz, DMSO- $\left.d_{6}\right) \delta(\mathrm{ppm})$ : $7.82(\mathrm{dd}, \mathrm{J}=7.9,1.5 \mathrm{~Hz}, 1 \mathrm{H}), 7.43(\mathrm{~m}, 1 \mathrm{H}), 7.32(\mathrm{~m}, 1 \mathrm{H}), 7.18(\mathrm{~s}, 2 \mathrm{H}), 7.00$ (d, J = 8.2 Hz, 1H), 6.27 (s, $1 \mathrm{H}) ;{ }^{13} \mathrm{C}$ NMR (100 MHz, DMSO- $\left.d_{6}\right) \delta$ (ppm): 169.79, 151.38, 147.60, 146.14, 133.29, 131.49, 130.55, 127.90, 118.77, 106.39, 101.41. NMR spectra are provided in Figures S1 and S2. The amount of EY impurity was quantified using UV-Vis spectroscopy at $516 \mathrm{~nm}$ with its molar absorptivity $\left(114097 \mathrm{M}^{-1} \mathrm{~cm}^{-}\right.$ $\left.{ }^{1}\right)$, providing $99.95 \%$ purity $\left(100-100 \times[\mathrm{EY}] /\left[\mathrm{EYH}_{2}\right]\right)$.

\section{UV-Vis spectroscopy for $\mathrm{EYH}_{2}$ quantification}

UV-Vis spectroscopy provides more convenient and accurate quantification of $\mathrm{EYH}_{2}$. The first method is to use its molar absorptivity $\left(10522 \mathrm{M}^{-1} \mathrm{~cm}^{-1}\right)$ at $312 \mathrm{~nm}$ in $0.1 \mathrm{M} \mathrm{NaOH}$ (Figure S3). The second method is to use the fact that $\mathrm{EYH}_{2}$ can be photo-activated to eosin $\mathrm{Y}(\mathrm{EY})$ with $100 \%$ recovery in inert gas-purged solution. In this method, $0.2 \mathrm{M}$ phosphate buffer solution ( $\mathrm{pH} 7.4$ ) containing a known amount of EY (ex. $1 \mu \mathrm{M})$ and a unknown amount of $\mathrm{EYH}_{2}$ is prepared in a sealable cuvette and purged with inert gas for 30 minutes. With frequent UV-Vis monitoring, the oxygen-free solution is irradiated by green light $(<5$ $\mathrm{mW} / \mathrm{cm}^{2}$ ) until the absorbance of eosin $\mathrm{Y}$ at $516 \mathrm{~nm}$ does not increase any more. From the maximum absorbance at $516 \mathrm{~nm}$, the final concentration $\left([\mathrm{EY}]_{0}+\left[\mathrm{EYH}_{2}\right]_{0}\right)$ of eosin $\mathrm{Y}$ can be obtained using its molar absorptivity (114097 $\left.\mathrm{M}^{-1} \mathrm{~cm}^{-1}\right)$ (Figure S4).

\section{Stability monitoring of $\mathrm{EYH}_{2}$}

On the day of monitoring, diluted $\mathrm{EYH}_{2}$ solutions were prepared by diluting the $\mathrm{EYH}_{2}$ stock solutions $\left(8.1 \mathrm{mM}\right.$ ) in DMSO stored at $25^{\circ} \mathrm{C}$ and $40^{\circ} \mathrm{C}$ (oven) by 100 -fold with $0.2 \mathrm{M}$ phosphate buffer (pH 7.4) or $0.1 \mathrm{M} \mathrm{NaOH}$ solution to make $1 \mathrm{~mL}$ solutions. Using $\mathrm{UV}$-Vis spectroscopy, $\mathrm{EY}$ and $\mathrm{EYH}_{2}$ concentrations 
in the diluted solutions were quantified to calculate $\left[\mathrm{EYH}_{2}\right] /\left[\mathrm{EYH}_{2}\right]_{0}$ and $[\mathrm{EY}] /\left[\mathrm{EYH}_{2}\right]_{0}$. Due to much smaller molar absorptivity of $\mathrm{EYH}_{2}$ than that of $\mathrm{EY},\left[\mathrm{EYH}_{2}\right] /\left[\mathrm{EYH}_{2}\right]_{0}$ did not show a decreasing trend even at $40^{\circ} \mathrm{C}$, but $[\mathrm{EY}] /\left[\mathrm{EYH}_{2}\right]_{0}$ increased over time. Thus, $\left(1-[\mathrm{EY}] /\left[\mathrm{EYH}_{2}\right]_{0}\right) \times 100(\%)$ was used to present remaining $\mathrm{EYH}_{2}$.

\section{UV-Vis spectroscopy setup for steady-state kinetic monitoring}

A fiber optic coupled UV-Vis spectrophotometer (JAZ, Ocean Optics, Orlando, FL, USA) was used to monitor absorbance within 300-800 nm range. JAZ Pulsed Xenon (190-1100 nm) was used as a light source for the probing beam. The probing beam was fed into a CUV-ALL-UV cuvette holder (Ocean Optics, Orlando, FL, USA) via a $400 \mu \mathrm{m}$ solarization-resistant fiber optic cable (QP400-2-SR, Ocean Optics, Orlando, FL, USA), and the collected beam was delivered to the UV-Vis spectrophotometer through a 115 $\mu \mathrm{m}$ solarization-resistant fiber optic cable (QP115-1-XSR, Ocean Optics, Orlando, FL, USA). The diameter of the probing beam in the sample was limited to $2 \mathrm{~mm}$ using collimating lens in the cuvette holder. SpectraSuite software was used to set parameters (55000 peak light intensity of probing beam, $10 \mathrm{~ms}$ integration time, 10 scans to average, 2 boxcar width, and monitoring time) for absorbance measurement. A reference spectrum for a cuvette and a buffer solution was collected prior to every experiment.

\section{$\mathbf{E Y H}_{2}$ stock solution for kinetic monitoring experiments}

For kinetic monitoring experiments, we used $\mathrm{EYH}_{2}$ stored at $4^{\circ} \mathrm{C}$ in high $\mathrm{pH}$ aqueous solution. This $\mathrm{EYH}_{2}$ stock solution was prepared by dissolving the precipitated $\mathrm{EYH}_{2}$ in $0.1 \mathrm{M} \mathrm{NaOH}$ instead of DMSO at the end of purification to eliminate any interference of DMSO with the EY amplification kinetics.

\section{Steady-state kinetic monitoring in deaerated system}

Four-clear sided cuvettes (BrandTech scientific, Inc., Essex, CT, USA) with $10 \mathrm{~mm}$ path length were filled with $1 \mathrm{~mL}$ of sample solutions, sealed, and purged with $\mathrm{N}_{2}$ at $0.1 \mathrm{~L} / \mathrm{min}$ for 30 minutes before running experiments. The cuvettes were covered with aluminum foil to prevent any light exposure during the purging. After removing dissolved oxygen, the cuvettes were placed in the cuvette holder, and the injection needle for the purging was taken out of the sample solution and kept at $2 \mathrm{~cm}$ above the liquid surface. Immediately after data acquisition started, the solution was irradiated by green light $\left(2.6 \mathrm{~mW} / \mathrm{cm}^{2}, \lambda_{\max }=\right.$ $535 \mathrm{~nm}$ ) from Klarus XT12GT and a green filter (Longhua, Shenzhen, China), which was perpendicular to

$$
\text { S-5 }
$$


the probing beam at the same z-plane (with regards to the beam centers). The solution was not stirred during the monitoring. The concentrations of EY, EY radical anion $\left(\mathrm{EY}^{\circ-}\right)$, and $\mathrm{EYH}_{2}$ were calculated by using molar absorptivity of the species: $\varepsilon(516 \mathrm{~nm}, \mathrm{EY})=114097 \mathrm{M}^{-1} \mathrm{~cm}^{-1}, \varepsilon(405 \mathrm{~nm}, \mathrm{EY})=3251 \mathrm{M}^{-1} \mathrm{~cm}^{-1}, \varepsilon(312$ $\mathrm{nm}, \mathrm{EY})=12439 \mathrm{M}^{-1} \mathrm{~cm}^{-1}, \varepsilon\left(405 \mathrm{~nm}, \mathrm{EY}^{\circ-}\right)=85000 \mathrm{M}^{-1} \mathrm{~cm}^{-1}$ (Figure S5), and $\varepsilon\left(312 \mathrm{~nm}, \mathrm{EYH}_{2}\right)=8900$ $\mathrm{M}^{-1} \mathrm{~cm}^{-1}$.

\section{Steady-state kinetic monitoring in air-saturated system}

Each four-clear sided cuvette was charged with a stirring bar and $1 \mathrm{~mL}$ of sample solution. The cuvettes were placed in the cuvette holder above a magnetic stirrer. Immediately after data acquisition started, the solution was stirred and irradiated by green light $\left(1.2 \mathrm{~mW} / \mathrm{cm}^{2}, \lambda_{\max }=535 \mathrm{~nm}\right)$ from the Klarus XT12GT and the green filter placed above the cuvette. The concentrations of EY was calculated by using molar absorptivity of the species: $\varepsilon(516 \mathrm{~nm}, \mathrm{EY})=114097 \mathrm{M}^{-1} \mathrm{~cm}^{-1}$.

\section{Preparation of eosin Y-conjugated streptavidin (streptavidin-EY)}

Eosin Y-conjugated streptavidin (streptavidin-EY) was prepared using the method previously described ${ }^{4}$ with slight modifications. Eosin 5-isothiocyanate (EITC, $1 \mathrm{mg}$ ) was dissolved in $100 \mu \mathrm{L}$ of DMSO to prepare a $10 \mathrm{mg} / \mathrm{mL}$ EITC stock solution. The EITC stock solution $(27 \mu \mathrm{L})$ was mixed with $250 \mu \mathrm{L}$ of a streptavidin (SA) solution $(6 \mathrm{mg} / \mathrm{mL})$ in $0.1 \mathrm{M}$ bicarbonate buffer solution ( $\mathrm{pH} 9.8)$ to give a total reaction volume of $277 \mu \mathrm{L}$, and the reaction mixture was protected from light and stored in a $4^{\circ} \mathrm{C}$ refrigerator for five hours. After the bioconjugation reaction, the desired product was purified by size-exclusion chromatography on Sephadex maxtrix (Micro G-25 Spin-Columns) using $1 \times$ PBS as eluent to give pink solution $(24 \mu \mathrm{M}$ conjugate, $867 \mu \mathrm{L})$. To determine the average number (2.6) of eosin $\mathrm{Y}$ molecules conjugated to each streptavidin, UV/Vis spectroscopy was used as previously described. ${ }^{4}$ The purified conjugates were diluted to make $50 \% \mathrm{v} / \mathrm{v}$ glycerol stock solution $(12.2 \mu \mathrm{M}$ conjugate $)$ and stored at $-20^{\circ} \mathrm{C}$ until use.

\section{Cellulose particle-based fluorescence assays with EY amplification}

Sample solutions $(900 \mu \mathrm{L})$ including 0-100 nM SARS-CoV-2 nucleocapsid protein $(\mathrm{N})$ in $1 \times$ PBS were mixed with $100 \mu \mathrm{L}$ of $10 \%$ Triton X-100 solution. Each detergent-treated sample was added to a centrifuge tube including microcrystalline cellulose $(2 \mathrm{mg}$ ) incubated with $10 \mu \mathrm{L}$ of $20 \mu \mathrm{M}$ capture binder (SsoNP.E2- 
CBD). After 5-minute incubation, the cellulose particles were separated from the supernatant using microcentrifuge (MiniStar, VWR), followed by another 5-minute incubation with $100 \mu \mathrm{L}$ of reporter binder (biotinylated MBP-SsoNP.E1, $200 \mathrm{nM}$ ) and streptavidin-EY (50 nM) in $0.2 \mathrm{M}$ phosphate buffer (pH 6) including 1\% BSA. After removing the supernatant via centrifugation, the cellulose particles were washed with $100 \mu \mathrm{L}$ of washing buffer (1\% BSA $1 \%$ CHAPS in $1 \times$ PBS). The washed cellulose particles were then resuspended with $100 \mu \mathrm{L}$ of $0.2 \mathrm{M}$ phosphate buffer (pH 6) including $12 \mu \mathrm{M} \mathrm{EYH}_{2}$ and $40 \mathrm{mM} \mathrm{mPEG}$. The suspension was moved to 96 well plate (black, flat bottom) and illuminated for 10 minutes under $5 \mathrm{~mW} / \mathrm{cm}^{2}$ green light $\left(\lambda_{\max }=530 \mathrm{~nm}\right)$ from LED (M530L4, Thorlabs, Newton, NJ, USA). The fluorescence intensity was measured using a plate reader (Infinite M200, Männedorf, Switzerland) before and after EY amplification.

\section{Cellulose particle-based colorimetric assays with EY-DAB amplification}

A sample solution $(1000 \mu \mathrm{L})$ including 0 or $10 \mathrm{nM}$ streptavidin-EY in $1 \times \mathrm{PBS}$ was added to a centrifuge tube including microcrystalline cellulose $(2 \mathrm{mg})$ incubated with $10 \mu \mathrm{L}$ of $20 \mu \mathrm{M}$ capture binder (rcSso7d.SA-CBD). After 5-minute incubation, the cellulose particles were separated from the supernatant using microcentrifuge (MiniStar, VWR), followed by washing with $1 \times$ PBS including $1 \%$ BSA and 1\% CHAPS. The washed cellulose particles in the tube were then resuspended with $25 \mu \mathrm{L}$ of $0.2 \mathrm{M} \mathrm{Na}_{2} \mathrm{HPO}_{4}$ solution (pH 9) including $12 \mu \mathrm{M} \mathrm{EYH}_{2}$ and $0.6 \mathrm{mM}$ DAB. The tube was illuminated for 10 minutes under $5 \mathrm{~mW} / \mathrm{cm}^{2}$ green light $\left(\lambda_{\max }=530 \mathrm{~nm}\right)$ from LED (M530L4, Thorlabs, Newton, NJ, USA). Then, the irradiated solution was applied to a wax-printed paper test zone ${ }^{5}$ with absorbent pad underneath it before imaging (X-E2S, Fujifilm, Tokyo, Japan). For non-amplified samples, the suspension with amplification reagents were applied to the paper test zone before irradiation.

\section{Colorimetric analysis}

Images were analyzed in ImageJ by quantifying average color difference between negative control (cellulose particles only) and samples (cellulose particles treated with streptavidin-EY and amplification reagents) in HSV (Hue, Saturation, Value) color space using a method reported in literature. ${ }^{6}$ 


\section{Model Development}

We proposed elementary reactions associated with dihydroeosin $\mathrm{Y}\left(\mathrm{EYH}_{2}\right)$ activation based on steadystate kinetic monitoring data and integrated the reactions into a classical photochemical process of EY (Table S1). To estimate unknown parameters and validate the proposed reactions, we first developed the simplest model for one-species system (EY) where all rate constants could be obtained from literature and increased complexity of the model by adding other species $\left(\mathrm{EYH}_{2}\right.$ and $\left.\mathrm{O}_{2}\right)$ and associated reactions to the system. Lastly, we performed sensitivity analysis to identify important model parameters that could cause significant uncertainty in outputs for increasing accuracy of the model.

\section{EY system}

This system includes only EY in deaerated buffer solutions ( $\mathrm{pH}$ 7.4). By absorbing green light, EY is excited to singlet state $\left({ }^{1} \mathrm{EY}^{*}\right)$ (Table S1, Eq. 1), whose energy is lost through vibrational relaxation and internal conversion (Eq. 2), fluorescence (Eq. 3), and intersystem crossing (Eq. 4). Due to its long lifetime (1.85 $\mathrm{ms}$ in water $)^{7}$ compared to the singlet state's $(1.21 \mathrm{~ns}),{ }^{8}$ the triplet $\mathrm{EY}\left({ }^{3} \mathrm{EY}^{*}\right)$ generated from intersystem crossing is mainly involved in chemical reactions. According to literature, ${ }^{9,10}$ five different pathways were proposed for disappearance of ${ }^{3} \mathrm{EY}^{*}$, but two triplet-triplet bimolecular reactions were excluded because the triplet concentration in the system was expected to be very low $\left(<10^{-9} \mathrm{M}\right)$ compared to EY concentration $\left(\sim 10^{-5} \mathrm{M}\right)$, making the phosphorescence (Eq. 5) and quenching by EY (Eq. 6) predominant. Another proposed reaction was generation of $\mathrm{EY}$ radical cation $\left(\mathrm{EY}^{\cdot+}\right)$ together with eosin $\mathrm{Y}$ radical anion $\left(\mathrm{EY}^{\cdot-}\right)$ from the bimolecular reaction between ${ }^{3} \mathrm{EY}^{*}$ and $\mathrm{EY}$. This reaction was also excluded

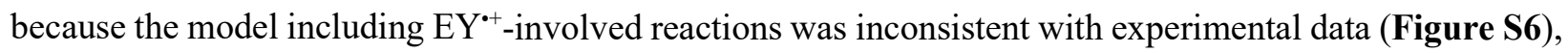
indicating that rapid back-electron transfer reaction of $\mathrm{EY}^{\cdot+}$ and $\mathrm{EY}^{\circ-}$ to produce two $\mathrm{EY}$ molecules nullifies the initial production of radicals in the low intensity light conditions as opposed to flash photolysis conditions.

\section{$\mathbf{E Y}+\mathbf{E Y H}_{2}$ system}

As can be seen in Figure 2, when $\mathrm{EYH}_{2}$ is activated by EY under light, $\mathrm{EY}^{-}$is generated as an intermediate species and reacts further to give EY. Given that triplet dyes and oxidizing radicals can oxidize other dihydroxanthene dyes, ${ }^{11-16}$ two potential activating substances in the system are ${ }^{3} \mathrm{EY}^{*}$ and $\mathrm{EY}^{\cdot+}$. As discussed earlier, the radical cation may not be produced at enough concentration to oxidize $\mathrm{EYH}_{2}$, otherwise the self-bimolecular reaction of $\mathrm{EY}^{\bullet+}$ can lead to photobleached EY (Figure S6), which is 
inconsistent with $100 \% \mathrm{EYH}_{2}$-to-EY recovery observed (Figure 2B). Furthermore, the products of $\mathrm{EYH}_{2}$ oxidation by $\mathrm{EY}^{\cdot+}$ are expected to be $\mathrm{EY}$ and $\mathrm{EY}^{\bullet-}$ (or $\mathrm{EYH}^{\bullet}$ ), but $\mathrm{EYH}_{2}$ activation resulted in $\mathrm{EY}$ and $\mathrm{EY}^{\circ-}$ at low or neutral $\mathrm{pH}$ and two $\mathrm{EY}^{\bullet-}$ at high $\mathrm{pH}$ (Figure S8). From the $\mathrm{pH}$-dependent $\mathrm{EYH}_{2}$ activation pathways, we proposed that $\mathrm{EYH}_{2}$ is oxidized by ${ }^{3} \mathrm{EY}^{*}$, producing one or two $\mathrm{EY}^{-}$depending on $\mathrm{pH}$. At high $\mathrm{pH},{ }^{3} \mathrm{EY}^{*}$ is reduced to $\mathrm{EY}^{-}$when oxidizing $\mathrm{EYH}_{2}$. The singly oxidized $\mathrm{EYH}_{2}$ might rapidly get deprotonated by base $\left(\mathrm{B}^{-}\right)$to become $\mathrm{EY}{ }^{-} \cdot{ }^{17}$ Instead of this electron transfer-proton transfer mechanism, $\mathrm{EYH}_{2}$ could form adduct with $\mathrm{B}^{-}$and associate with ${ }^{3} \mathrm{EY}^{*}$ to undergo concerted electron-proton transfer where $\mathrm{EYH}_{2}$ give $\mathrm{e}^{-}$to ${ }^{3} \mathrm{EY}^{*}$ and $\mathrm{H}^{+}$to $\mathrm{B}^{-} \cdot{ }^{17}$ At lower $\mathrm{pH}$, the one-electron oxidized $\mathrm{EYH}_{2}$ appears to undergo $1 \mathrm{e}^{-/ 1 \mathrm{H}^{+}}$transfer to buffer components and become EY. Because the $\mathrm{EY}+\mathrm{EYH}_{2}$ system was investigated at $\mathrm{pH}$ 7.4, we included the lower $\mathrm{pH} \mathrm{EYH}$ oxidation reaction (Eq. 7) for the kinetic model. Additionally, physical quenching of ${ }^{3} \mathrm{EY}^{*}$ by $\mathrm{EYH}_{2}$ (Eq. 8) was added to the model because this quenching reaction could significantly contribute to decay of ${ }^{3} \mathrm{EY}^{*}$ in the system where initial amounts of $\mathrm{EYH}_{2}$ are 4to 12-times the initial amount of EY. The fate of $E Y^{--}$radicals was described with acid-base equilibrium (Eq. 9-10) and pH-dependent disproportionation reactions (Eq. 11-13) as previously proposed for the decay of fluorescein radical anion, ${ }^{13}$ and the rate constants for these reactions were determined by estimating diffusion controlled limit (Table S1) or using the relationship between the disproportionation rate constants and observed decay rates of $\mathrm{EY}^{-}$at various $\mathrm{pH}$ (Figure S9). Finally, we constructed an ODE (ordinary differential equation) model for $\mathrm{EY}+\mathrm{EYH}_{2}$ system (Figure S10) and determined the unknown rate constants $\left(\mathrm{k}_{7}=1.45 \times 10^{8} \mathrm{M}^{-1} \mathrm{~s}^{-1}\right.$ and $\left.\mathrm{k}_{8}=1.73 \times 10^{9} \mathrm{M}^{-1} \mathrm{~s}^{-1}\right)$ for Eq. 7 and Eq. 8 by fitting the model with 12.9 $\mu \mathrm{M} \mathrm{EYH}_{2}$ data. As demonstrated in Figure 2, the model results are in good agreement with the concentration profiles of $\mathrm{EY}$ and $\mathrm{EYH}_{2}$ in $4.3 \mu \mathrm{M}$ and $8.6 \mu \mathrm{M} \mathrm{EYH} 2$ cases. Unfortunately, however, attempts to find the unknown parameters for accurately capturing the concentration profile of EY ${ }^{-}$were not successful. One reason for the discrepancy is that the radical concentration is particularly sensitive to kinetic parameters obtained from literature, which were measured or estimated in slightly different conditions. The other reason is that the model ignored the oxygen dissolution and diffusion from air although there could be a slight leak due to improper sealing of the cuvette. Indeed, the concentration of $\mathrm{EY}^{-}$could be very sensitive to the leak because the oxidation of $\mathrm{EY}^{\circ-}$ by oxygen is almost a diffusioncontrolled reaction $\left(1 \times 10^{9} \mathrm{M}^{-1} \mathrm{~s}^{-1}\right) .{ }^{18}$ By considering the exposure to oxygen, the model could better predict the radical concentration profile (Figure S11). Therefore, we expect that if the air leak was strictly avoided, $\mathrm{EY}^{--}$would decay much slowly as predicted by the current model (Figure 2C). 


\section{$\mathrm{EY}+\mathrm{EYH}_{2}+\mathrm{O}_{2}$ system}

In air-saturated solutions, $\mathrm{EY}^{-}$was not detectable because the radical is quickly oxidized to EY by oxygen $(\sim 0.25 \mathrm{mM})^{19}$, producing superoxide $\left(\mathrm{O}_{2}{ }^{-}\right)$(Eq. 14). The superoxide ends up with hydrogen peroxide $\left(\mathrm{H}_{2} \mathrm{O}_{2}\right)$ through series of reactions (Eq. 15-20) while $\mathrm{O}_{2}{ }^{-}$and $\mathrm{H}_{2} \mathrm{O}_{2}$ are not involved in $E Y \mathrm{H}_{2}$ activation (Figure S12). As shown in Figure 1C, the EY amplification becomes sluggish in the presence of oxygen, which is mainly because ${ }^{3} \mathrm{EY}^{*}$ can also be quenched by oxygen, producing ground-state EY and ${ }^{1} \mathrm{O}_{2}$ (Eq. 21). Electron transfer from ${ }^{3} \mathrm{EY}^{*}$ to oxygen could also occur, but it was ignored because the reaction rate of $\mathrm{O}_{2}^{--}$generation is much slower than energy transfer to oxygen and the back electron transfer makes the lifetime of $\mathrm{EY}^{\bullet+} \ldots \mathrm{O}_{2}{ }^{--}$complex very short $(\sim 1 \mathrm{~ms}){ }^{20,21}$ The singlet oxygen is known to decay through interactions with solvent (Eq. 22) ${ }^{22}$ and dissolved oxygen (Eq. 23). ${ }^{12}$

The kinetic model updated with the above reactions could not predict the trend of experimental data (Figure S13). The model provided much slower $\mathrm{EYH}_{2}$ activation than experimental data and 100\% recovery of $\mathrm{EYH}_{2}$ to $\mathrm{EY}$, but in reality significant loss of $\mathrm{EY}$ species $\left(\mathrm{EY}, \mathrm{EY}^{\circ-}\right.$, and $\mathrm{EYH}_{2}$ ) occurred when 4-12 $\mu \mathrm{M} \mathrm{EYH}_{2}$ was activated by EY under green light in the presence of oxygen. To address this deviation, we focused on the reactivity of ${ }^{1} \mathrm{O}_{2}$, which is one of the most reactive species that is generated in the system and has higher energy by $94 \mathrm{~kJ} / \mathrm{mol}$ than the ground-state oxygen. ${ }^{23}$ The singlet oxygen has been proposed as an activating molecule for other dihydroxanthene dyes previously, ${ }^{12,16}$ and is known to oxidize hydroquinone to benzoquinone, ${ }^{24}$ so ${ }^{1} \mathrm{O}_{2}$ is plausible to contribute to $\mathrm{EYH}_{2}$ oxidation (Eq. 24). Additionally, ${ }^{1} \mathrm{O}_{2}$ has been reported to participate in Diels-Alder type reactions on various chromophores such as anthracenes and perylenes, which results in a loss of conjugation. ${ }^{25-28}$ Substituted phenols can rapidly react with singlet oxygen to yield oxygenated products. ${ }^{29,30}$ Therefore, the oxidation of $\mathrm{EYH}_{2}$ and EY by ${ }^{1} \mathrm{O}_{2}$ could be disruptive, which leads to degradation of $\mathrm{EYH}_{2}$ (Eq. 25) and $\mathrm{EY}$ (Eq. 26). These ${ }^{1} \mathrm{O}_{2}$-driven reactions (Eqs. 24-26) were experimentally confirmed using a ${ }^{1} \mathrm{O}_{2}$ quencher (sodium azide) and a ${ }^{1} \mathrm{O}_{2}$ enhancer (deuterium oxide) (Figure S14). The experiment with superoxide dismutase (SOD) also revealed that $\mathrm{O}_{2}{ }^{-}$could slowly degrade $\mathrm{EY}$ and $\mathrm{EYH}_{2}$, but the impact was negligible compared to ${ }^{1} \mathrm{O}_{2}$ (Figure S14), so the reactions were not considered in the modeling. Using the rate constants $\left(\mathrm{k}_{24}=2.90 \times 10^{8} \mathrm{M}^{-1} \mathrm{~s}^{-1}\right.$ and $\mathrm{k}_{25}=1.23 \times 10^{9} \mathrm{M}^{-1} \mathrm{~s}^{-1}$ ) for the $\mathrm{EYH}_{2}$ activation and degradation estimated by fitting the $12 \mu \mathrm{M} \mathrm{EYH}_{2}$ data, the model successfully described the EY generation kinetics and $\mathrm{EYH}_{2}$-to-EY recovery (model: $34.3 \%$; experiment: $34.5 \%$ ) in 4 and $8 \mu \mathrm{M} \mathrm{EYH}_{2}$ cases (Figure 3A). The recovery was calculated using ([EY] $]_{\max }$ $\left.[\mathrm{EY}]_{\text {initial }}\right) /\left[\mathrm{EYH}_{2}\right]_{\text {initial }} \times 100(\%)$. 


\section{Sensitivity analysis}

The model describes EY amplification in air-saturated solutions with 26 elementary reactions (Table S1). Most of the rate constants were obtained from literature by choosing ones measured in aqueous solution at $\mathrm{pH}$ as close to 7.4 as possible. However, not all of them were measured at $\mathrm{pH} 7.4$, so the uncertainty of the obtained parameters could cause errors in estimating rate constants of the proposed reactions associated with $\mathrm{EYH}_{2}$, which might be the reason for the slight deviation in the $4 \mu \mathrm{M} \mathrm{EYH}{ }_{2}$ case (Figure 3A). Thus, we evaluated the impacts of fluctuations in rate constants employed in the model for $\mathrm{EY}+\mathrm{EYH}_{2}+\mathrm{O}_{2}$ system to identify rate constants that could significantly change outputs of the model. As shown in Figure S15, the final product concentrations, particularly [EY] and [degraded EY], were greatly changed by excited state kinetics of $\mathrm{EY}\left(\mathrm{k}_{2}, \mathrm{k}_{3}\right.$, and $\left.\mathrm{k}_{4}\right)$, reactions between ${ }^{3} \mathrm{EY}^{*}$ and $\mathrm{EYH}_{2}\left(\mathrm{k}_{7}\right.$ and $\left.\mathrm{k}_{8}\right)$, and ${ }^{1} \mathrm{O}_{2}$-involved reactions $\left(\mathrm{k}_{21}, \mathrm{k}_{22}, \mathrm{k}_{24}, \mathrm{k}_{25}\right.$, and $\left.\mathrm{k}_{26}\right)$. In light of these results, it is advisable to measure the above important rate constants in the same buffer conditions of interest for increasing the robustness and reliability of the model in the future. 


\section{Table}

Table S1. Reaction network of EY amplification and parameters for kinetic modeling. To ensure that all chemical equations were balanced, actual charges and degree of protonation of $\mathrm{EY}\left(=\mathrm{EY}^{2-}\right)$ and $\mathrm{EYH}_{2}(=$ $\mathrm{EYH}^{3-}$ ) at $\mathrm{pH} 7.4$ were considered.

\begin{tabular}{|c|c|c|c|c|c|}
\hline \# & Reaction & \multicolumn{3}{|c|}{ Rate constant } & References \\
\hline 1 & $\mathrm{EY}^{2-}+\mathrm{h} v \rightarrow{ }^{1}\left[\mathrm{EY}^{2-}\right]^{*}$ & \multicolumn{3}{|c|}{${ }^{\circ} R_{1}=I_{0} / d \times\left(1-10^{-\varepsilon(\lambda) \times[E Y] \times d}\right) / E^{\prime}(\lambda)$} & 31 \\
\hline 2 & ${ }^{1}\left[\mathrm{EY}^{2-}\right]^{*} \rightarrow(\mathrm{ic}) \mathrm{EY}^{2-}$ & ${ }^{b} \mathrm{k}_{2}$ & $1.20 \mathrm{E}+08$ & $1 / \mathrm{s}$ & \multirow{3}{*}{$8,32,33$} \\
\hline 3 & ${ }^{1}\left[\mathrm{EY}^{2-}\right]^{*} \rightarrow(\mathrm{f}) \mathrm{EY}^{2-}$ & ${ }^{b} k_{3}$ & $2.00 \mathrm{E}+08$ & $1 / \mathrm{s}$ & \\
\hline 4 & ${ }^{1}\left[\mathrm{EY}^{2-}\right]^{*} \rightarrow(\text { isc })^{3}\left[\mathrm{EY}^{2-}\right]^{*}$ & ${ }^{\mathrm{b}} \mathrm{k}_{4}$ & $5.00 \mathrm{E}+08$ & $1 / \mathrm{s}$ & \\
\hline 5 & ${ }^{3}\left[\mathrm{EY}^{2-}\right]^{*} \rightarrow(\mathrm{p}) \mathrm{EY}^{2-}$ & $\mathrm{k}_{5}$ & $5.40 \mathrm{E}+02$ & $1 / \mathrm{s}$ & 9 \\
\hline 6 & ${ }^{3}\left[\mathrm{EY}^{2-}\right]^{*}+\mathrm{EY}^{2-} \rightarrow 2 \mathrm{EY}^{2-}$ & $\mathrm{k}_{6}$ & $3.00 \mathrm{E}+08$ & $\mathrm{~L} /(\mathrm{mol} \cdot \mathrm{s})$ & 9 \\
\hline 7 & ${ }^{3}\left[\mathrm{EY}^{2-}\right]^{*}+\mathrm{EYH}^{3-} \rightarrow \mathrm{EY}^{\cdot 3-}+\mathrm{EY}^{2-}+\mathrm{H}^{+}+\mathrm{e}^{-}$ & $\mathrm{k}_{7}$ & $1.45 \mathrm{E}+08$ & $\mathrm{~L} /(\mathrm{mol} \cdot \mathrm{s})$ & This work \\
\hline 8 & ${ }^{3}\left[\mathrm{EY}^{2-}\right]^{*}+\mathrm{EYH}^{3-} \rightarrow \mathrm{EY}^{2-}+\mathrm{EYH}^{3-}$ & $\mathrm{k}_{8}$ & $1.73 \mathrm{E}+09$ & $\mathrm{~L} /(\mathrm{mol} \cdot \mathrm{s})$ & This work \\
\hline 9 & $\mathrm{EY}^{\cdot 3-}+\mathrm{H}_{2} \mathrm{PO}_{4}^{-} \rightarrow \mathrm{EYH}^{\cdot 2-}+\mathrm{HPO}_{4}^{2-}$ & ${ }^{\mathrm{c}} \mathrm{K}_{9}$ & $2.00 \mathrm{E}+09$ & $\mathrm{~L} /(\mathrm{mol} \cdot \mathrm{s})$ & Calculated \\
\hline 10 & $\mathrm{EYH}^{\cdot 2-}+\mathrm{HPO}_{4}^{2-} \rightarrow \mathrm{EY}^{\cdot 3-}+\mathrm{H}_{2} \mathrm{PO}_{4}^{-}$ & ${ }^{\mathrm{c}} \mathrm{k}_{10}$ & $1.00 \mathrm{E}+10$ & $\mathrm{~L} /(\mathrm{mol} \cdot \mathrm{s})$ & Calculated \\
\hline 11 & $\mathrm{EY}^{\bullet-}+\mathrm{EY}^{\cdot 3-}+\mathrm{H}^{+} \rightarrow \mathrm{EY}^{2-}+\mathrm{EYH}^{3-}$ & $\mathrm{k}_{11}$ & $1.20 \mathrm{E}+04$ & $\mathrm{~L} /(\mathrm{mol} \cdot \mathrm{s})$ & This work \\
\hline 12 & $\mathrm{EY}^{\cdot 3-}+\mathrm{EYH}^{\cdot 2-} \rightarrow \mathrm{EY}^{2-}+\mathrm{EYH}^{3-}$ & $\mathrm{k}_{12}$ & $3.00 \mathrm{E}+05$ & $\mathrm{~L} /(\mathrm{mol} \cdot \mathrm{s})$ & This work \\
\hline 13 & $\mathrm{EYH}^{\cdot 2-}+\mathrm{EYH}^{\cdot 2-} \rightarrow \mathrm{EY}^{2-}+\mathrm{EYH}^{3-}+\mathrm{H}^{+}$ & $\mathrm{k}_{13}$ & $1.00 \mathrm{E}+07$ & $\mathrm{~L} /(\mathrm{mol} \cdot \mathrm{s})$ & This work \\
\hline 14 & $\mathrm{EY}^{\cdot 3-}+\mathrm{O}_{2} \rightarrow \mathrm{EY}^{2-}+\mathrm{O}_{2}^{\cdot-}$ & $\mathrm{k}_{14}$ & $1.00 \mathrm{E}+09$ & $\mathrm{~L} /(\mathrm{mol} \cdot \mathrm{s})$ & 18 \\
\hline 15 & $\mathrm{O}_{2}^{{ }^{-}-}+\mathrm{H}^{+} \rightarrow \mathrm{HO}_{2}^{-}$ & $\mathrm{k}_{15}$ & $1.00 \mathrm{E}+10$ & $\mathrm{~L} /(\mathrm{mol} \cdot \mathrm{s})$ & 34 \\
\hline 16 & $\mathrm{HO}_{2}{ }^{\circ} \rightarrow \mathrm{O}_{2}^{{ }^{-}-}+\mathrm{H}^{+}$ & $\mathrm{k}_{16}$ & $1.58 \mathrm{E}+05$ & $1 / \mathrm{s}$ & 34 \\
\hline 17 & $\mathrm{HO}_{2}^{\cdot}+\mathrm{HO}_{2}^{\cdot} \rightarrow \mathrm{H}_{2} \mathrm{O}_{2}+{ }^{1} \mathrm{O}_{2}$ & $\mathrm{k}_{17}$ & $8.30 \mathrm{E}+05$ & $\mathrm{~L} /(\mathrm{mol} \cdot \mathrm{s})$ & 34,35 \\
\hline 18 & $\mathrm{O}_{2}^{--}+\mathrm{HO}_{2}^{\cdot} \rightarrow \mathrm{HO}_{2}^{-}+{ }^{-1} \mathrm{O}_{2}$ & $\mathrm{k}_{18}$ & $9.70 \mathrm{E}+07$ & $\mathrm{~L} /(\mathrm{mol} \cdot \mathrm{s})$ & 34,35 \\
\hline 19 & $\mathrm{HO}_{2}^{-}+\mathrm{H}^{+} \rightarrow \mathrm{H}_{2} \mathrm{O}_{2}$ & $\mathrm{k}_{19}$ & $2.60 \mathrm{E}+10$ & $\mathrm{~L} /(\mathrm{mol} \cdot \mathrm{s})$ & 34 \\
\hline 20 & $\mathrm{H}_{2} \mathrm{O}_{2} \rightarrow \mathrm{HO}_{2}^{-}+\mathrm{H}^{+}$ & $\mathrm{k}_{20}$ & $3.70 \mathrm{E}-02$ & $1 / \mathrm{s}$ & 34 \\
\hline 21 & ${ }^{3}\left[\mathrm{EY}^{2-}\right]^{*}+\mathrm{O}_{2} \rightarrow \mathrm{EY}^{2-}+{ }^{1} \mathrm{O}_{2}$ & $\mathrm{k}_{21}$ & $1.00 \mathrm{E}+09$ & $\mathrm{~L} /(\mathrm{mol} \cdot \mathrm{s})$ & 10,18 \\
\hline 22 & ${ }^{1} \mathrm{O}_{2} \rightarrow \mathrm{O}_{2}$ & ${ }^{\mathrm{d}} \mathrm{k}_{22}$ & $4.40 \mathrm{E}+05$ & $1 / \mathrm{s}$ & 22 \\
\hline 23 & ${ }^{1} \mathrm{O}_{2}+\mathrm{O}_{2} \rightarrow 2 \mathrm{O}_{2}$ & ${ }^{\mathrm{e}} \mathrm{k}_{23}$ & $9.46 \mathrm{E}+08$ & $\mathrm{~L} /(\mathrm{mol} \cdot \mathrm{s})$ & 12 \\
\hline 24 & ${ }^{1} \mathrm{O}_{2}+\mathrm{EYH}^{3-} \rightarrow \mathrm{HO}_{2}{ }^{\cdot}+\mathrm{EY}^{\cdot 3-}$ & $\mathrm{k}_{24}$ & $2.90 \mathrm{E}+08$ & $\mathrm{~L} /(\mathrm{mol} \cdot \mathrm{s})$ & This work \\
\hline 25 & ${ }^{1} \mathrm{O}_{2}+\mathrm{EYH}^{3-} \rightarrow$ degraded product & $\mathrm{k}_{25}$ & $1.23 \mathrm{E}+09$ & $\mathrm{~L} /(\mathrm{mol} \cdot \mathrm{s})$ & This work \\
\hline 26 & ${ }^{1} \mathrm{O}_{2}+\mathrm{EY}^{2-} \rightarrow$ degraded product & ${ }^{f} k_{26}$ & $3.00 \mathrm{E}+07$ & $\mathrm{~L} /(\mathrm{mol} \cdot \mathrm{s})$ & 36 \\
\hline
\end{tabular}

${ }^{\mathrm{a}} \mathrm{I}_{0}=$ light intensity $\left(\mathrm{mW} / \mathrm{cm}^{2}\right), \mathrm{d}=$ optical path length $(\mathrm{cm}), \varepsilon(\lambda)=$ molar absorptivity of eosin $\mathrm{Y}$ as a function of wavelength $(\lambda),[E Y]=$ concentration $(\mathrm{mol} / \mathrm{L})$ of eosin $\mathrm{Y}, \mathrm{E}^{\prime}(\lambda)=$ energy $(\mathrm{J} / \mathrm{mol})$ of photons at wavelength of $\lambda$.

${ }^{\mathrm{b}}$ Estimated using $\varphi_{\mathrm{f}}=0.24, \mathrm{k}_{3}=2.0 \times 10^{8} \mathrm{~s}^{-1}$ in $10 \mathrm{mM}$ PBS from ref. 8 and $\varphi_{\mathrm{T}}=0.61$ in $\mathrm{pH} 9.5$ water from ref. 32. Fluorescence quantum yield $\left(\varphi_{\mathrm{f}}\right)$ does not change depending on $\mathrm{pH}$ if $\mathrm{pH}>5$ according to ref. 33 .

${ }^{\mathrm{c}}$ Estimated from the diffusion-controlled limit $\left(\mathrm{k}_{10}=4 \pi \mathrm{DRN} \mathrm{A} \approx 1 \times 10^{10} \mathrm{M}^{-1} \mathrm{~s}^{-1}\right)$ and the relationship of $\mathrm{k}_{10} / \mathrm{k}_{9}=\mathrm{K}_{\mathrm{a}}\left(10^{-6.5}\right) / \mathrm{K}_{2}\left(10^{-7.21}\right)=5.1$. Here, $\mathrm{K}_{\mathrm{a}}$ is acid dissociation constant of $\mathrm{EYH}^{*}{ }^{9}$ and $\mathrm{K}_{2}$ is acid dissociation constant of $\mathrm{H}_{2} \mathrm{PO}_{4}^{-}$.

${ }^{\mathrm{d}}$ Average value in aqueous solution from Table 1 of ref. 22.

${ }^{\text {e }}$ Estimated using $\mathrm{k}_{23} / \mathrm{k}_{22}=2150$, average value from ref. 12 .

${ }^{\mathrm{f}}$ Estimated using quantum yield $\left(2.5 \times 10^{-4}\right)$ of eosin $\mathrm{Y}$ photobleaching in water at $27^{\circ} \mathrm{C}$ from ref. 36 . 


\section{Figures}

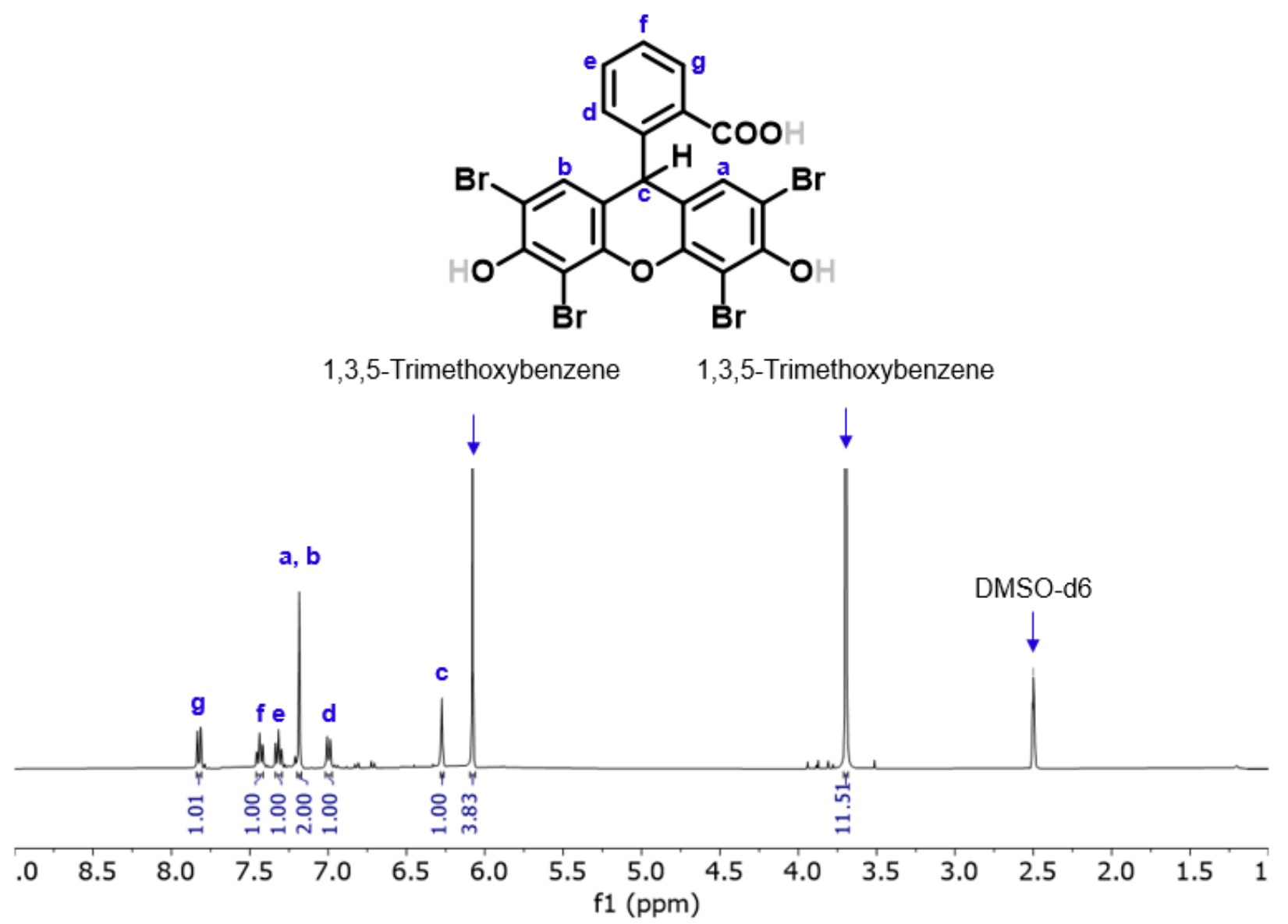

Figure S1. ${ }^{1} \mathrm{H}$ NMR spectrum $\left(400 \mathrm{MHz}, \mathrm{DMSO}-d_{6}\right)$ of $\mathrm{EYH}_{2}$. The ${ }^{1} \mathrm{H}$ NMR spectrum was recorded on a Bruker Avance Neo spectrometer operating at $400 \mathrm{MHz}$ and referenced to the solvent residual peak resulting from incomplete deuteration of DMSO- $d_{6}$. 


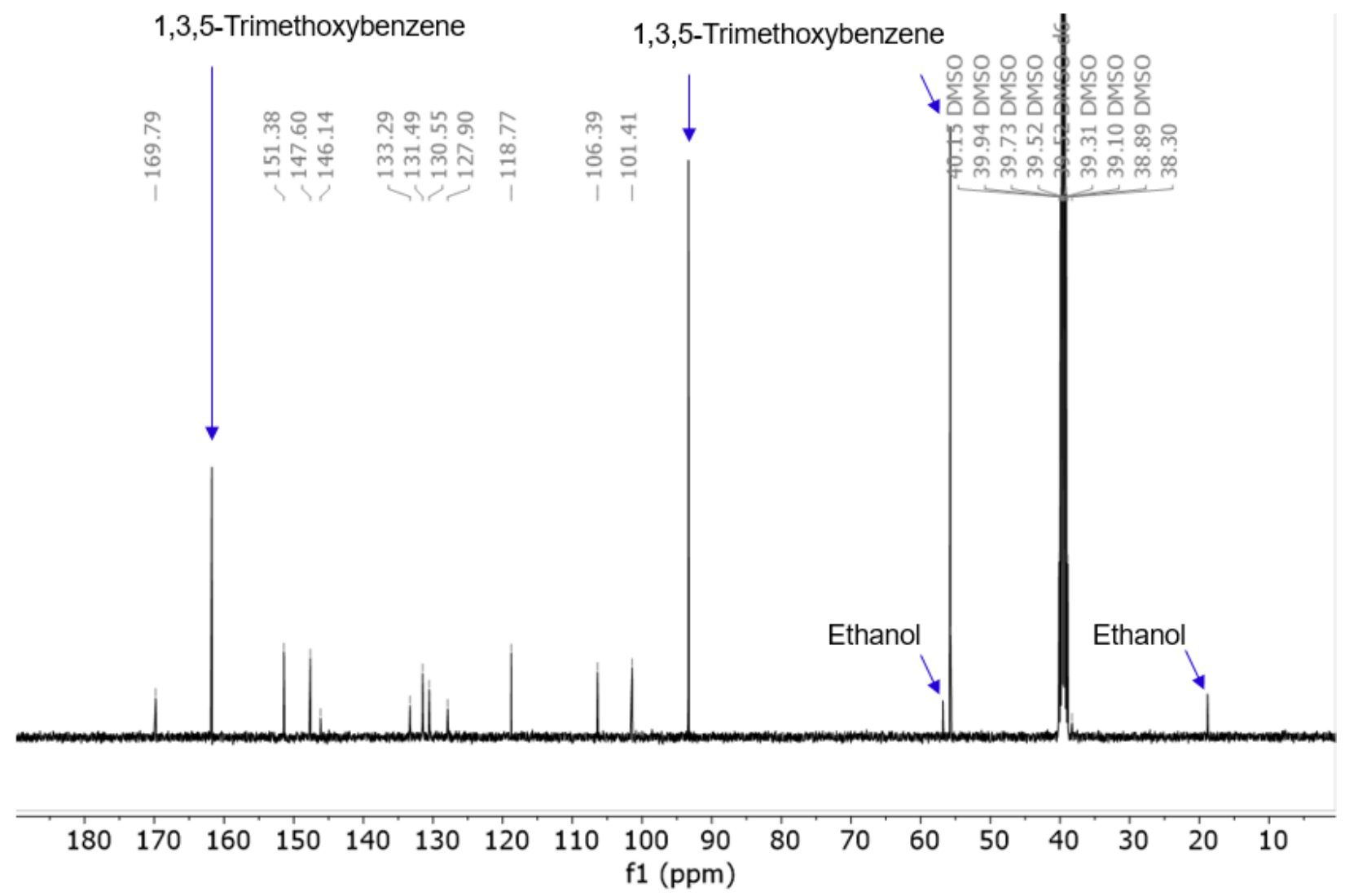

Figure S2. ${ }^{13} \mathrm{C}$ NMR spectrum $\left(100 \mathrm{MHz}\right.$, DMSO- $\left.d_{6}\right)$ of $\mathrm{EYH}_{2}$. The ${ }^{13} \mathrm{C}$ NMR spectrum was recorded on a Bruker Avance Neo spectrometer operating at $100 \mathrm{MHz}$ and referenced to DMSO- $d_{6}$. 


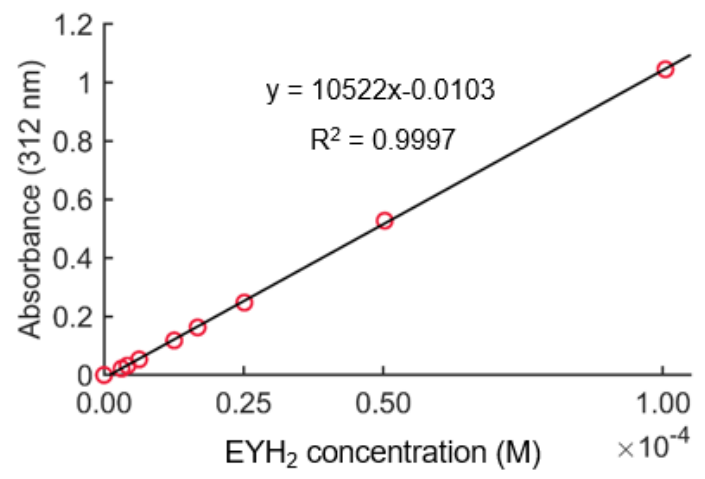

Figure S3. Absorbance of $\mathrm{EYH}_{2}$ in $0.1 \mathrm{M} \mathrm{NaOH}$ solution at $312 \mathrm{~nm}$. Molar absorptivity of $\mathrm{EYH}_{2}$ at 312 $\mathrm{nm}$ in $0.1 \mathrm{M} \mathrm{NaOH}$ solution is $10522 \mathrm{M}^{-1} \mathrm{~cm}^{-1}$. In $\mathrm{pH} 7.4$ phosphate buffer $(0.2 \mathrm{M})$, corrected molar absorptivity $\left(8900 \mathrm{M}^{-1} \mathrm{~cm}^{-1}\right)$ should be used due to $\mathrm{pH}$ dependence of its absorbance.

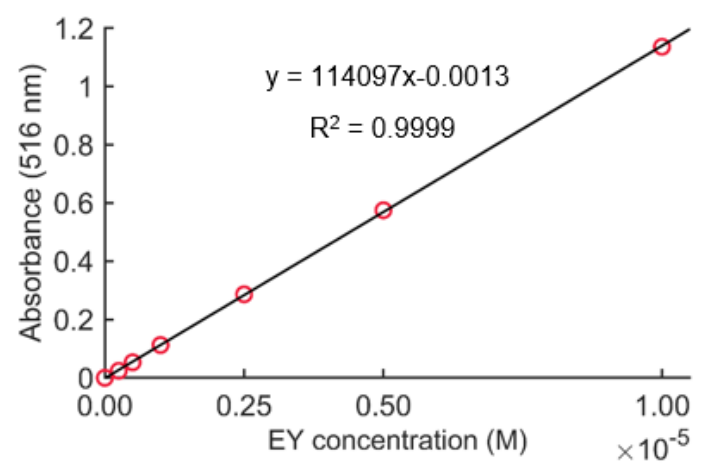

Figure S4. Absorbance of eosin Y (EY) in $0.2 \mathrm{M}$ phosphate buffer ( $\mathrm{pH} 7.4)$ at $516 \mathrm{~nm}$. Molar absorptivity of EY at $516 \mathrm{~nm}$ in the buffer solution is $114097 \mathrm{M}^{-1} \mathrm{~cm}^{-1}$. 
(A)

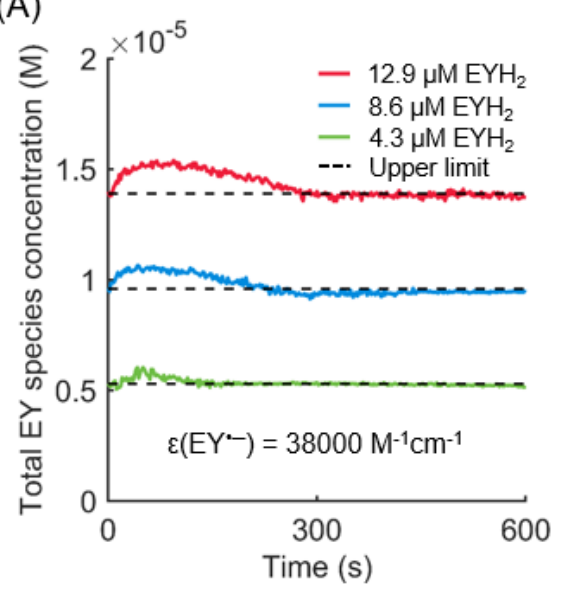

(B)

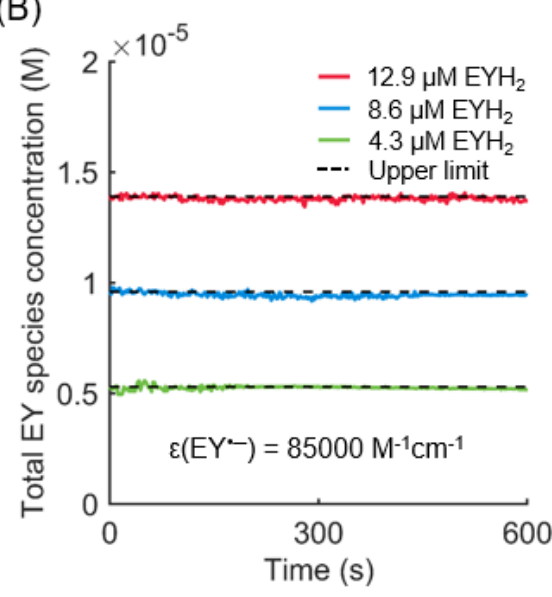

Figure S5. Estimation of molar absorptivity of $\mathrm{EY}^{--}$at $405 \mathrm{~nm}$ using mass balance of eosin $\mathrm{Y}(\mathrm{EY})$ species. In the deaerated systems initially containing $1 \mu \mathrm{M} \mathrm{EY}$ and 4.3-12.9 $\mu \mathrm{M} \mathrm{EYH}$, the molar absorptivity $\left(38000 \mathrm{M}^{-1} \mathrm{~cm}^{-1}\right)$ from literature ${ }^{9,37}$ overestimated the concentration of $\mathrm{EY}^{\circ-}$, making the total concentration of eosin Y species inconsistent with the law of conservation of mass. We found that the molar absorptivity of $85000 \mathrm{M}^{-1} \mathrm{~cm}^{-1}$ provided reasonable total eosin $\mathrm{Y}$ species concentration. In literature, ${ }^{38}$ it was proposed that different forms of $\mathrm{EY}^{-}$showing different lifetimes could be generated during photoreduction of eosin Y with allylthiourea and EDTA, and their molar absorptivity could be different. This observation suggests that the $\mathrm{EY}^{-}$generated from $\mathrm{EYH}_{2}$ activation may not be the same species as the EY- obtained from flash photolysis experiments, or may form loosely bound complexes with other species in the system, leading to change in molar absorptivity. 
(A)

(a) ${ }^{3} \mathrm{EY}+\mathrm{EY} \stackrel{\mathrm{k}_{a}}{\longrightarrow} \mathrm{EY}^{\cdot-}+\mathrm{EY}^{\cdot+}$

(b) $\mathrm{EY}^{\cdot-}+\mathrm{EY}^{++} \stackrel{\mathrm{k}_{\mathrm{b}}}{\longrightarrow} \mathrm{EY}+\mathrm{EY}$

(c) $E Y^{\circ+}+\mathrm{EY}^{++} \stackrel{\mathrm{k}_{\mathrm{c}}}{\longrightarrow}$ Product
(B)

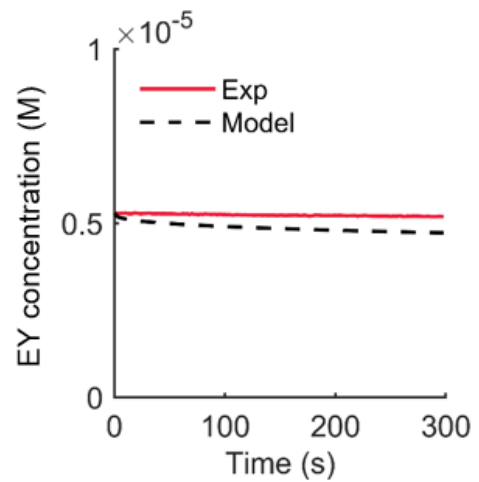

(C)

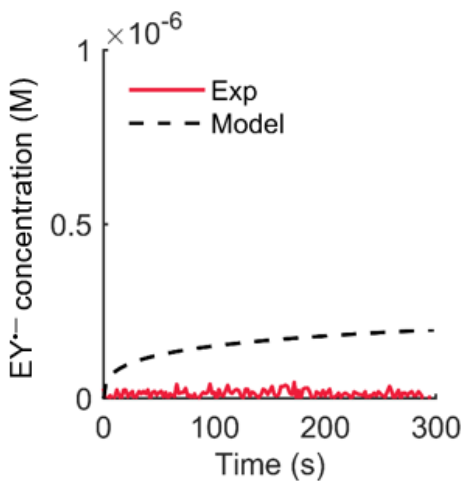

Figure S6. Discrepancy between experimental data and model results due to the generation of eosin Y radical cation $\left(\mathrm{EY}^{\cdot+}\right)$ in the EY-only system. (A) Proposed reactions for $\mathrm{EY}^{\cdot+}$ generation and decay. According to literature, ${ }^{9,10} \mathrm{EY}^{\cdot+}$ was detected at around $460 \mathrm{~nm}$ during flash photolysis of eosin $\mathrm{Y}$ in the absence of oxygen. It was proposed that $\mathrm{EY}^{\cdot+}$ together with eosin $\mathrm{Y}$ radical anion $\left(\mathrm{EY}^{\circ-}\right)$ could be produced from the bimolecular reaction (a) between triplet eosin $\mathrm{Y}\left({ }^{3} \mathrm{EY}^{*}\right)$ and ground-state eosin $\mathrm{Y}(\mathrm{EY})$, and the radicals could decay through back-electron transfer reaction (b). Another decay process (c) for EY ${ }^{\bullet+}$ was proposed for generating unidentified form of bleached EY. ${ }^{39,40}(\mathrm{~B}, \mathrm{C})$ Comparison of experimental data and model results. Considering the EY ${ }^{\cdot+}$-involved reactions $\left(\mathrm{k}_{\mathrm{a}}=7 \times 10^{7} \mathrm{M}^{-1} \mathrm{~s}^{-1},{ }^{9,10} \mathrm{k}_{\mathrm{b}}=8 \times 10^{8} \mathrm{M}^{-1} \mathrm{~s}^{-1},{ }^{38,39}\right.$ and $\mathrm{k}_{\mathrm{c}}$ $=1 \times 10^{8} \mathrm{M}^{-1} \mathrm{~s}^{-1}$ ), a kinetic model was developed to describe the behavior of one component (EY) system where eosin $\mathrm{Y}$ in deaerated solution was irradiated under green light $\left(2.6 \mathrm{~mW} / \mathrm{cm}^{2}, \lambda_{\max }=535 \mathrm{~nm}\right)$. The model formulated with the EY ${ }^{\cdot+}$-involved reactions a-c and reactions 1-6 and 9-13 in Table S1 predicted (B) decrease in EY concentration and (C) increase in $\mathrm{EY}^{\cdot-}$ concentration during irradiation while no change in those concentrations was observed in experiments. This discrepancy suggests that the self-bimolecular reaction of $\mathrm{EY}^{\cdot+}$ might not be effective under our irradiation condition due to its low concentration or rapid back-electron transfer reaction in the loosely bound complex $\left(\mathrm{EY}^{-\cdots} \mathrm{EY}^{\cdot+}\right)$. Both the cases provide good agreement between experimental data and model results. 
(A)

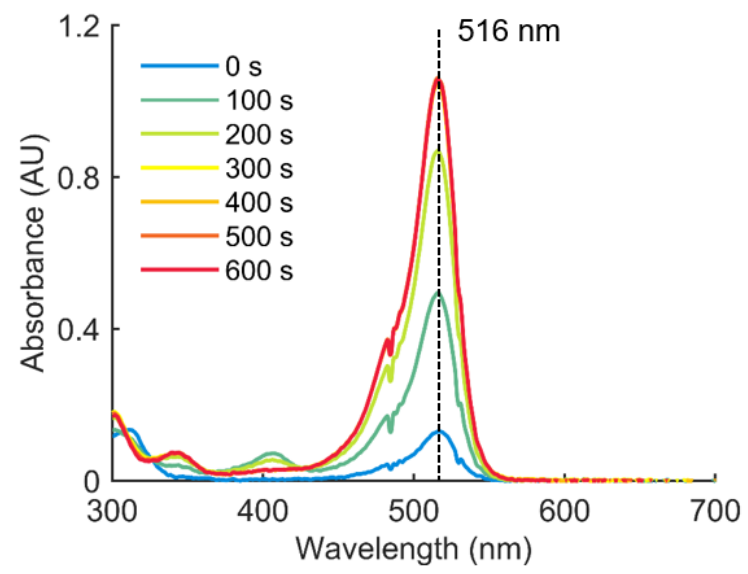

(B)

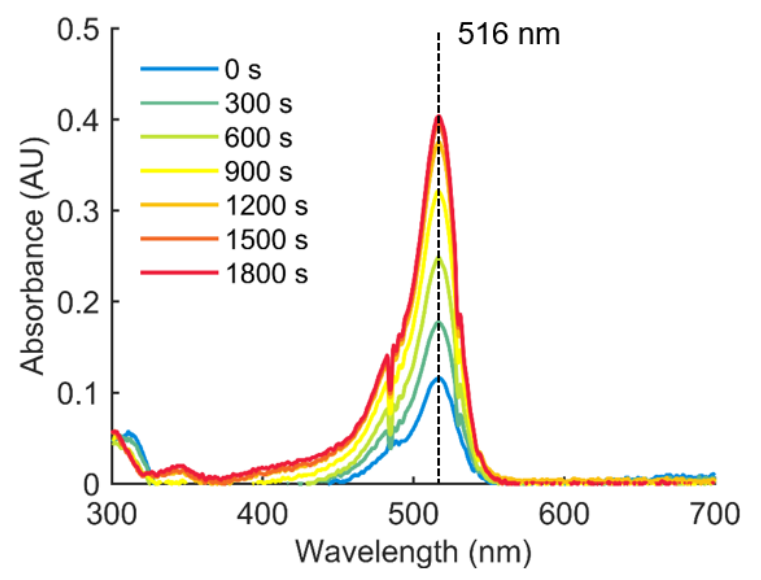

Figure S7. Absorbance vs. wavelength plots of UV-Vis absorbance change over time. (A) A deaerated solution including $8.6 \mu \mathrm{M} \mathrm{EYH}_{2}$ and $1 \mu \mathrm{M} \mathrm{EY}$ was monitored under $2.6 \mathrm{~mW} / \mathrm{cm}^{2}$ green light $\left(\lambda_{\max }=535\right.$ $\mathrm{nm}$ ). (B) An air-saturated solution including $8 \mu \mathrm{M} \mathrm{EYH}_{2}$ and $1 \mu \mathrm{M} \mathrm{EY}$ was monitored under $1.2 \mathrm{~mW} / \mathrm{cm}^{2}$ green light $\left(\lambda_{\max }=535 \mathrm{~nm}\right)$. 
(A)
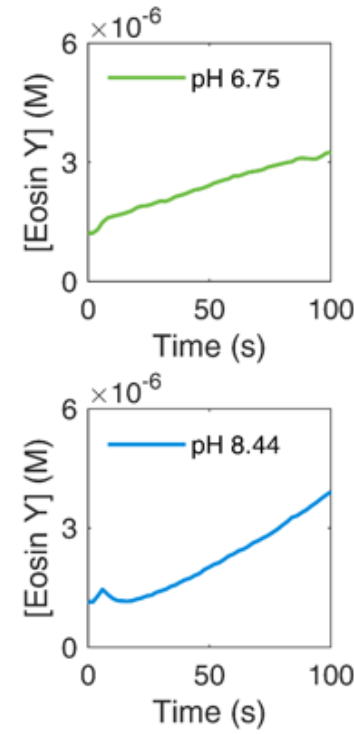

(B)
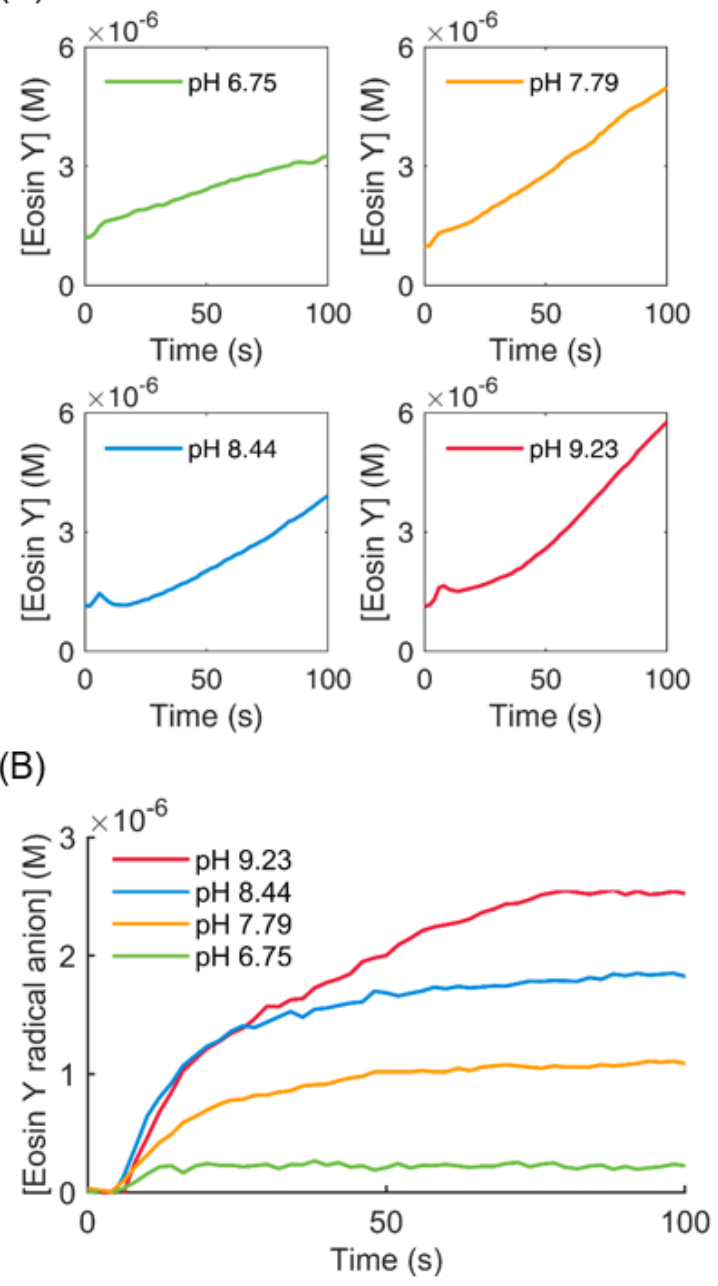

(C)

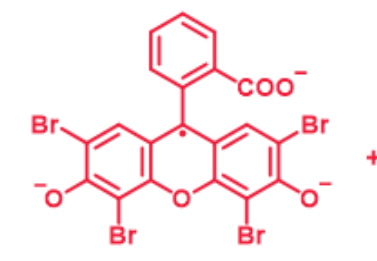

$\mathrm{EY}^{-\mathrm{C}}$

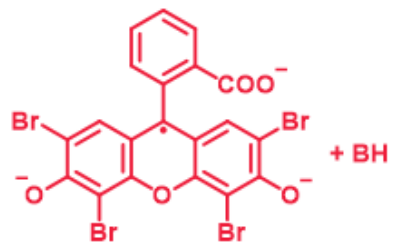

$\mathrm{EY}^{--}$

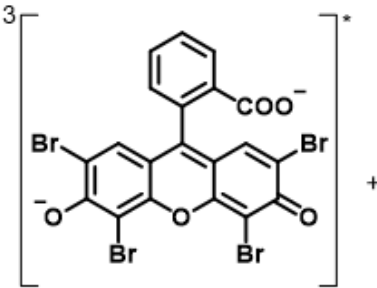

${ }^{3} \mathrm{EY}^{\star}$<smiles>[BH3-]CCCCCC</smiles>

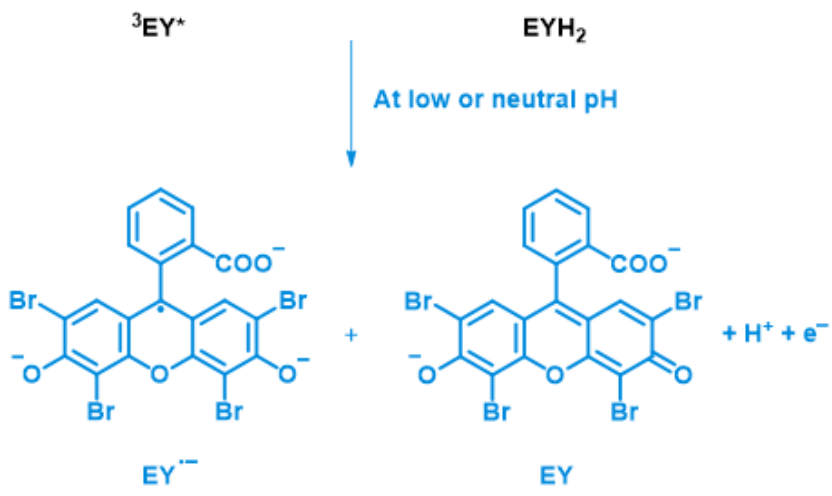

Figure S8. $\mathrm{pH}$ dependent $\mathrm{EYH}_{2}$ activation pathways. The deaerated solutions with various $\mathrm{pH}$ containing $1 \mu \mathrm{M}$ EY and $12.9 \mu \mathrm{M} \mathrm{EYH}_{2}$ were irradiated under green light $\left(2.6 \mathrm{~mW} / \mathrm{cm}^{2}, \lambda_{\max }=535 \mathrm{~nm}\right)$. During the irradiation, eosin $\mathrm{Y}(\mathrm{EY})$ concentration and $\mathrm{EY}$ radical anion $\left(\mathrm{EY}^{\circ-}\right)$ concentration were monitored at 516 $\mathrm{nm}$ and $405 \mathrm{~nm}$, respectively. (A) EY concentrations in different $\mathrm{pH}$ solutions. During the first few seconds, EY concentrations increased very fast regardless of $\mathrm{pH}$. Afterwards, EY concentration increased at slower rates in $\mathrm{pH} 6.75$ and $\mathrm{pH} 7.79$ solutions. Interestingly, however, EY concentration decreased for a few seconds at higher $\mathrm{pH}$. (B) EY ${ }^{\bullet-}$ concentrations in different $\mathrm{pH}$ solutions. During the first few seconds, no $\mathrm{EY}^{--}$was detected in all solutions. Afterwards, more $\mathrm{EY}^{-}{ }^{-}$was observed at higher $\mathrm{pH}$. The initial change in $\mathrm{EY}$ and $\mathrm{EY}^{-}$- concentrations indicates that there was a small amount of remaining oxygen in the solution, and oxygen oxidized $\mathrm{EY}^{\bullet-}$ back to EY quickly. From the $\mathrm{pH}$-dependent kinetics of EY and EY ${ }^{\cdot-}$ generation after oxygen depletion, we proposed that $\mathrm{EYH}_{2}$ is oxidized by triplet $\mathrm{EY}\left({ }^{3} \mathrm{EY}^{*}\right)$, generating one or two $\mathrm{EY}^{\circ-}$ depending on $\mathrm{pH}$. (C) $\mathrm{pH}$ dependent $\mathrm{EYH}_{2}$ activation pathways. 
(A)

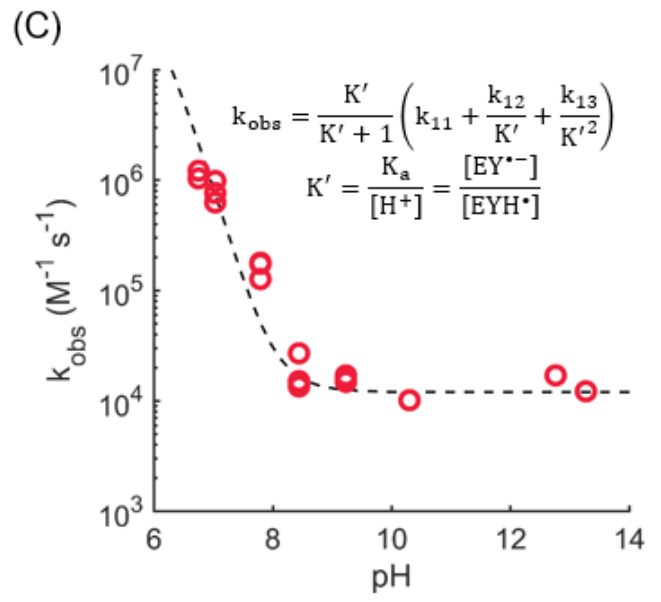

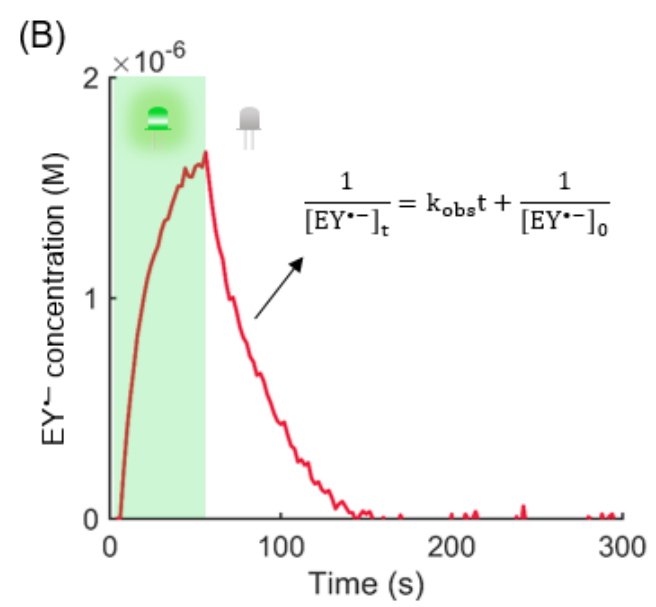

(D)

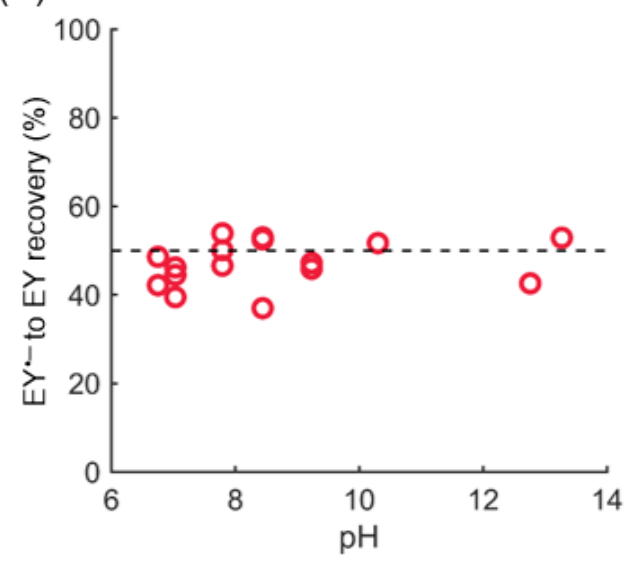

Figure S9. Estimating rate constants for EY radical disproportionation reactions. (A) EY radical decay pathways. $\mathrm{EY}^{\bullet-}$ is in equilibrium with $\mathrm{EYH}^{\bullet}$. Disproportionation reaction of $\mathrm{EY}^{--}+\mathrm{EY}^{-} \rightarrow \mathrm{EY}+\mathrm{EYH}_{2}$ has been proposed previously, ${ }^{39}$ but the reaction rate has never been measured considering $\mathrm{pH}$ dependent kinetics of EY radical decay. As proposed in literature for fluorescein radical decay, ${ }^{13}$ we proposed three different disproportionation reactions of $\mathrm{EY}^{\bullet-}$ and $\mathrm{EYH}^{\bullet}$ to account for the $\mathrm{pH}$ dependent kinetics. (B) Measuring observed rate constants of $\mathrm{EY}^{--}$decay. The sample data shows the radical generation under light and the radical decay in the absence of light at $\mathrm{pH}$ 8.44. In all radical decay experiments, deaerated buffer solutions ( $\mathrm{pH}<8$ : $0.2 \mathrm{M}$ phosphate, $8<\mathrm{pH}<10.5$ : $0.2 \mathrm{M}$ borate, and $12<\mathrm{pH}$ : $\mathrm{NaOH}$ ) including $1 \mu \mathrm{M} \mathrm{EY}$ and $12.9 \mu \mathrm{M} \mathrm{EYH}_{2}$ were irradiated with $2.6 \mathrm{~mW} / \mathrm{cm}^{2}$ green light $\left(\lambda_{\max }=535 \mathrm{~nm}\right)$ for 50 seconds, and the absorbance (at 300-700 nm) was monitored in the absence of light. The second order rate law well described the decrease in $\mathrm{EY}^{\circ-}$ concentration over time, and the observed rate constant $\left(\mathrm{k}_{\mathrm{obs}}\right)$ at each $\mathrm{pH}$ was obtained from the plot of $1 /\left[\mathrm{EY}^{-}\right]_{\mathrm{t}}$ vs. t. (C) The observed rate constants at various $\mathrm{pH}$. Red circles represent the measured $\mathrm{k}_{\mathrm{obs}}$. Using $\mathrm{K}_{\mathrm{a}}=10^{-6.5}$ from ref. 9 and the relationship between $\mathrm{k}_{\mathrm{obs}}$ and disproportionation reaction rate constants $\left(\mathrm{k}_{11}, \mathrm{k}_{12}\right.$, and $\left.\mathrm{k}_{13}\right)$ from literature, ${ }^{13}$ the following parameters were determined: $\mathrm{k}_{11}=1.20 \times 10^{4}$ $\mathrm{M}^{-1} \mathrm{~s}^{-1}, \mathrm{k}_{12}=3.00 \times 10^{5} \mathrm{M}^{-1} \mathrm{~s}^{-1}$, and $\mathrm{k}_{13}=1.00 \times 10^{7} \mathrm{M}^{-1} \mathrm{~s}^{-1}$. (D) $\mathrm{EY}$ recovery from $\mathrm{EY}^{--}$decay. By comparing S-20 
the change in $\mathrm{EY}^{\cdot-}$ and $\mathrm{EY}$ concentrations, we confirmed that $50 \%$ of $\mathrm{EY}^{--}$was oxidized to EY, which is consistent with the proposed disproportionation reactions.

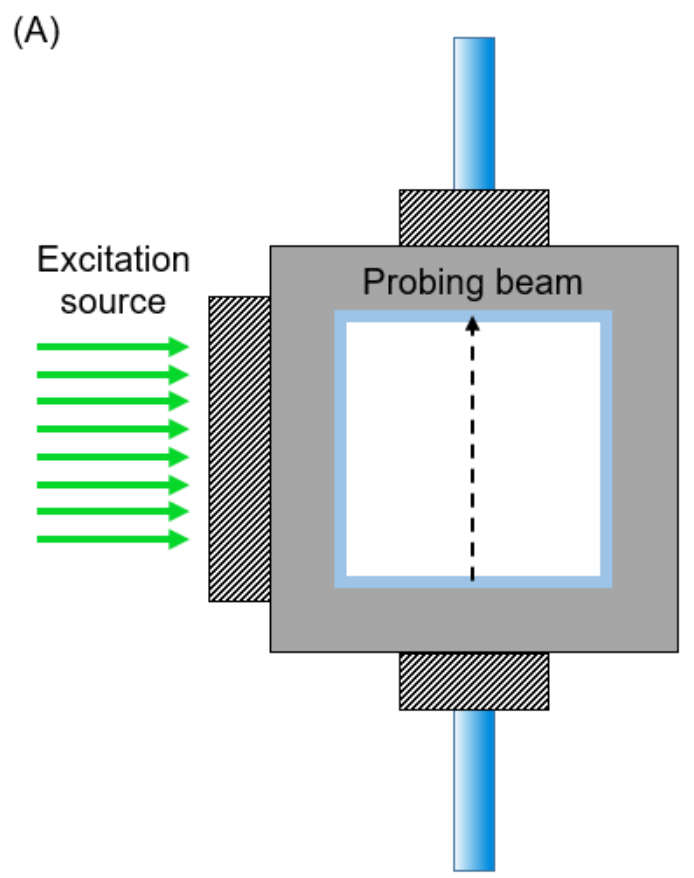

(B)

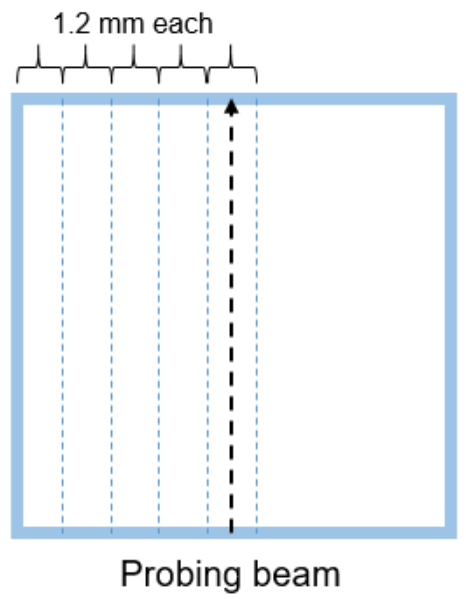

Figure S10. Schematic of fiber optic UV-Vis spectroscopy set-up for kinetic monitoring of EY, EY ${ }^{\bullet-}$, and $\mathrm{EYH}_{2}$ in the deaerated solutions. (A) The sample solution was purged with $\mathrm{N}_{2}$ in a sealed cuvette, and activating light $\left(\lambda_{\max }=535 \mathrm{~nm}\right)$ was shone from left. To minimize the effect of oxygen diffusion, the probing beam was located $4 \mathrm{~mm}$ below the gas-liquid interface, and the solution was not stirred during the monitoring. (B) Schematic of multilayered model. Due to the no-stirring condition, a EY concentration gradient - the closer to the light source, the higher the concentration - occurred, making light intensity throughout the cuvette not uniform because EY close to the light source could absorb light and reduce the intensity for distant EY. To account for this spatial variation of light intensity, we divided the cuvette into multiple layers and assumed well-mixed condition in each layer including the light intensity. This way could simplify the kinetic model and reduce the computational cost. Given that one-dimensional mean squared displacement is $\sqrt{2 \mathrm{D} \Delta \mathrm{t}} \approx 1.1 \mathrm{~mm}$ for $\mathrm{D}=10^{-9} \mathrm{~m}^{2} \mathrm{~s}^{-1}$ and $\Delta \mathrm{t}=600 \mathrm{~s}$, we used $1.2 \mathrm{~mm}$ for the layer thickness. The light intensity in each layer was determined by subtracting light intensity absorbed by EY in all the previous layers from original light intensity. To compare model results with experimental data, we used the concentrations calculated from the $5^{\text {th }}$ layer where the probing beam passed through the sample. 
(A)

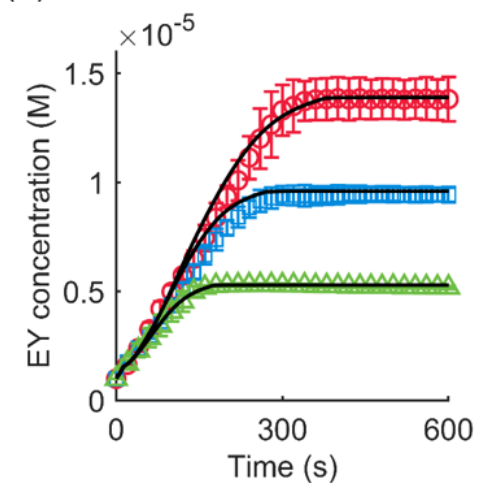

(B)

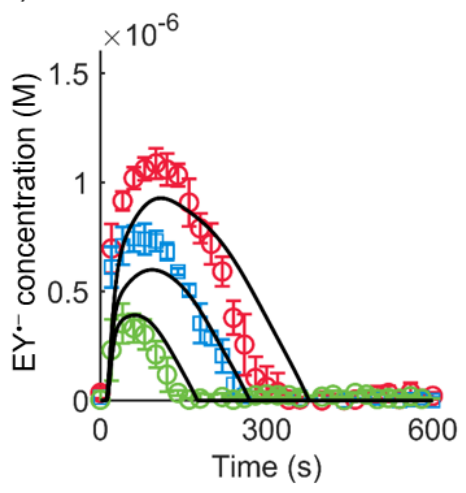

(C)

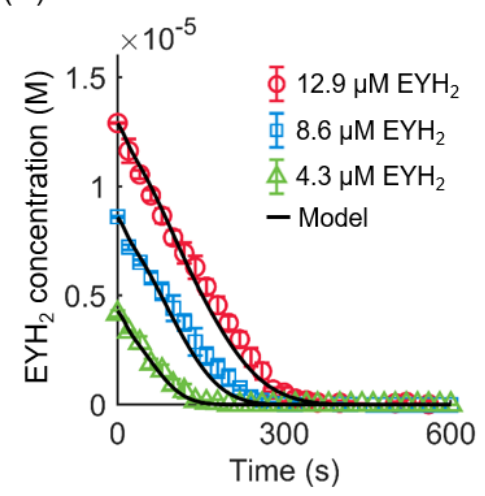

Figure S11. The effect of oxygen dissolution and diffusion from air on kinetic model results for deaerated solutions. If there is a slight leak of air due to improper sealing of the cuvette, the oxygen diffused from air can rapidly oxidize $\mathrm{EY}^{--}$to EY. Using the estimated rate $\left(4 \times 10^{-9} \mathrm{M} / \mathrm{s}\right)$ for the oxygen diffusion from literature $\left(2.39 \times 10^{-7} \mathrm{M} / \mathrm{min}\right){ }^{41}$ the unknown rate constants $\left(\mathrm{k}_{7}=1.0 \times 10^{8} \mathrm{M}^{-1} \mathrm{~s}^{-1}\right.$ and $\left.\mathrm{k}_{8}=1.2 \times 10^{9} \mathrm{M}^{-1} \mathrm{~s}^{-1}\right)$ for Eq. 7 and Eq. 8 were determined by fitting the model with $12.9 \mu \mathrm{M} \mathrm{EYH}_{2}$ data $\left(\mathrm{EY}, \mathrm{EY}^{\circ}\right.$, and $\mathrm{EYH}_{2}$ concentration profiles). Black solid lines demonstrate the concentration of each species predicted by the kinetic model with considering the oxygen diffusion from air.

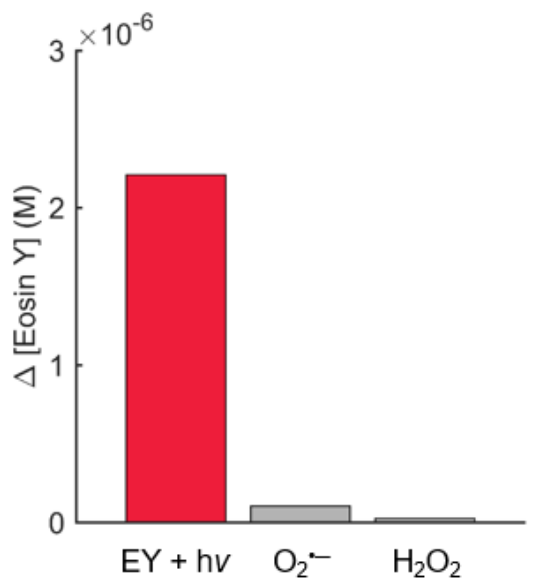

Figure S12. Reactivity of superoxide $\left(\mathrm{O}_{2}{ }^{--}\right)$and hydrogen peroxide $\left(\mathrm{H}_{2} \mathrm{O}_{2}\right)$ against $\mathrm{EYH}_{2}$. Activation of $\mathrm{EYH}_{2}(8 \mu \mathrm{M})$ in air-saturated $\mathrm{pH} 7.4$ phosphate buffer $(0.2 \mathrm{M})$ was monitored upon green light irradiation $\left(1.2 \mathrm{~mW} / \mathrm{cm}^{2}, \lambda_{\max }=535 \mathrm{~nm}\right)$ with $1 \mu \mathrm{M} \mathrm{EY}$, addition of potassium superoxide $\left(\mathrm{KO}_{2}\right)$ at final concentration of $35 \mathrm{mM}$, or including $350 \mu \mathrm{M} \mathrm{H}_{2} \mathrm{O}_{2}$ in the buffer solution. After ten minutes, the change in EY concentration was presented above. Compared to photosensitized oxidation of $\mathrm{EYH}_{2}, \mathrm{O}_{2}{ }^{--}$and $\mathrm{H}_{2} \mathrm{O}_{2}$ showed much smaller effects on $\mathrm{EYH}_{2}$ activation - the increase in EY concentration by $\mathrm{O}_{2}{ }^{-}$could also be due to ${ }^{1} \mathrm{O}_{2}$ generated by one-electron transfer from $\mathrm{O}_{2}{ }^{-42}$ - even though their concentrations used here were 
unattainable in the EY amplification experiments according to the kinetic model. It estimates that maximum concentrations of $\mathrm{O}_{2}{ }^{--}$and $\mathrm{H}_{2} \mathrm{O}_{2}$ are less than $100 \mathrm{nM}$ and $2 \mu \mathrm{M}$, respectively, when the solution including $8 \mu \mathrm{M} \mathrm{EYH}{ }_{2}$ and $1 \mu \mathrm{M} \mathrm{EY}$ is irradiated with $1.2 \mathrm{~mW} / \mathrm{cm}^{2}$ green light $\left(\lambda_{\max }=535 \mathrm{~nm}\right)$ for 30 minutes.

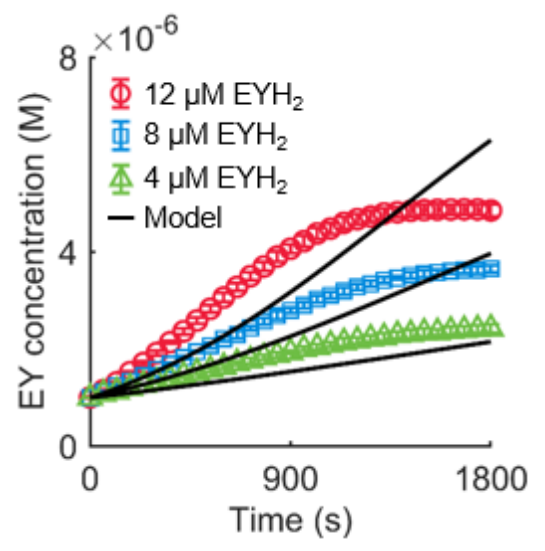

Figure S13. Impact of $\mathrm{EYH}_{2}$ activation and degradation by singlet oxygen on model results. A kinetic model was constructed to describe EY amplification under $1.2 \mathrm{~mW} / \mathrm{cm}^{2}$ green light $\left(\lambda_{\max }=535 \mathrm{~nm}\right)$ in airsaturated pH 7.4 phosphate buffer $(0.2 \mathrm{M})$ containing $1 \mu \mathrm{M}$ EY and 4-12 $\mu \mathrm{M} \mathrm{EYH}_{2}$. The model considered quenching of triplet EY by oxygen, but ignored any reactions between $\mathrm{EYH}_{2}$ and singlet oxygen. The model predicted much slower $\mathrm{EYH}_{2}$ activation than experimental data given that more than $50 \%$ of $\mathrm{EYH}_{2}$ were expected to be unreacted at 1800 seconds. In reality, there was a significant loss of EY species (EY, EYand $\mathrm{EYH}_{2}$ ) during the activation of $\mathrm{EYH}_{2}$, and the highest concentration of $\mathrm{EY}$ was achieved at 1800 seconds. 
(A)

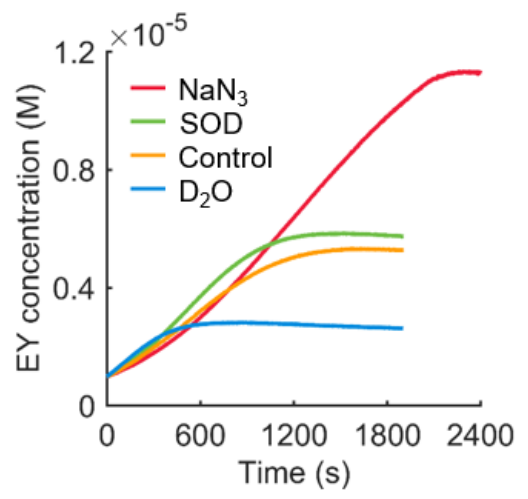

(B)

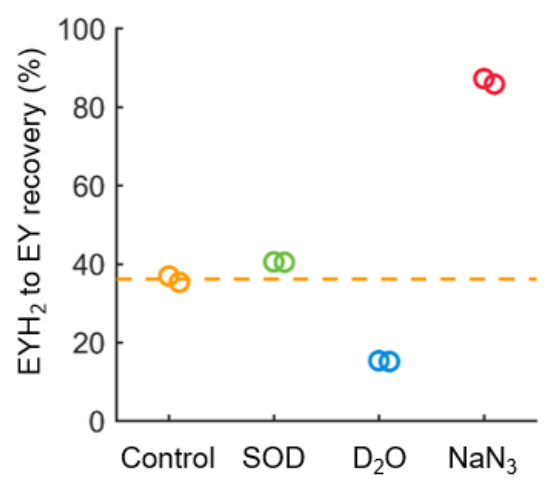

Figure S14. Effects of sodium azide $\left(\mathrm{NaN}_{3}\right)$, superoxide dismutase (SOD), and deuterium oxide $\left(\mathrm{D}_{2} \mathrm{O}\right)$ on EY amplification in air-saturated solutions. The control solution included $12 \mu \mathrm{M} \mathrm{EYH}, 1 \mu \mathrm{M} \mathrm{EY}$, and $\sim 0.25 \mathrm{mM}$ oxygen in $0.2 \mathrm{M}$ phosphate buffer $\left(\mathrm{pH}\right.$ 7.4). The $\mathrm{NaN}_{3}$ solution and the SOD solution were prepared by adding $10 \mathrm{mM} \mathrm{NaN}_{3}$ and $3 \mu \mathrm{M}$ SOD to the control solutions, respectively. The $\mathrm{D}_{2} \mathrm{O}$ solution $\left(>90 \% \mathrm{D}_{2} \mathrm{O}\right.$ at the final concentration) was prepared by replacing the phosphate buffer with a $\mathrm{D}_{2} \mathrm{O}$-based phosphate buffer in the control solution. The prepared solutions were irradiated under $1.2 \mathrm{~mW} / \mathrm{cm}^{2}$ green light $\left(\lambda_{\max }=535 \mathrm{~nm}\right)$. (A) Steady-steady kinetics of EY amplification monitored at $516 \mathrm{~nm}$ during the irradiation. (B) The recovery of EY from $\mathrm{EYH}_{2}$. The orange dotted line represents the recovery (36\%) obtained in the control solution. The recovery increased to $86.5 \%$ with the singlet oxygen $\left({ }^{1} \mathrm{O}_{2}\right)$ quencher $\left(\mathrm{NaN}_{3}\right)$, and it decreased to $15.2 \%$ with the increased lifetime of ${ }^{1} \mathrm{O}_{2}$ in $\mathrm{D}_{2} \mathrm{O}$. These results are in strong agreement with the proposed $\mathrm{EYH}_{2}$ degradation by ${ }^{1} \mathrm{O}_{2}$. Interestingly, there was minor improvement in the recovery with the SOD, which could be due to slow $\mathrm{EY}$ and $\mathrm{EYH}_{2}$ degradation by superoxide $\left(\mathrm{O}_{2}{ }^{--}\right)$.

By dividing the apparent EY generation rates at initial time points $(0-200 \mathrm{~s})$ by the $\mathrm{EYH}_{2}$-to-EY recovery, we estimated initial $\mathrm{EYH}_{2}$ activation rates: Control $(8.49 \mathrm{nM} / \mathrm{s}), \mathrm{SOD}(8.64 \mathrm{nM} / \mathrm{s}), \mathrm{D}_{2} \mathrm{O}(28.5 \mathrm{nM} / \mathrm{s})$, and $\mathrm{NaN}_{3}(2.82 \mathrm{nM} / \mathrm{s})$. The fact that the $\mathrm{EYH}_{2}$ activation rate is faster in $\mathrm{D}_{2} \mathrm{O}$ than in $\mathrm{H}_{2} \mathrm{O}$ indicates that ${ }^{1} \mathrm{O}_{2}$ contributes to not only degradation of $\mathrm{EY}$ and $\mathrm{EYH}_{2}$, but also activation of $\mathrm{EYH}_{2}$. The addition of SOD did not significantly affect the $\mathrm{EYH}_{2}$ activation rate, reconfirming that $\mathrm{O}_{2}{ }^{-}$is not involved in the $\mathrm{EYH}_{2}$ activation as shown in Figure S12. In the case of the $\mathrm{NaN}_{3}$ solution, the $\mathrm{EYH}_{2}$ activation rate is lower than that of the control, which is because $\mathrm{NaN}_{3}$ slowly quenches triplet eosin $\mathrm{Y}\left({ }^{3} \mathrm{EY}^{*}\right){ }^{43}$ 


\begin{tabular}{|c|c|c|c|c|c|c|c|c|c|c|c|c|c|}
\hline & $E Y$ & ${ }^{1} \mathrm{EY}^{*}$ & ${ }^{3} \mathrm{EY}^{*}$ & $\mathrm{EYH}_{2}$ & $\mathrm{EY}^{*-}$ & $\mathrm{O}_{2}$ & ${ }^{1} \mathrm{O}_{2}$ & $\mathrm{O}_{2}^{--}$ & $\mathrm{HO}_{2}^{\circ}$ & $\mathrm{H}_{2} \mathrm{O}_{2}$ & $\mathrm{HO}_{2}^{-}$ & $\mathrm{EYH}^{\circ}$ & degraded products \\
\hline $\mathrm{k}_{2}$ & 1.487 & 4.591 & 4.747 & 7.147 & 4.804 & 0.058 & 4.743 & 2.300 & 2.300 & 2.865 & 2.793 & 4.804 & 2.659 \\
\hline $\mathrm{k}_{3}$ & 2.456 & 7.464 & 7.714 & 11.991 & 7.888 & 0.097 & 7.708 & 3.751 & 3.751 & 4.703 & 4.588 & 7.888 & 4.371 \\
\hline $\mathrm{k}_{4}$ & 3.300 & 11.126 & 11.495 & 14.664 & 10.925 & 0.128 & 11.484 & 5.432 & 5.432 & 6.591 & 6.407 & 10.925 & 6.073 \\
\hline$k_{5}$ & 0.021 & 0.016 & 0.071 & 0.101 & 0.069 & 0.001 & 0.071 & 0.033 & 0.033 & 0.041 & 0.040 & 0.069 & 0.038 \\
\hline$k_{8}$ & 0.027 & 0.019 & 0.130 & 0.170 & 0.095 & 0.001 & 0.130 & 0.044 & 0.044 & 0.046 & 0.045 & 0.095 & 0.045 \\
\hline $\mathrm{k}_{7}$ & 9.535 & 6.593 & 6.831 & 15.643 & 12.669 & 0.073 & 6.863 & 5.805 & 5.804 & 11.505 & 11.343 & 12.664 & 2.125 \\
\hline$k_{8}$ & 0.571 & 0.430 & 1.254 & 2.057 & 1.858 & 0.020 & 1.252 & 0.920 & 0.920 & 1.186 & 1.146 & 1.858 & 1.071 \\
\hline$k_{9}$ & 0.000 & 0.000 & 0.000 & 0.000 & 1.236 & 0.000 & 0.000 & 0.000 & 0.000 & 0.001 & 0.000 & 23.426 & 0.000 \\
\hline$k_{10}$ & 0.000 & 0.000 & 0.000 & 0.000 & 1.012 & 0.000 & 0.000 & 0.000 & 0.000 & 0.000 & 0.000 & 19.189 & 0.000 \\
\hline $\mathrm{k}_{11}$ & 0.000 & 0.000 & 0.000 & 0.000 & 0.000 & 0.000 & 0.000 & 0.000 & 0.000 & 0.000 & 0.000 & 0.000 & 0.000 \\
\hline $\mathrm{k}_{12}$ & 0.000 & 0.000 & 0.000 & 0.000 & 0.000 & 0.000 & 0.000 & 0.000 & 0.000 & 0.000 & 0.000 & 0.000 & 0.000 \\
\hline$k_{13}$ & 0.000 & 0.000 & 0.000 & 0.000 & 0.000 & 0.000 & 0.000 & 0.000 & 0.000 & 0.000 & 0.000 & 0.000 & 0.000 \\
\hline $\mathrm{k}_{14}$ & 0.000 & 0.000 & 0.000 & 0.000 & 20.001 & 0.000 & 0.000 & 0.000 & 0.000 & 0.000 & 0.000 & 19.979 & 0.000 \\
\hline$k_{15}$ & 0.001 & 0.001 & 0.003 & 0.003 & 0.004 & 0.003 & 0.002 & 10.458 & 11.928 & 1.404 & 1.222 & 0.004 & 0.001 \\
\hline$k_{16}$ & 0.001 & 0.001 & 0.004 & 0.003 & 0.004 & 0.003 & 0.002 & 11.688 & 10.650 & 1.405 & 1.242 & 0.004 & 0.001 \\
\hline$k_{17}$ & 0.000 & 0.000 & 0.000 & 0.000 & 0.000 & 0.000 & 0.000 & 0.000 & 0.000 & 0.000 & 0.000 & 0.000 & 0.000 \\
\hline $\mathrm{k}_{18}$ & 0.001 & 0.001 & 0.003 & 0.003 & 0.004 & 0.003 & 0.002 & 10.458 & 10.458 & 1.407 & 1.225 & 0.004 & 0.001 \\
\hline$k_{19}$ & 0.000 & 0.000 & 0.000 & 0.000 & 0.000 & 0.000 & 0.000 & 0.000 & 0.000 & 0.002 & 19.998 & 0.000 & 0.000 \\
\hline $\mathrm{k}_{20}$ & 0.000 & 0.000 & 0.000 & 0.000 & 0.000 & 0.000 & 0.000 & 0.000 & 0.000 & 0.002 & 23.166 & 0.000 & 0.000 \\
\hline$k_{21}$ & 7.445 & 5.408 & 23.850 & 13.646 & 9.029 & 0.052 & 4.905 & 4.039 & 4.039 & 8.480 & 8.402 & 9.024 & 1.211 \\
\hline $\mathrm{k}_{22}$ & 2.094 & 1.515 & 1.642 & 19.156 & 14.322 & 0.191 & 14.687 & 6.156 & 6.156 & 4.905 & 4.745 & 14.317 & 10.141 \\
\hline $\mathrm{k}_{23}$ & 0.427 & 0.286 & 0.282 & 0.320 & 0.126 & 0.005 & 0.291 & 0.055 & 0.055 & 0.058 & 0.058 & 0.126 & 0.219 \\
\hline $\mathrm{k}_{24}$ & 6.938 & 4.835 & 5.114 & 11.715 & 9.185 & 0.111 & 5.048 & 5.230 & 5.230 & 16.278 & 16.093 & 9.190 & 1.542 \\
\hline $\mathrm{k}_{25}$ & 5.564 & 3.854 & 3.399 & 15.137 & 17.752 & 0.177 & 3.619 & 9.108 & 9.108 & 7.418 & 7.587 & 17.752 & 15.294 \\
\hline $\mathrm{k}_{26}$ & 1.177 & 0.852 & 0.924 & 10.206 & 7.789 & 0.105 & 8.256 & 3.450 & 3.450 & 2.761 & 2.668 & 7.786 & 5.651 \\
\hline
\end{tabular}

Figure S15. Sensitivity analysis of rate constants employed in the model for $\mathrm{EY}+\mathrm{EYH}_{2}+\mathrm{O}_{2}$ system. The sensitivity $\left(S_{i, j}\right)$ was defined as $\frac{1}{1800} \sum_{t=1}^{1800} \frac{k_{i}}{c_{j}(t)}\left(\frac{\partial c_{j}(t)}{\partial k_{i}}\right) \approx \frac{1}{1800} \sum_{t=1}^{1800} \frac{k_{i}}{\Delta k_{i}} \sqrt{\left(\frac{c_{j}\left(t, k_{i}+\Delta k_{i}\right)-c_{j}\left(t, k_{i}\right)}{c_{j}\left(t, k_{i}\right)}\right)^{2}}$ to compare the fractional change of species' concentrations $\left(\mathrm{c}_{\mathrm{j}}\right)$ over all time points $(1800 \mathrm{~s})$ when one rate constant $\left(\mathrm{k}_{\mathrm{i}}\right)$ was changed. To calculate the values, $25 \%$ increase of rate constants was used. The cut-off value of 0.5 was used to identify important parameters $\left(\mathrm{k}_{2}, \mathrm{k}_{3}, \mathrm{k}_{4}, \mathrm{k}_{7}, \mathrm{k}_{8}, \mathrm{k}_{21}, \mathrm{k}_{22}, \mathrm{k}_{24}, \mathrm{k}_{25}\right.$, and $\left.\mathrm{k}_{26}\right)$ that significantly impacted the final product concentrations, particularly [EY] and [degraded EY]. 


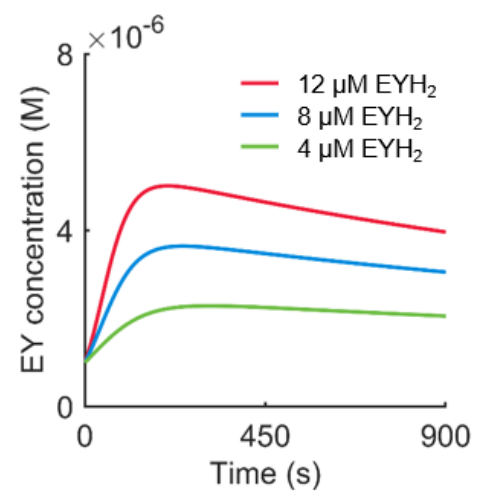

Figure S16. Model prediction for $\mathrm{EY}+\mathrm{EYH}_{2}+\mathrm{O}_{2}$ system irradiated by higher light intensity $(10 \times 1.2$ $\left.\mathrm{mW} / \mathrm{cm}^{2}\right)$. The kinetic model predicted EY amplification under $12 \mathrm{~mW} / \mathrm{cm}^{2}$ green light $\left(\lambda_{\max }=535 \mathrm{~nm}\right)$ in air-saturated $\mathrm{pH} 7.4$ phosphate buffer $(0.2 \mathrm{M})$ containing $1 \mu \mathrm{M} \mathrm{EY}$ and $4-12 \mu \mathrm{M} \mathrm{EYH}$. Compared to 1.2 $\mathrm{mW} / \mathrm{cm}^{2}$ cases (Figure 3A), the rate of $\mathrm{EY}$ amplification increased, but $\mathrm{EYH}_{2}$-to-EY recovery barely changed $(\sim 35 \%)$, limiting the maximum EY concentration. After most of $\mathrm{EYH}_{2}$ was consumed at around 200 s, EY concentration slowly decreased due to ${ }^{1} \mathrm{O}_{2}$-induced degradation.

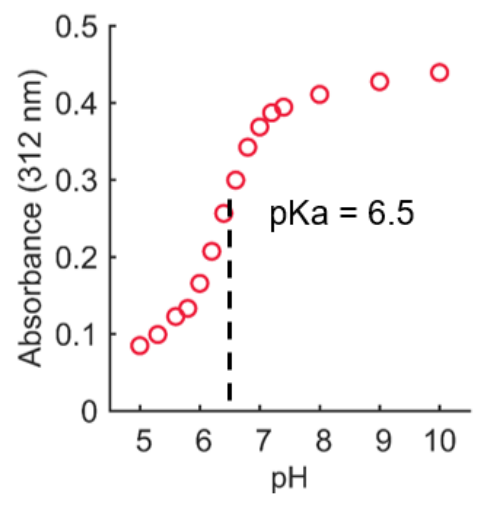

Figure S17. $\mathrm{pK}_{\mathrm{a}}$ of $\mathrm{EYH}_{2}$. Absorbance of $\mathrm{EYH}_{2}$ (at $312 \mathrm{~nm}$ ) was measured in buffered solutions with various $\mathrm{pH}$. The $\mathrm{pH}$ at the inflection point of the $\mathrm{pH}$-absorbance curve was determined as the $\mathrm{pK}_{\mathrm{a}}$. 


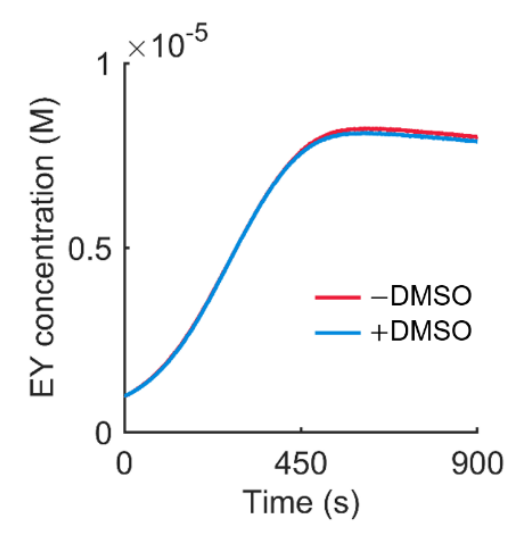

Figure S18. Effect of DMSO on EY amplification in air-saturated solution. Phosphate buffer solutions (pH 6, $0.2 \mathrm{M}$ ) containing $12 \mu \mathrm{M} \mathrm{EYH}_{2}$ and $1 \mu \mathrm{M} \mathrm{EY}$ with or without $10 \mathrm{mM}$ DMSO were irradiated under 15 $\mathrm{mW} / \mathrm{cm}^{2}$ green light $\left(\lambda_{\max }=530 \mathrm{~nm}\right)$. As demonstrated, DMSO at the final concentration of $10 \mathrm{mM}$ does not affect the EY amplification in air-saturated solution, so it can be used for storing $\mathrm{EYH}_{2}$. 
(A)

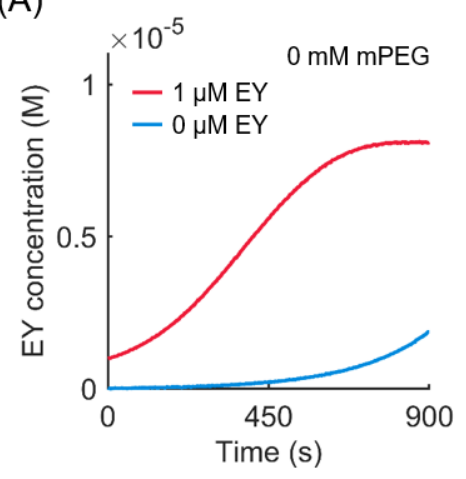

(C)

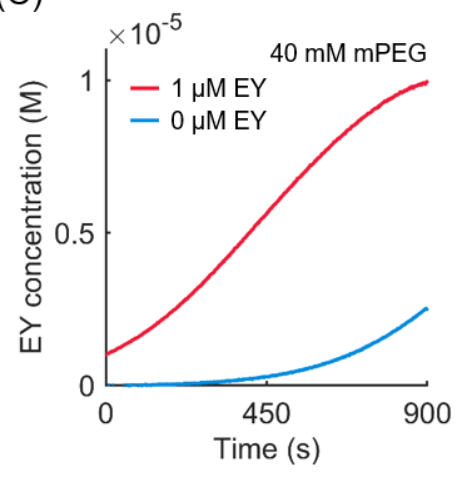

(B)

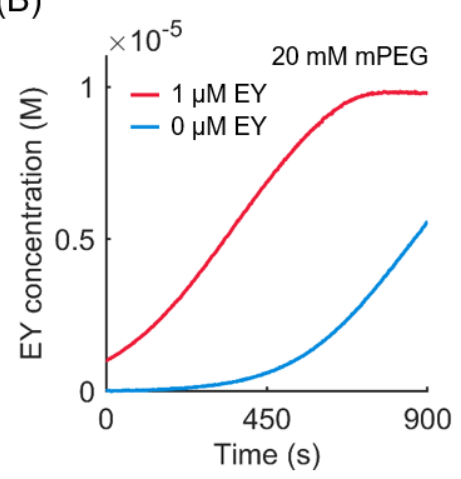

(D)

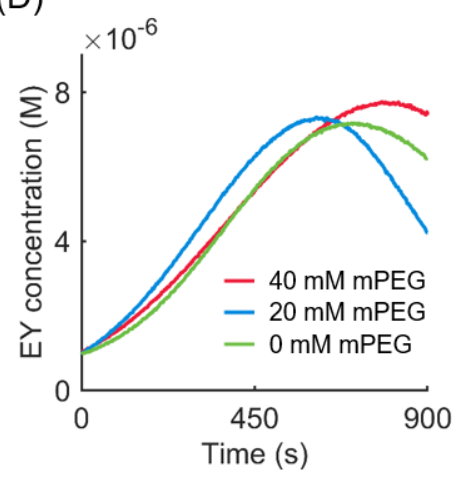

Figure S19. Effect of methoxy poly(ethylene glycol) (mPEG) on EY amplification and optimization of mPEG concentration. Phosphate buffer solutions ( $\mathrm{pH} 6,0.2 \mathrm{M}$ ) including $12 \mu \mathrm{M} \mathrm{EYH}_{2}, 1$ or $0 \mu \mathrm{M} \mathrm{EY}$, and 0-40 mM mPEG $\left(M_{n}=1900\right)$ were irradiated under $10 \mathrm{~mW} / \mathrm{cm}^{2}$ green light $\left(\lambda_{\max }=530 \mathrm{~nm}\right)$. (A) $0 \mathrm{mM}$ mPEG (B) $20 \mathrm{mM}$ mPEG (C) $40 \mathrm{mM}$ mPEG (D) Difference in EY concentration between the $1 \mu \mathrm{M}$ EY and $0 \mu \mathrm{M}$ EY cases calculated from plots A, B, and C. Optimal mPEG concentration (40 mM) was determined because it provided the largest difference in the EY concentration. 


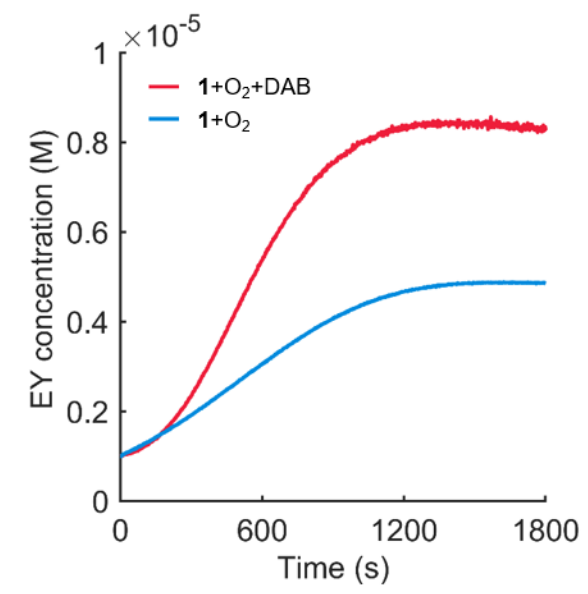

Figure S20. Extended monitoring of EY amplification with oxygen and DAB. System 1 represents $1 \mu \mathrm{M}$ $\mathrm{EY}$ and $12 \mu \mathrm{M} \mathrm{EYH}_{2}$ in $\mathrm{pH} 7.4$ phosphate buffer $(0.2 \mathrm{M})$. The concentrations of added oxygen and DAB were $\sim 0.25 \mathrm{mM}$ and $0.6 \mathrm{mM}$, respectively. The addition of $\mathrm{DAB}$ increased the $\mathrm{EYH}_{2}$-to-EY recovery from $34 \%$ to $60.5 \%$. 
(A)

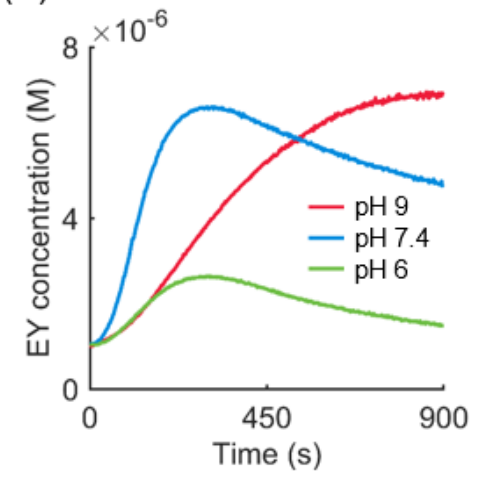

(B)

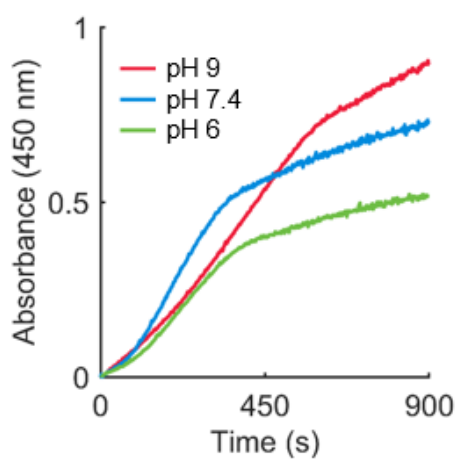

(C)

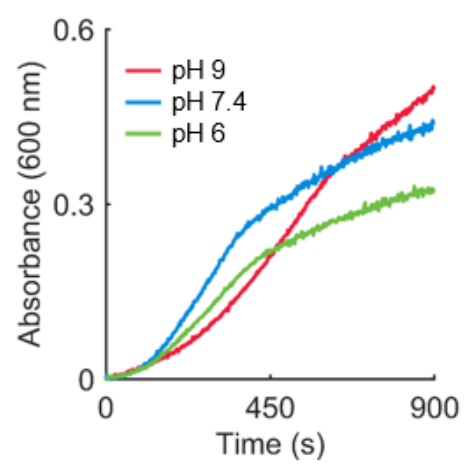

Figure S21. Effect of $\mathrm{pH}$ on EY amplification-coupled DAB polymerization (EY-DAB amplification). Phosphate solutions ( $\mathrm{pH}$ 6, 7.4 or 9, $0.2 \mathrm{M}$ ) containing $12 \mu \mathrm{M} \mathrm{EYH}_{2}, 1 \mu \mathrm{M} \mathrm{EY}$, and 0.6 mM DAB were irradiated under $10 \mathrm{~mW} / \mathrm{cm}^{2}$ green light $\left(\lambda_{\max }=530 \mathrm{~nm}\right)$ while monitoring $(\mathrm{A}) \mathrm{EY}$ concentration at $516 \mathrm{~nm}$ and DAB polymerization at (B) $450 \mathrm{~nm}$ and (C) $600 \mathrm{~nm}$. Considering the highest EY recovery and DAB polymer absorbance, $\mathrm{pH} 9$ was determined as the optimal for EY-DAB amplification.

(A)

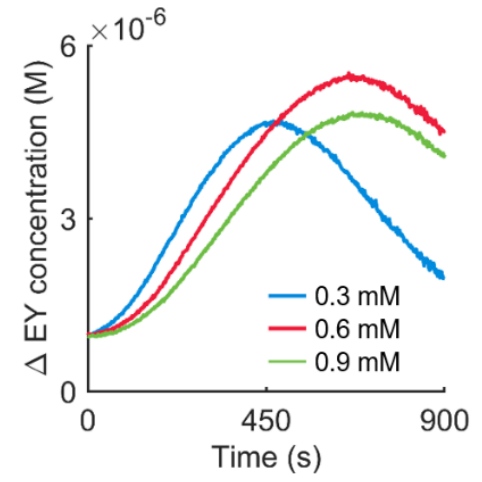

(B)

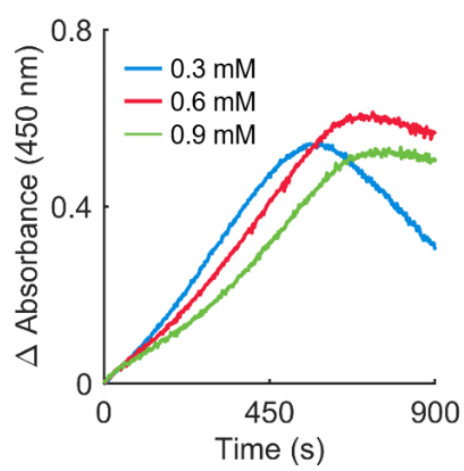

(C)

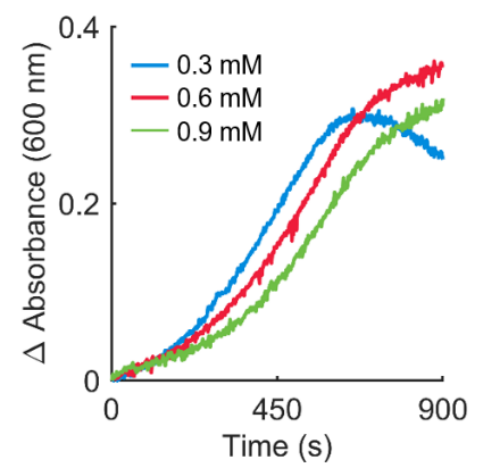

Figure S22. Effect of DAB concentration on EY-DAB amplification. Phosphate solutions (pH 9, $0.2 \mathrm{M}$ ) containing $12 \mu \mathrm{M} \mathrm{EYH}_{2}, 0$ or $1 \mu \mathrm{M} \mathrm{EY}$, and $0.3-0.9 \mathrm{mM} \mathrm{DAB}$ were irradiated under $10 \mathrm{~mW} / \mathrm{cm}^{2}$ green light $\left(\lambda_{\max }=530 \mathrm{~nm}\right)$. (A) Differences in EY concentration, (B) Differences in absorbance at $450 \mathrm{~nm}$, and (C) Differences in absorbance at $600 \mathrm{~nm}$ between the $1 \mu \mathrm{M}$ EY and $0 \mu \mathrm{M}$ EY cases were calculated for various DAB concentrations $(0.3,0.6$, and $0.9 \mathrm{mM})$. Optimal DAB concentration $(0.6 \mathrm{mM})$ was determined because it provided the largest difference in the EY concentration and DAB polymer absorbance. 
(A)

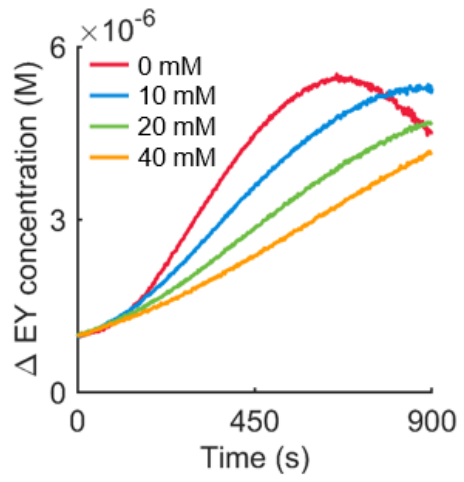

(B)

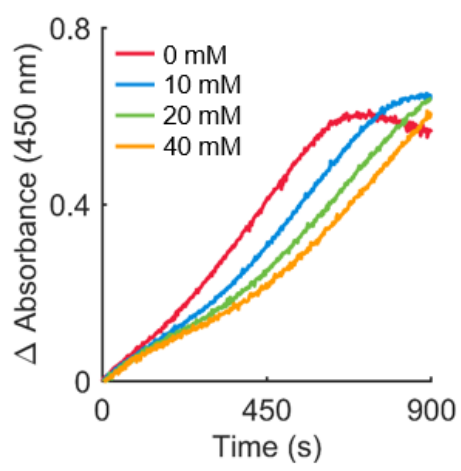

(C)

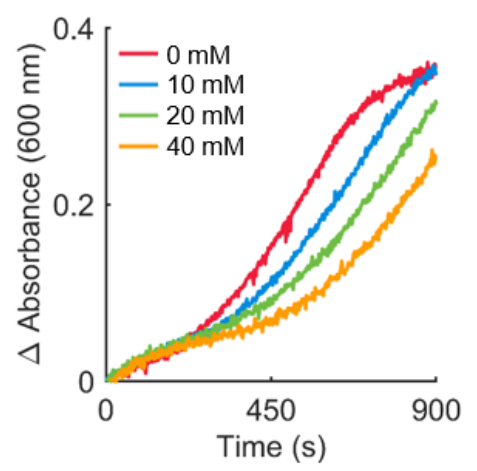

Figure S23. Effect of mPEG concentration on EY-DAB amplification. Phosphate solutions (pH 9, 0.2 M) containing $12 \mu \mathrm{M} \mathrm{EYH}_{2}, 0$ or $1 \mu \mathrm{M} \mathrm{EY,} 0.6 \mathrm{mM} \mathrm{DAB}$, and 0-40 mM mPEG were irradiated under 10 $\mathrm{mW} / \mathrm{cm}^{2}$ green light $\left(\lambda_{\max }=530 \mathrm{~nm}\right)$. (A) Differences in EY concentration, (B) Differences in absorbance at $450 \mathrm{~nm}$, and (C) Differences in absorbance at $600 \mathrm{~nm}$ between the $1 \mu \mathrm{M}$ EY and $0 \mu \mathrm{M}$ EY cases were calculated for various mPEG concentrations $(0,10,20$, and $40 \mathrm{mM})$. Optimal mPEG concentration ( $0 \mathrm{mM})$ was determined because it provided the largest difference in the EY concentration and DAB polymer absorbance.

(A)

\section{Before EY-DAB amplification}

$0 \mathrm{nM}$
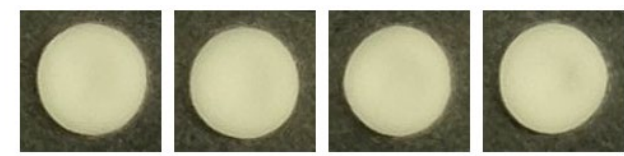

$10 \mathrm{nM}$
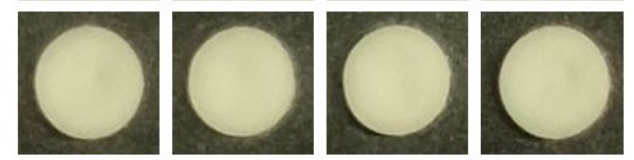

(B)

After EY-DAB amplification

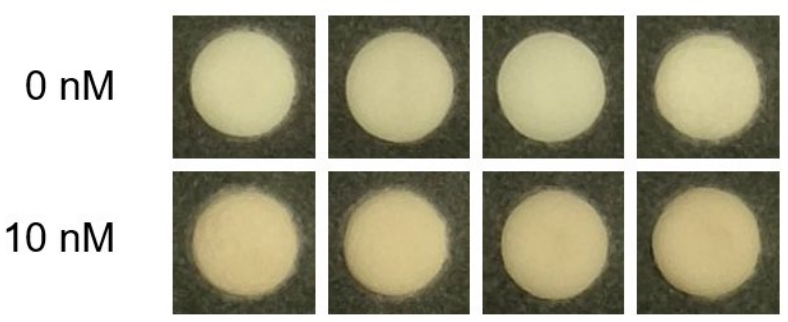

Figure S24. Cellulose-based colorimetric assay results (A) before and (B) after EY-DAB amplification. The positive control samples with $10 \mathrm{nM}$ streptavidin-EY produced brown precipitates after EY-DAB amplification, allowing visual detection of the EY-labeled streptavidin. 


\section{References}

(1) Kim, S.; Yee, E.; Miller, E. A.; Hao, Y.; Tay, D. M. Y.; Sung, K.-J.; Jia, H.; Johnson, J. M.; Ball, A.; Conway, H.; Saeed, M.; Mace, C. R.; Yurt, D. Y.; Sikes, H. D. Developing a SARS-CoV-2 Antigen Test Using Engineered Affinity Proteins. ChemRxiv. DOI: 10.26434/chemrxiv.14442785.v1

(2) Miller, E. A.; Baniya, S.; Osorio, D.; Maalouf, Y. J. Al; Sikes, H. D. Paper-Based Diagnostics in the Antigen-Depletion Regime: High-Density Immobilization of rcSso7d-Cellulose-Binding Domain Fusion Proteins for Efficient Target Capture. Biosens. Bioelectron. 2018, 102, 456-463.

(3) Weng, G.; Mahmoud, M. A.; El-Sayed, M. A. Nanocatalysts Can Change the Number of Electrons Involved in Oxidation-Reduction Reaction with the Nanocages Being the Most Efficient. J. Phys. Chem. C 2012, 116, 24171-24176.

(4) Yee, E. H.; Lathwal, S.; Shah, P. P.; Sikes, H. D. Detection of Biomarkers of Periodontal Disease in Human Saliva Using Stabilized, Vertical Flow Immunoassays. ACS Sensors 2017, 2 (11), 15891593.

(5) Kim, S.; Hao, Y.; Miller, E. A.; Tay, D. M. Y.; Yee, E.; Kongsuphol, P.; Jia, H.; McBee, M.; Preiser, P. R.; Sikes, H. D. Vertical Flow Paper-Based Assays for SARS-CoV-2 Antibody Detection in Human Serum. ACS Sensors 2021, DOI: 10.1021/acssensors.1c00235

(6) Lathwal, S.; Sikes, H. D. Assessment of Colorimetric Amplification Methods in a Paper-Based Immunoassay for Diagnosis of Malaria. Lab Chip 2016, 16 (8), 1374-1382.

(7) Bilski, P.; Dabestani, R.; Chignell, C. F. Photoprocesses of Eosine and Rose Bengal Ion Pairs with Cationic Surfactant in Non-Polar Solvent: Application in Photosensitization Studies. $J$.

Photochem. Photobiol. A Chem. 1994, 79, 121-130.

(8) Zhang, X. F.; Zhang, J.; Liu, L. Fluorescence Properties of Twenty Fluorescein Derivatives: Lifetime, Quantum Yield, Absorption and Emission Spectra. J. Fluoresc. 2014, 24, 819-826.

(9) Kasche, V.; Lindqvist, L. Transient Species in the Photochemistry of Eosin. Photochem. Photobiol. 1965, 4, 923-933.

(10) Rizzuto, F.; Spikes, J. D. The Eosin-Sensitized Photooxidation of Substituted Phenylalanines and Tyrosines. Photochem. Photobiol. 1977, 25, 465-476.

(11) Uchida, K.; Koizumi, M. Photosensitized Oxidation of Leuco-Uranine. II. Kinetics of an AcridineSensitized Photoöxidation in the Deaerated Solution. Bull. Chem. Soc. Jpn. 1962, 35 (11), 18751881.

(12) Usui, Y.; Iwanaga, C.; Koizumi, M. Reactions of Singlet Oxygen and Half-Reduced Oxygen Which Are Produced Simultaneously by the Interaction of Triplet Dye and Oxygen. Bull. Chem. Soc. Jpn. 1969, 42, 1231-1239.

(13) Krüger, U.; Memming, R. Formation and Reactions of Long Lived Xanthene Dye Radicals. I. Photochemical Studies on Reactions of Semireduced Fluoresceïn. Berichte der BunsenGesellschaft für Phys. Chemie 1974, 78 (7), 670-678.

(14) Wardman, P. Fluorescent and Luminescent Probes for Measurement of Oxidative and Nitrosative Species in Cells and Tissues: Progress, Pitfalls, and Prospects. Free Radic. Biol. Med. 2007, 43 (7), 995-1022. 
(15) Wrona, M.; Patel, K. B.; Wardman, P. The Roles of Thiol-Derived Radicals in the Use of 2',7'Dichlorodihydrofluorescein as a Probe for Oxidative Stress. Free Radic. Biol. Med. 2008, 44, 5662 .

(16) Daghastanli, N. A.; Itri, R.; Baptista, M. S. Singlet Oxygen Reacts with 2',7'-

Dichlorodihydrofluorescein and Contributes to the Formation of 2',7'-Dichlorofluorescein.

Photochem. Photobiol. 2008, 84, 1238-1243.

(17) Weinberg, D. R.; Gagliardi, C. J.; Hull, J. F.; Murphy, C. F.; Kent, C. A.; Westlake, B. C.; Paul, A.; Ess, D. H.; McCafferty, D. G.; Meyer, T. J. Proton-Coupled Electron Transfer. Chem. Rev. 2012, $112(7), 4016-4093$.

(18) Görner, H. Oxygen Uptake Induced by Electron Transfer from Donors to the Triplet State of Methylene Blue and Xanthene Dyes in Air-Saturated Aqueous Solution. Photochem. Photobiol. Sci. 2008, 7, 371-376.

(19) Concentration of dissolved oxygen in water. http://water.usgs.gov/software/DOTABLES (Accessed on April 2021)

(20) Usui, Y.; Koizumi, M. An Interpretation of the Photochemical Behavior of a Dye - Reducing Agent - Oxygen System on the Basis of a Switch-over of the Primary Processes. Bull. Chem. Soc. Jpn. 1967, 40, 440-446.

(21) Natera, J. E.; Massad, W. A.; Amat-Guerri, F.; García, N. A. Elementary Processes in the EosinSensitized Photooxidation of 3,3'-Diaminobenzidine for Correlative Fluorescence and Electron Microscopy. J. Photochem. Photobiol. A Chem. 2011, 220 (1), 25-30.

(22) Wilkinson, F.; Brummer, J. G. Rate Constants for the Decay and Reactions of the Lowest Electronically Excited Singlet State of Molecular Oxygen in Solution. J. Phys. Chem. Ref. Data 1981, 10 (4), 809-999.

(23) DeRosa, M. C.; Crutchley, R. J. Photosensitized Singlet Oxygen and Its Applications. Coord. Chem. Rev. 2002, 233-234, 351-371.

(24) Trashin, S.; Rahemi, V.; Ramji, K.; Neven, L.; Gorun, S. M.; De Wael, K. Singlet Oxygen-Based Electrosensing by Molecular Photosensitizers. Nat. Commun. 2017, 8, 16108.

(25) Foote, C. S. Photosensitized Oxygenations and the Role of Singlet Oxygen. Acc. Chem. Res. 1968, $1(4), 104-110$.

(26) Schmidt, R.; Drews, W.; Brauer, H.-D. Wavelength-Dependent Photostable or Photoreversible Photochromic System. J. Phys. Chem. 1982, 86, 4909-4913.

(27) Maeda, H.; Nanai, Y.; Mizuno, K.; Chiba, J.; Takeshima, S.; Inouye, M. Photooxygenation of Alkynylperylenes. Formation of Dibenzo[jk,mn]phenanthrene-4,5-diones. J. Org. Chem. 2007, 72, 8990-8993.

(28) Filatov, M. A.; Baluschev, S.; Landfester, K. Protection of Densely Populated Excited Triplet State Ensembles against Deactivation by Molecular Oxygen. Chem. Soc. Rev. 2016, 45 (17), 4668-4689.

(29) Tratnyek, P. G.; Holgné, J. Oxidation of Substituted Phenols in the Environment: A QSAR Analysis of Rate Constants for Reaction with Singlet Oxygen. Environ. Sci. Technol. 1991, 25, 1596-1604.

(30) Al-Nu'Airat, J.; Dlugogorski, B. Z.; Gao, X.; Zeinali, N.; Skut, J.; Westmoreland, P. R.; Oluwoye, S-33 
I.; Altarawneh, M. Reaction of Phenol with Singlet Oxygen. Phys. Chem. Chem. Phys. 2019, 21, 171-183.

(31) Ligon, S. C.; Husár, B.; Wutzel, H.; Holman, R.; Liska, R. Strategies to Reduce Oxygen Inhibition in Photoinduced Polymerization. Chem. Rev. 2014, 114 (1), 557-589.

(32) Encinas, M. V.; Rufs, A. M.; Bertolotti, S. G.; Previtali, C. M. Xanthene Dyes/Amine as Photoinitiators of Radical Polymerization: A Comparative and Photochemical Study in Aqueous Medium. Polymer (Guildf). 2009, 50 (13), 2762-2767.

(33) Slyusareva, E. A.; Gerasimova, M. A. pH-Dependence of the Absorption and Fluorescent Properties of Fluorone Dyes in Aqueous Solutions. Russ. Phys. J. 2014, 56 (12), 1370-1377.

(34) Kralik, P.; Kusic, H.; Koprivanac, N.; Bozic, A. L. Degradation of Chlorinated Hydrocarbons by $\mathrm{UV} / \mathrm{H}_{2} \mathrm{O}_{2}$ : The Application of Experimental Design and Kinetic Modeling Approach. Chem. Eng. J. 2010, 158 (2), 154-166.

(35) Corey, E. J.; Mehrotra, M. M.; Khan, A. U. Water Induced Dismutation of Superoxide Anion Generates Singlet Molecular Oxygen. Biochem. Biophys. Res. Commun. 1987, 145 (2), 842-846.

(36) Imamura, M.; Koizumi, M. Irreversible Photobleaching of the Solution of Fluorescent Dyes. I. Kinetic Studies on the Primary Process. Bull. Chem. Soc. Jpn. 1955, 28 (2), 117-124.

(37) Zwicker, E. F.; Grossweiner, L. I. Transient Measurements of Photochemical Processes in Dyes. II. The Mechanism of the Photosensitized Oxidation of Aqueous Phenol by Eosin. J. Phys. Chem. 1963, 67 (3), 549-555.

(38) Ohno, T.; Kato, S.; Koizumi, M. Intermediates in the Photoreduction of Eosine as Revealed by a Flash-Photolysis Study. Bull. Chem. Soc. Jpn. 1966, 39, 232-239.

(39) Chrysochoos, J.; Ovadia, J.; Grossweiner, L. I. Pulse Radiolysis of Aqueous Eosin. J. Phys. Chem. 1967, 71 (6), 1629-1636.

(40) Seret, A.; van de Vorst, A. The Photochemistry of the Semi-Oxidized Form of Eosin Y and Rose Bengal in Aqueous Sodium Dodecylsulphate Solutions. J. Photochem. Photobiol. A Chem. 1988, 43 (2), 193-206.

(41) Dhiman, S. B.; Naik, D. B. Dissolution and Diffusion of Oxygen in Deaerated Water and Escape of Oxygen to the Atmosphere from an Oxygen Saturated Aqueous Solution: An Investigation by a Pulse Radiolysis Technique. Ind. Eng. Chem. Res. 2009, 48 (9), 4312-4315.

(42) Khan, A. U. Singlet Molecular Oxygen from Superoxide Anion and Sensitized Fluorescence of Organic Molecules. Science 1970, 168 (3930), 476-477.

(43) Kraljić, I.; Lindqvist, L. Laser Photolysis Study of Triplet Eosin and Thionine Reactions in Photosensitized Oxidations. Photochem. Photobiol. 1974, 20 (4), 351-355. 